\title{
THE INFLUENCE OF OUTCOME MEASURES IN ASSESSING CLIENT CHANGE AND TREATMENT DECISIONS
}

\author{
A dissertation presented to \\ the faculty of \\ the College of Arts and Sciences of Ohio University \\ In partial fulfillment \\ of the requirements for the degree \\ Doctor of Philosophy
}

Derek R. Hatfield

August 2006 
This dissertation entitled

\title{
THE INFLUENCE OF OUTCOME MEASURES IN ASSESSING CLIENT CHANGE AND TREATMENT DECISIONS
}

\author{
by \\ DEREK R. HATFIELD \\ has been approved \\ for the Department of Psychology \\ and the College of Arts and Sciences by
}

Benjamin M. Ogles

Professor of Psychology

Benjamin M. Ogles

Dean, College of Arts and Sciences 
HATFIELD, DEREK R., Ph.D., August 2006, Psychology

\section{THE INFLUENCE OF OUTCOME MEASURES IN ASSESSING CLIENT}

\section{CHANGE AND TREATMENT DECISIONS (175 pp.)}

Director of Dissertation: Benjamin M. Ogles

Research is beginning to demonstrate the clinical utility of providing clinicians with information concerning client progress via routinely administered outcome measures. Clients who are deteriorating while in therapy and those not progressing as expected appear to be the ones who benefit most from this intervention. However, little is known about the process that leads to improved outcomes in the context of feedback. One way to approach this issue is through a clinical judgment and decision making framework applied to mid-treatment decision making tasks. As such, information from an outcome measure could be viewed as additional information that might alert therapists to cues of client progress (or lack thereof) that they were not previously aware of. This study investigated the influence that additional information in the form of outcome measures and client verbal reports can have on clinician judgment of client change. Despite clinicians reporting that verbal report is more influential in their actual clinical practice than outcome measure information, both sources of information had an equal impact on judgments of client change. Negative information (from either source) influenced clinicians more than positive information. Several clinician variables were also examined. Following their judgment of client change, clinicians indicated what treatment decision they would make. A majority of clinicians chose to alter treatment in some manner, although information indicating 
client improvement led some clinicians to continue treatment in the same manner as they had been. Outcome measure report indicating client deterioration led more clinicians to alter treatment than client verbal report of deterioration. Insight oriented therapists were more likely to continue treatment-as-usual than were cognitivebehavioral therapists. Finally, clinician confidence in their treatment decision was studied, with most clinicians indicating they were highly confident in their chosen treatment decision. Implications for these findings were discussed, along with future directions for additional research.

Approved

$$
\text { Benjamin M. Ogles }
$$

Professor of Psychology 
This work is dedicated to Danielle, Meagan, and Spencer. They truly defined my graduate school experience. 


\section{Acknowledgments}

I would like to thank my wife, Danielle, for her constant support and encouragement. I am grateful for my children, who helped me to keep life "real" during graduate school. My deep appreciation goes to my advisor, Dr. Ben Ogles, for his time and effort spent in the preparation and completion of this dissertation. More than that, I am thankful that he has been an excellent mentor, both personally and professionally. For their time and recommendations, I would like to express appreciation to my committee members: Dr. John Garske, Dr. Bruce Carlson, Dr. Doug Mann, and Dr. Lee Coleman. Finally, I would like to thank all of my family and friends for their encouragement and support. 
Table of Contents

Page

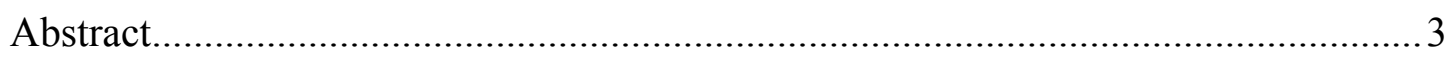

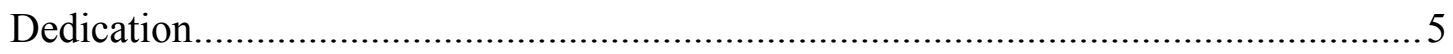

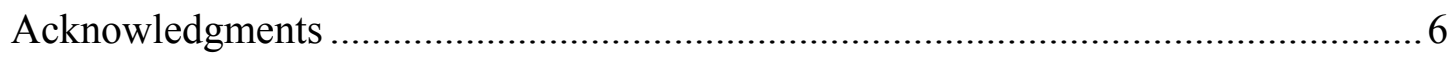

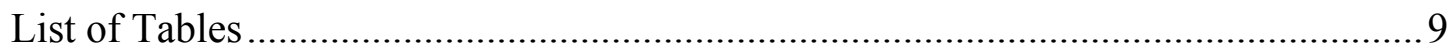

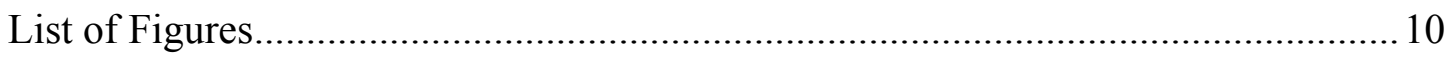

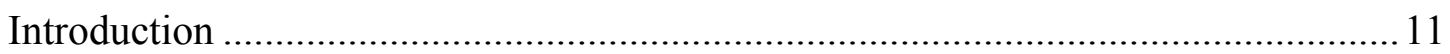

Overview of Clinical Judgment and Decision Making ................................ 14

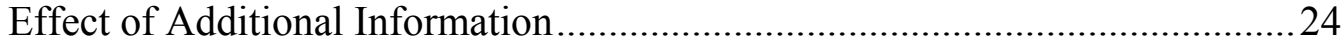

Confidence............................................................................ 25

Pursuit of Information ................................................................ 27

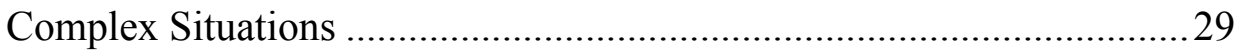

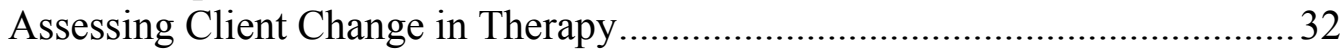

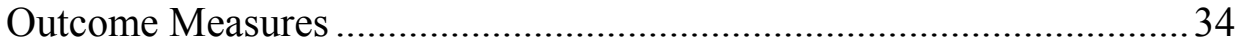

Effects of Providing Outcome Measure Feedback to Therapists ..................... 40

Lambert's Feedback Studies...............................................................43

Studying Outcome Measures and Verbal Report as Additional

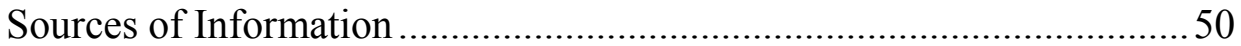

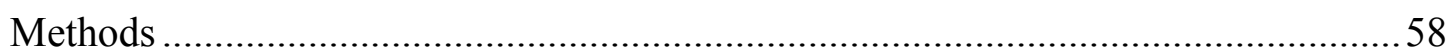

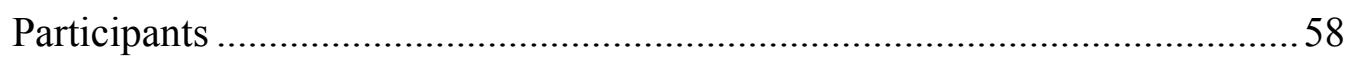

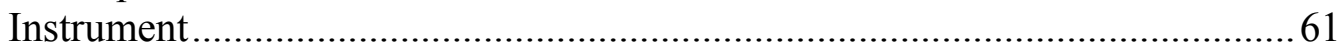

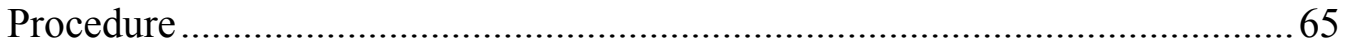

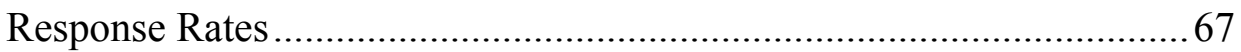

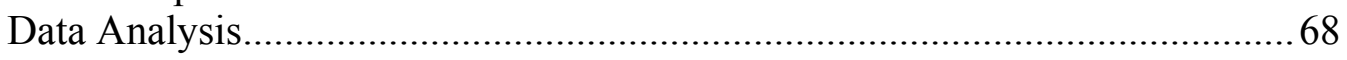




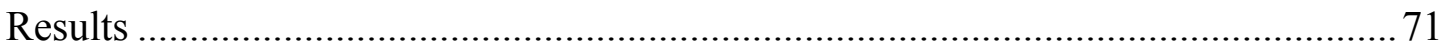

Judgment of Client Change ............................................................................

Verbal Report vs. Outcome Measure Report ..........................................71

Negative Change vs. Positive Change …………………….....................75

Clinician Differences........................................................................

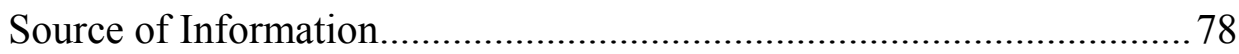

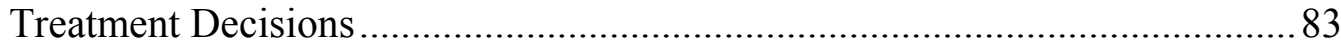

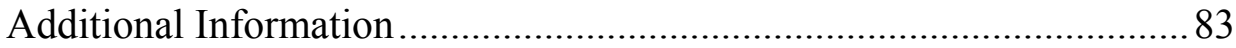

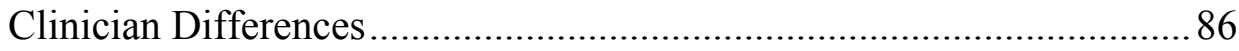

Sub-Choices Decision Analysis ......................................................... 91

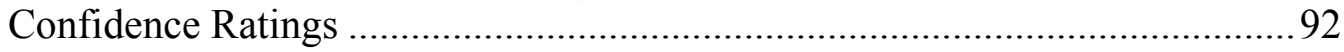

Treatment Decisions .........................................................................92

Verbal Report vs. Outcome Measure Report ……………………….......93

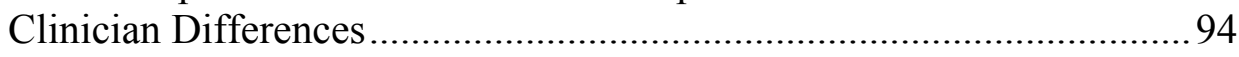

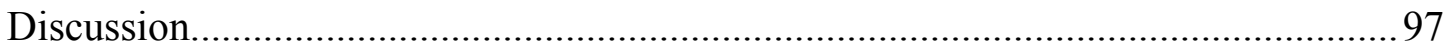

Judgment of Client Change …………………………...............................97

Verbal Report vs. Outcome Measure Report ……………………...........98

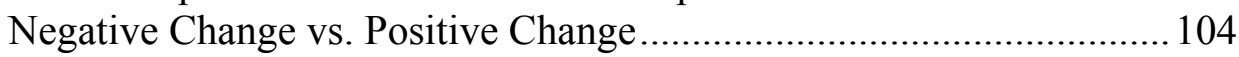

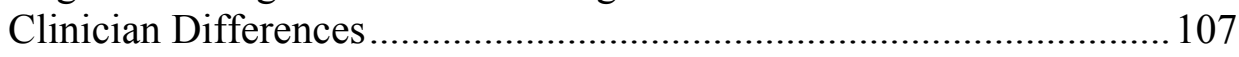

Source of Information......................................................................... 110

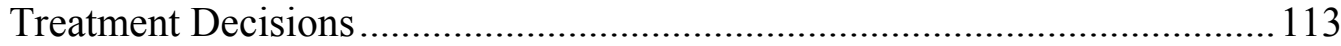

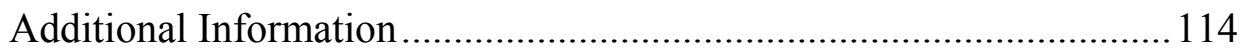

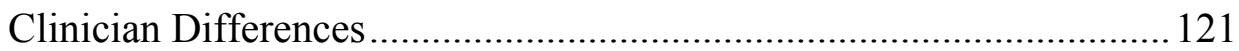

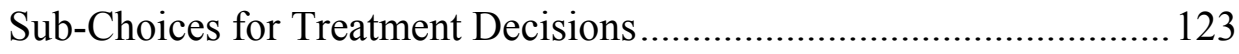

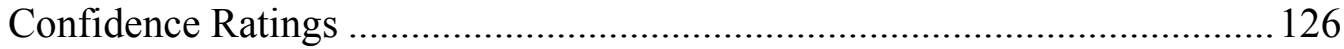

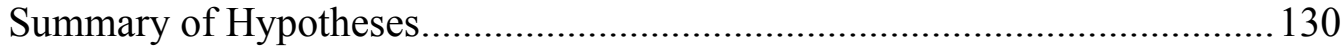

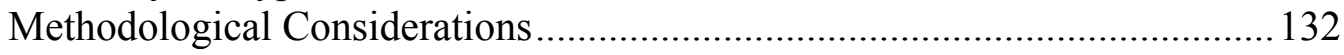

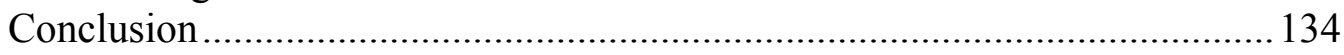

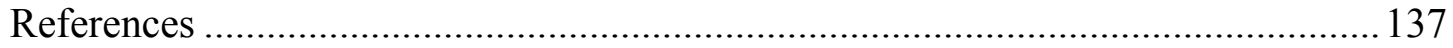

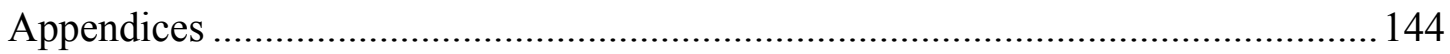

A Demographic Page .............................................................................. 144

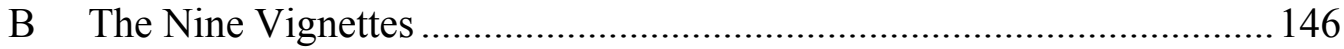

C Sample Vignette with Questions.............................................................. 152

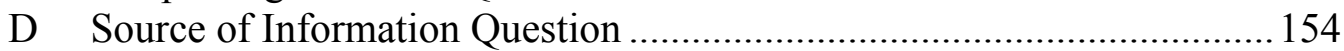

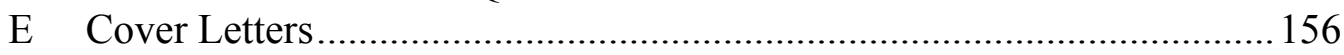

F Source of Information "Other" Responses ................................................. 159

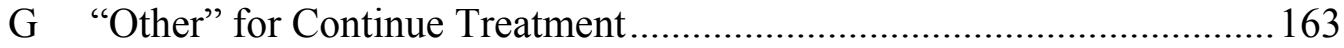

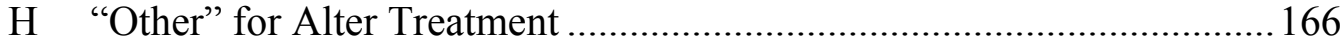

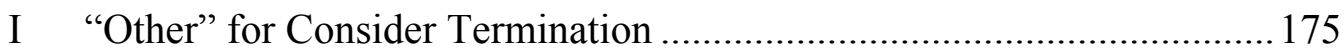




\section{List of Tables}

Table

Page

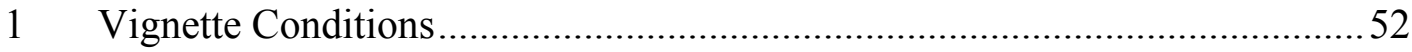

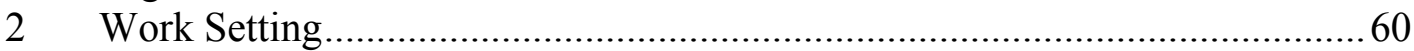

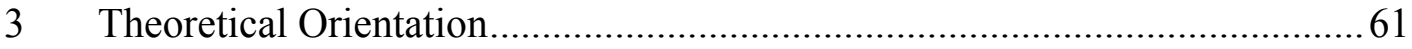

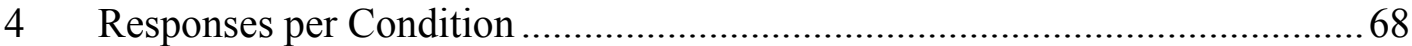

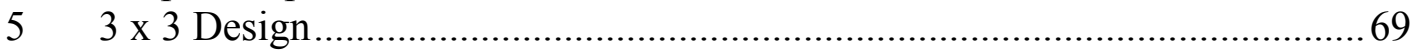

6 Judgment of Client Change by Condition ................................................ 72

$7 \quad$ Effect Sizes of Judgment Differences ....................................................... 74

8 Self Reported Relative Influence of Each Source of Information...................79

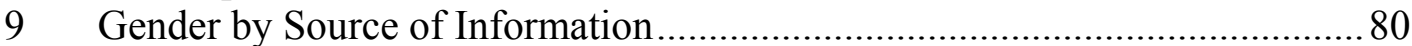

10 Outcome Measure Use by Source of Information ....................................... 81

11 Work Setting by Source of Information .................................................... 81

12 Theoretical Orientation by Source of Information .................................... 82

13 Therapy Hours per Week by Source of Information .................................. 82

14 Years Since Licensure by Source of Information......................................... 82

15 Treatment Decision by Condition ............................................................. 84

16 Logistic Regression for Client Verbal and Outcome Measure Report............85

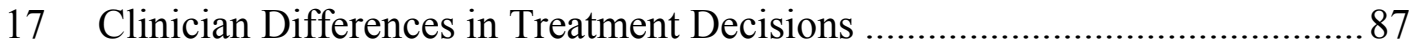

18 Logistic Regression Analysis for Gender ............................................. 88

19 Logistic Regression Analysis for Theoretical Orientation ............................ 89

20 Logistic Regression Analysis for Years Since Licensure..............................90

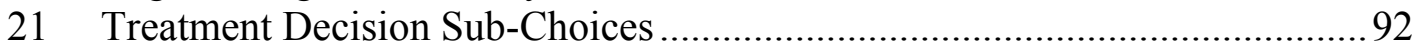

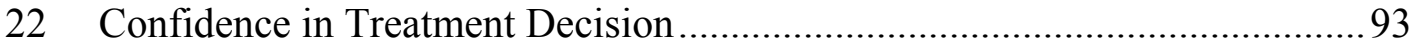

23 Confidence of Treatment Decision by Condition..........................................99

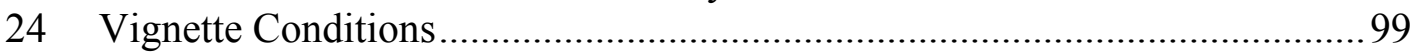

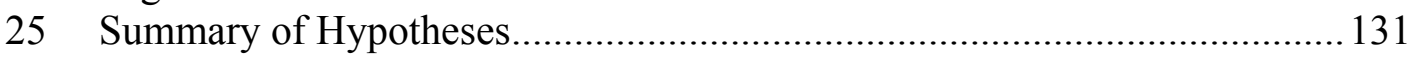




\section{List of Figures}

$\begin{array}{lll}\text { Figure } & \text { Page }\end{array}$

1 Client Verbal Report and Outcome Measure Report for Judgment of Client Change................................................................................ 73 


\section{Introduction}

There is very little research that directly studies the effects that judgments of client change have on clinical decision making. In a recent series of studies, however, Michael Lambert's research team demonstrated that under certain circumstances, giving therapists feedback concerning client progress (via routinely administered outcome measures) can improve the efficiency and effectiveness of therapy (Lambert, et al., 2001; Lambert, et al., 2002; Whipple, et al., 2003). For clients who were not improving as expected (or perhaps even getting worse), clients of therapists who received outcome measure feedback tended to improve more than clients whose therapists did not receive feedback. In addition, for clients who were improving as expected, clients of therapists who received feedback attained the same amount of therapeutic improvement, though in fewer sessions than clients whose therapists did not receive feedback.

The findings from these preliminary studies are potentially important to the practice of clinical psychology. Available research indicates that between $5-10 \%$ of clients deteriorate (post-therapy outcomes are statistically worse than pre-therapy conditions) while in therapy (Lambert \& Ogles, 2004; Mohr, 1995). The feedback studies just mentioned demonstrated that providing therapists feedback in the form of outcome measures can potentially enhance the therapeutic outcome for a significant portion of the $5-10 \%$ of clients who deteriorate or do not improve as expected. Also, in an era of cost containment increased efficiency is highly desirable. Thus, if the use 
of outcome measures can contribute to some clients reaching an adequate amount of improvement in fewer sessions, then research exploring this possibility is important.

There will be a detailed consideration of these studies in a later section. It is important now to note that Lambert, et al. (2001) described the effects that providing feedback had on client outcomes. However, they did not articulate many hypotheses concerning the mechanisms for this effect. Judging client change and making subsequent treatment decisions is a complex task in which many variables are at play. Lambert's feedback studies touch on only one small part of the process.

In the feedback studies, after the therapists received the feedback they presumably altered the way they thought about the case or perhaps even altered the manner of intervention. The researchers did not control therapist responses, and the exact influence of the additional information provided by outcome measures is unknown. The outcome measure provided another source of information for the clinician's task of assessing client progress (or lack thereof). Following up on the findings of these studies, this dissertation attempted to further investigate the effect that outcome measures might have on the clinical assessment of client change and subsequent treatment decisions based upon that assessment.

The results of these studies can be placed more generally in the framework of clinical judgment and decision making. In order for clinicians to make appropriate treatment decisions, they must be able to judge whether the client is improving, failing to improve, or perhaps even getting worse. The assessment of client progress is a task of judgment, and following the judgment is the necessity of deciding which course of 
action to take. If the client is improving, the therapist might make a decision to move towards termination of therapy. If the client is not improving or getting worse, the therapist might decide that the treatment has not been effective for this client and that a change of some manner needs to be made in the treatment being offered. Another interpretation of no change is that despite the lack of client progress, the treatment is sufficiently effective and more time is required for the client to respond positively and therefore, a continuation of the current treatment plan is the appropriate decision.

There are unfortunately few studies directly investigating the precise effect that additional information (such as feedback from outcome measures) can have on clinical decision making during the later stages of therapy. In light of this deficiency of research concerning clinical judgment and decision making in regards to assessing client progress, this study proposes to begin exploration in this area. Understanding how clinicians judge client progress and how various factors influence subsequent treatment decisions is an important area of exploration that has been understudied.

The research study for this dissertation utilized brief clinical vignettes. Client verbal report of change and outcome measure report were the two pieces of information that were manipulated in the vignettes. The effects of these manipulations on clinician judgment of client change and treatment decisions were investigated. Clinician differences were also explored. This study represents a small component of the potential research in the area of clinical judgment and decision making, and will hopefully be the beginning of future research investigations into how clinicians judge client change and make subsequent treatment decisions. What follows in the 
introduction of this dissertation is a description of the most closely related research, much of which is found in the clinical judgment and decision making literature.

The next section begins with a brief review of research in the area of clinical judgment and decision making. Most of the research in clinical judgment has investigated clinician psychodiagnostic accuracy and interrater reliability in diagnostic tasks. In addition, research related to assessment of treatment needs will be summarized. There will then be a review of research, both in and out of clinical psychology, regarding the effect that additional information can have on decision making in various circumstances.

Attention will then focus on issues involved in assessing client change in therapy, including a specific consideration of outcome measures representing additional sources of information and a detailed description of the Lambert feedback studies. Due to an increased emphasis on quality assurance and cost effectiveness aims, outcome measures are beginning to be used more routinely as part of clinical practice. The specific points of investigation for this dissertation arise from the results of the feedback studies that utilized outcome measures. Finally, a description of hypotheses and overview of how the hypotheses were investigated will be provided. First, however, a brief background of related research will be beneficial. Overview of Clinical Judgment and Decision Making

The field of judgment and decision making has a long and rich history (Goldstein \& Hogarth, 1997). Research has focused on numerous areas, from various perspectives. The basic framework from which much of the judgment research is 
conducted is labeled the lens model, developed by Egon Brunswik (Hastie \& Dawes, 2001). This framework is helpful in that it can apply to all types of judgment tasks, including clinical judgments.

In making judgments, people must infer information about something in their environment from cues they observe. For example, in judging another's biological age, the actual age is not directly observable. There are cues, however, that give information regarding the biological age, such as hair color, skin texture, voice, dress, and several others. In the lens model framework, the cues are considered the "lens" through which the person must look in order to infer another's age. The individual judging the other's age then observes the cues and interprets them through the particular set of psychological characteristics he or she possesses (such as previous experience or certain cognitive processes specific to the individual). In most areas of human judgment, cues available in the environment are necessary to make any judgment. The fewer the cues, the less likely an accurate judgment will be made. Judgment research has become quite sophisticated, but much of it has roots in the lens model framework. Although interesting, a review of all judgment research is beyond the scope of this dissertation.

One application of research in judgment and decision making has been the specialized field of clinical decision making (Dowie \& Elstein, 1988). Some areas of clinical judgment have been well studied, while others have received little attention. Judging client progress and deciding what to do following that judgment is only one phase of therapy. Clinicians make many decisions in a variety of contexts and 
attempting to list all them is nearly an impossible task. For most clinicians, the first objective in therapy is to form an initial conceptualization of the client's issues, often including the formation of a diagnosis. This is done through the gathering of information, in one form or another, and then integrating all the information into a conceptualization of a client's problems and the processes that both caused and are maintaining current impairments in functioning. Several judgments must be made in making a diagnosis, whether clinicians adhere to the specific criteria sets of the DSM or if the diagnosis rather represents an informal case conceptualization.

The decision of what treatment to pursue for a particular client will usually be contingent on the judgment made by the clinician concerning the initial assessment. Depending on the nature of the client's problems, the clinician will decide what the treatment aims and goals are for therapeutic work. Once treatment goals are chosen, appropriate treatment interventions are selected which the clinician feels will best help the client achieve the therapeutic goals.

Throughout therapy, clinicians must decide what topics to pursue, given that clients will often provide a large amount of information. Clinicians will make decisions regarding which client comments might be beneficial for further exploration, and which client comments will be momentarily passed over. Clinicians must also make accurate interpretations of the information presented to them. Even with appropriate understandings of single pieces of information, the clinician must be able to integrate an incredibly diverse amount of information (which can sometimes be contradictory). 
Of all the research exploring clinician judgment and decision making, however, most has focused on judgments and treatments made during the initial stages of therapy. In fact, the majority of research in this area concerns clinician accuracy, reliability, and validity of diagnostic assessments (e.g., Garb, 1998). There has been a considerable amount of effort to determine what biases exist and other cognitive errors in making diagnoses. In addition, there has been some research regarding the assessment of treatment needs and decisions of initial treatment choice by clinicians.

There has been little research of clinical judgment and decision making in regards to tasks later in therapy. Making diagnoses and assessing initial treatment needs are both done predominantly at the beginning of therapy. Judgments and decisions made at later stages of therapy, however, are arguably as important as those made early in therapy. Accurately judging client progress, or lack thereof, and then making appropriate treatment decisions based on that judgment can naturally have a substantial impact on the client's overall therapeutic outcome.

The tasks performed by clinicians are not simplistic judgment and decision making procedures. "From intake to termination of treatment, practitioners collect information, formulate hypotheses, and make judgments and decisions. The data in clinical practice do not 'speak for themselves'; they must be interpreted. Clinicians are constantly confronted by an enormous amount of information, and they can only process a subset of it at a given time" (Turk, Salovey, \& Prentice, 1988). The complexity of dealing with such a large amount of information (and not infrequently, contradictory information) can sometimes lead to errors on the part of the clinician 
(Ward, 1999). Some research suggests that clinicians not only make occasional mistakes, but rather are habitually "off the mark" (Dawes, 1994; Garb, 1998). Taking another perspective, Schoen (1988) describes clinicians as being experts who, given natural limits, are the best available people to accomplish this exceedingly difficult synthesizing of information. Obtaining a better understanding of how clinicians make decisions, the errors which are most common, and what factors influence clinical decision making is of vital importance if improved training is to lead to enhanced services offered to clients.

While there is very little research concerning judgments of client change and treatment decisions in the later stages of treatment, there has been considerable research conducted in the area of clinician psychodiagnostic accuracy and interrater reliability in diagnostic tasks. Howard Garb (1998) has compiled the most comprehensive review of this literature. He demonstrated that results from research concerning clinician accuracy in making correct diagnoses are quite varied. There are many studies that show how clinicians cannot arrive at the same diagnosis after being exposed to the same information. Conversely, other studies provide support for the reliability of clinicians' judgments of diagnoses. He also documents studies which have demonstrated biases and errors related to race, gender, and age. Other researchers have also compiled reviews of this literature demonstrating various cognitive errors that clinicians make in judgment and decision making tasks (Dawes, 1994; Dowie \& Elstein; 1988; Dumont, 1993; Rabinowitz, 1993). Despite the amount 
of research in this area, Rock (1994) found that clinicians are mostly unfamiliar with the clinical judgment literature.

There are three areas of research that are related to this dissertation's topic of assessing client progress and making the subsequent treatment decisions: 1) the phenomenon of anchoring and adjustment (Tversky \& Kahneman, 1982), 2) confirmatory hypothesis bias (Turk \& Salovey, 1985), and 3) difficulty assessing treatment needs (Garb, 1998). Beginning with anchoring, Hastie and Dawes (2001) explain that an original estimation or hypothesis becomes the "anchor," and not only serves as a salient starting point for the judgment, but it biases the nature of additional information that is sought and retrieved downstream in the later stages of judgment and decision making. This type of anchoring can have significant effects in clinical practice. "Anchoring describes the tendency for decision makers to rely too heavily on early information in the decision process. Initial estimates or predictions, based on preliminary appraisals, serve as the basis for subsequent judgments. Clinicians may fail to see improvement in a client's condition because they are anchored to an initial judgment of the client's mental state" (Turk, Salovey, \& Prentice, 1988).

For example, Gregory Mumma (2002) had clinicians view videotapes of actorsimulated patients responding to questions from a standardized diagnostic interview. Clinicians who had prior information about a clear-cut history of depression rated the severity of current symptoms lower than did clinicians who did not have access to the prior history, but had watched the same tape. Another example was a study conducted by Pain and Sharpley (1989). They found that in presenting client information to 
counselors, the order that information was presented significantly altered the counselors' clinical judgment. Negative information presented earlier adversely affected ratings of good information presented later. Therefore, clinicians' judgments of actual clients might be different depending on what order information is presented.

In a more theoretical consideration of anchoring, Arkes and Harkness (1980) argued that the act of making a diagnosis can influence subsequent recall of symptoms. Imagine that following a clinician making a diagnosis for the client, the clinician may then incorrectly recall the client as having a symptom typically associated with the diagnosis, when in fact the client might not have that particular symptom. Likewise, if a symptom does not commonly occur among clients having a specific diagnosis, a clinician may not remember that a client has the symptom due to the original diagnosis. In other words, they have a tendency to remember more "category-consistent" symptoms and traits than "category-inconsistent" symptoms and traits. Empirical research suggests that similar cognitive errors do occur when clinicians remember information about clients (Garb, 1998; Lee, Barak, Uhlemann, \& Patsula, 1995; Murdock, 1988; Strohmer, Shivy, \& Chiodo, 1990). In considering the judgment of a diagnosis or most other clinical decisions, an important type of error to consider is a phenomenon known as confirmatory bias. Several studies have been conducted which have found a confirmatory hypothesis bias in clinicians (Dumont, 1993; Ellis, Robbins, Schult, Ladany, \& Banker, 1990; Friendlander \& Phillips, 1984; Friendlander \& Stockman, 1983). To illustrate how confirmatory hypothesis bias might operate in a clinical scenario, consider the process 
of making a diagnosis. Making a diagnosis in an intake interview is much like the process of hypothesis testing. As the clinician begins gathering information, she will start forming potential hypotheses that will subsequently be tested and either rejected or submitted to more investigation. For example the clinician might form an initial hypothesis that her client has Major Depressive Disorder and will begin an attempt to find evidence for or against that hypothesis. What often occurs in clinical (and basic human) judgment, however, is that once a hypothesis is formed, the clinician will tend to pay more attention to information that confirms the "correctness" of the original hypothesis. Due to this confirmatory hypothesis testing, the clinician puts more weight on evidence supporting the hypothesis, and much less on information that might refute it.

Just as clinicians can make errors in making diagnostic decisions, errors are also possible in assessing treatment needs. Indeed, if a clinician has an inaccurate case conceptualization and has misdiagnosed the client, there is a high probability that the decision for treatment will be less than ideal. In other words, even if a "correct" decision for treatment is made, it will be seriously flawed because of the incorrect assessment of the client's diagnosis and problems. Conversely, even if the diagnosis and case conceptualization are correct, this by no means guarantees that the clinician will make the best decision on the most appropriate treatment.

Wilson and Evans (1983) used 118 doctoral psychologists, all of whom were members of the American Association of Behavior Therapy, in studying treatment goal agreement. The psychologists were given three case histories of children with the 
following behavioral problems: fearfulness, conduct disorder, and social withdrawal. It was assumed that these problems lend themselves to specified behavioral treatments. In this study, when psychologists identified a single primary target behavior for each case, they agreed only $39 \%$ of the time.

Felton and Nelson (1984) also found that six clinical psychologists, who were all trained in behavioral assessment, were in agreement approximately $60 \%$ of the time in describing treatment proposals. This is intriguing since behavioral therapists might be the most likely to agree on appropriate treatments. Some studies have demonstrated poor interrater reliability for psychiatrists making treatment decisions (Keller et al., 1986; Nierenberg, 1991). Bickman, Karver, and Schut (1997) studied clinicians who were to assign children and adolescents to the most appropriate levelof-care (e.g., outpatient, intermediate nonresidential care, intermediate residential care, residential treatment center, or inpatient care). In the cases in which the clinicians agreed that there was sufficient information to make a decision, the kappa coefficient for interrater reliability was only .03 .

If research demonstrates that clinicians sometimes have difficulty agreeing which treatment decisions are most appropriate, it seems reasonable that they would also have the same difficulty making appropriate decisions concerning tasks later in therapy similar to judgment and decision tasks early in therapy. Though most of the research concerning the assessment of treatment needs is situated in the beginning phases of therapy, it is closely related to the task of judging whether a change in the treatment plan is necessary following client change (improvement or deterioration). 
Similar to the initial stages of therapy, if clinicians do not always accurately assess client progress they will likely not make optimal treatment decisions concerning the remainder of therapy. Even if a clinician accurately judged that a client was not making progress, would he or she then choose the most appropriate alteration to the treatment?

Garb (1998) recognizes that "unfortunately, the cognitive processes of clinicians engaged in treatment planning have rarely been the object of empirical study." In summarizing the information contained in this section, it is important to note that clinicians do not always make the same judgments and decisions, even with the same information. Other factors can influence clinical judgment, such as the sequence in which information is conveyed. Much of the research in this area does not directly study the assessment of client change which might occur after therapy has commenced for some time. This dissertation represents a very specific and basic investigation of factors influencing clinician judgment and decision making in the later stages of therapy.

With heavy caseloads and so much information to process about each individual (not to mention many of the cognitive biases and errors mentioned earlier) it is relatively safe to assume that many clinicians might miss some cues concerning a lack of progress in therapy. Feedback given to therapists alerting them to potential treatment failure could then lead the clinician towards a different set of decisions to choose from. In this sense, outcome measures serve as an additional source of 
information presented to the clinician. The next section details research related to the effects that additional information can have on judgment and decision making. Effect of Additional Information

An interesting body of research exists concerning the effects of additional information on judgment, decision making, and confidence. Returning to the lens model, additional sources of information can be viewed as more cues from which to make judgments. Clinicians are generally trained to obtain as much information as possible before making a judgment or decision. This is a good rule of thumb for all areas of clinical practice, though therapists are often constrained by time and other practical barriers in obtaining an ideal amount of information. Clinicians are therefore left to make decisions based on what information is available to them. Presumably, clinicians' confidence in their decisions will vary greatly depending on how much information they had available initially and what degree of additional information becomes available later.

Returning once again to the Lambert feedback studies, each of the clinicians were conducting therapy in their normal manner and likewise were making judgments concerning client progress using the same method that they were accustomed to. When clinicians were given feedback from outcome measures, the feedback represented an additional source of information that the clinicians could use to make a clinical judgment of client change. In this section, a sample of relevant studies will be described which address the effects of additional information on clinician judgment, decision making, and confidence. 
Confidence. In a classic study of clinician accuracy and confidence, Oskamp (1965) demonstrated a common effect of additional information. In his study, he offered judges (a fourth of which were clinical psychologists) information about a published case and measured the accuracy of their clinical judgments about the case as well as their confidence in their judgment. After the initial presentation of the case material, he subsequently gave 3 more sets of information to the judges, measuring both accuracy and confidence after each administration of information. The additional sets of information gave primarily the same information as the initial set and consequently, accuracy ratings reached a ceiling quickly. The judges' accuracy did not substantially increase as more information was presented, though their confidence ratings did increase markedly and steadily. Even though their accuracy (or inaccuracy) remained constant, the judges became more confident that they were indeed accurate.

Research has given support to the notion that clinicians can also be overconfident (Smith \& Dumont, 2002). In clinical practice, this means that even though the accuracy of clinicians' judgments might be questionable, they can become more confident in their potentially faulty judgments with additional information. This is a particularly alarming finding for clinicians when considering a demonstrated tendency of people to pay greater attention to information that confirms their original hypotheses, even at the neglect of disconfirming information (Pitz, 1969). As they do this, they will focus on additional confirmatory information (even if it is infrequent relative to available disconfirming information) while at the same time become more 
and more confident about the accuracy of their original hypothesis. This possibility underscores the importance of making accurate hypotheses early in the judgment process. Unfortunately, however, this is usually the time with the least amount of information.

In contrast, Peterson and Pitz (1986) conducted a study in which confidence decreased with additional information. The difference was that, unlike the Oskamp study, they presented additional information which was not a replication of previously available information. In fact, the subjects in this study actually became more accurate with the addition of information, but their confidence decreased as their accuracy increased. Peterson and Pitz argued that the reduction in overconfidence occurred because, when more information was available, subjects became aware of alternative possibilities. They found that subjects gave more extreme estimates when less information was available and exhibited more certainty about their predictions. With less information, subjects actually had fewer reasons to consider alternative decisions or judgments.

Conceptually, clinical extensions of Peterson and Pitz's research are readily imagined. For example, a therapist determines to treat a client for Generalized Anxiety Disorder (GAD) because many of the symptoms are evident. Based on the hypothesis that GAD is the client's problem, the therapist begins treatment with no apparent need to consider alternative treatments. The therapist might even be quite confident that the proscribed treatment for GAD is the best treatment option for the client. In a subsequent session, the client discloses severe marital difficulties. 
Because of this additional information, the therapist then begins to wonder if treating the marital problems might provide more symptom relief for the client than would the treatment for GAD. Given this additional information, the therapist might be less confident in his treatment decision because of the new alternative, yet potentially could be more accurate.

Now consider this in light of this dissertation's topic. A therapist is conducting ongoing therapy with a client. Without additional information that the client is failing to progress in treatment, the therapist is likely to continue conducting therapy "business as usual" since there does not appear to be a need to consider treatment alternatives. Information, such as an outcome measure, indicating that the client is not progressing as expected might have the effect of decreasing the therapist's confidence in maintaining the status quo and increase the likelihood that the therapist will begin to consider new treatment alternatives.

Pursuit of Information. Does the pursuit of additional information in and of itself affect decision making? Bastardi and Shafir (1998) tested the effect that the pursuit of useless information had on decision making in a number of different scenarios. In each of the control conditions, all the information that was necessary to make a decision was presented at the same time and subjects were then able to choose behavior A or B. In the experimental conditions, all of the information was the same, except that one piece of information was said to be unavailable until the next day. This information appeared relevant, but in these scenarios was not required to make the decision. The subjects in these conditions were also offered choices A and B, but 
this time behavior $\mathrm{C}$ was added. The third choice was to wait until the next day to find out the additional information (which was really unnecessary to make the decision in the first place). In each different scenario, a majority of the subjects chose to wait for the information.

Immediately following this, the subjects in the experimental conditions who chose to wait were given the additional information, which was exactly the same as what was presented initially in the control condition. Subjects who chose to wait were then offered choices A and B. Intriguingly, the results were different than in the control conditions. These subjects were offered the exact same information, yet as a group, tended to choose a different behavior. The only manipulation was that the subjects read on a paper that there was a day's wait until they could obtain one additional piece of information (which, remember, was not critical for the decision anyway).

Redelmeier, Shafir, and Aujla (2001) replicated this finding with health professionals. The same results were found when testing dialysis nurses, practicing urologists, and academic physicians in their own areas of expertise. This phenomenon possibly has far reaching implications for mental health professionals as well and there are several potential studies which could further investigate this phenomenon. There are also conceptually many clinical extensions of this research. Consider the situation in which a new client informs his therapist that he is motivated to change his life now, and that he went to another therapist a year prior before he "was ready to change," resulting in the prior therapy experience not working out. The therapist decides to 
wait and seek the previous therapist's progress notes of the case before completing her assessment.

In regards to assessing client change, another example is the client who verbally describes how she is not getting better after 8 sessions of therapy and outcome measures corroborate the client's claim. The therapist, however, decides to wait until he can view her service satisfaction survey before he determines whether he needs to alter the treatment plan (satisfaction questionnaires often yield positive satisfaction with services). The act of pursuing the satisfaction survey information might make that information more important than it would have been had it been immediately available. Will the pursuit of the additional information, in and of itself, change the behavior of the therapist? Hopefully not, but in studies of other professionals the actual pursuit of additional information apparently changed the subjective weighting of that additional information.

Complex Situations. There is also research demonstrating that additional information can actually lead to not making decisions and keeping the status quo in complex situations. Recalling the previous discussion of anchoring, Hastie and Dawes (2001) suggest that the most common anchor is the status quo. In complex and uncertain situations, people will sometimes choose to defer their decision (Tversky \& Shafir, 1992). As an example, Redelmeier and Shafir (1995) presented family physicians a hypothetical problem of a patient in which the physician has already decided to refer the patient to an orthopedic consultant for consideration of hip replacement surgery. The physicians are then told that before sending the patient 
away, they notice that there is one medication that this patient has not tried (ibuprofen). The decisions that could be made were to refer and also start a new medication, or to refer and not begin a new medication. Under these conditions, 53\% chose to refer and not to start a new medication. However, when the same information was presented and two medications were listed as having not been tried, $72 \%$ of the physicians chose to refer without starting a new medication. These results suggest that due to the conflict of having to choose between two medications, many physicians decided to maintain the status quo and not make any changes to the already decided upon treatment plan.

In a second investigation, Redelmeier and Shafir (1995) tested this effect on neurosurgeons. After having been given information concerning two patients, neurosurgeons were asked to choose which to operate on since there was only 1 operating table available. Most chose patient 1 under this scenario instead of patient 2. A second condition added a third patient. In this scenario (in which patients 1 and 3 were similar, though not identical), most surgeons chose to operate on patient 2 rather than either patients 1 or 3. It appears that surgeons had difficulty choosing between patients 1 and 3 and decided to avoid the conflict and chose patient 2 instead (even though patient 1 was chosen over patient 2 when presented alone).

In clinical work, decisions are often conflicted. Contradictory information is present leading to uncertainty concerning the appropriate course of action. To date, there is no research investigating whether therapists tend to delay making decisions when the choice is difficult. But it raises an interesting question whether this same 
decision making tendency is at play in treatment decisions. For example, after a few sessions of therapy with a particular client, it appears to some degree that the client is not improving in therapy. However, the therapist has received mixed information about what might be a helpful change in the treatment being offered. In the event that the decision as to what treatment alteration might be best is a difficult and conflicted one, might the therapist choose rather to maintain the status quo and continue therapy as it has been going (as the physicians did)?

As can be seen, additional information does not always make the clinician's job any easier. The additional information might lead to enough conflict that it makes effective decision making problematic. The pursuit of additional information might lead clinicians to alter the subjective weight of the information that they are pursuing. In certain situations, additional information can create an exaggerated sense of confidence without an accompanying increase in accuracy. On the other hand, in some situations additional information can trigger the realization of alternative decisions not presently considered. Most of the studies in this section were not conducted on clinical psychologists and it is uncertain if the findings would extend to clinical tasks like judgment of client change and the following treatment decision. It is expected, however, that in clinical work all of these effects of additional information may play a role. Perhaps it is hopeful thinking that most of the time, despite a tendency to ignore disconfirming information, the process of receiving more information aids the clinician in taking into account alternatives he or she had not previously considered. 


\section{Assessing Client Change in Therapy}

A crucial task of successful therapy is assessing client improvement. In the event that a client is not making positive changes in therapy or perhaps is even getting worse, successful treatment depends on the clinician recognizing this and acting appropriately (perhaps by making some sort of alteration to the treatment). As has been noted, there has been little research in the area of clinical judgment and decision making regarding clinician assessment of client progress.

Weiss, Rabinowitz, and Spiro (1996) compiled a review of studies that deal with agreement between therapists and their clients in their evaluation of problems, process, and outcomes of therapy. In regards to client and therapist agreement of change (outcome), they found 23 studies dealing with agreement about change as a result of therapy. Some researchers emphasized the tendency of both therapists and clients to note positive change more than negative change. Five of the studies reported that therapists evaluated the results of therapy more positively than did their clients, while seven others found the opposite. Unfortunately, the authors found that the extent of agreement reported depended primarily on how agreement was measured and consequently they call for more uniform research methods investigating client and therapist agreement of change.

In a related line of research, Horvath and Symonds (1991) found that both clients' and observers' reports of therapeutic alliance appear to be more predictive of outcome than therapists' judgments of alliance. Research has demonstrated a strong association between the alliance and outcome (Lambert \& Ogles, 2004). If outcome 
and alliance are associated, then therapists who subjectively assess client change via their own impressions of the alliance might be less accurate in assessing outcome and change than their clients.

In relation to making judgments about therapeutic change, there are several potential sources of information that might influence a clinician's judgment. It is reasonable to assume that a significant portion of the information that a clinician receives comes from the client's verbal report. However, there are additional sources of information that might factor into clinicians' judgments of client progress in therapy. Regardless of the client's verbal report, clinicians might make observations of client behavior or affect during the session that might be informative in assessing client improvement or deterioration. Significant others might provide additional information about a client's therapeutic change or lack of change. Some agencies and individuals use measures of client satisfaction with services received as a way to gauge therapeutic effectiveness. Another source of information is outcome measures. There are an increasing number of therapists who have outcome measure data available (Hatfield \& Ogles, 2004) which can serve as an additional source of information when making judgments concerning client progress.

Research is beginning to demonstrate that these various sources of information offer distinct perspectives that may or may not be related. As was implied by the research just described, it is possible that client and therapist perception of the client's improvement might not completely agree. Since the therapist is the trained individual and is an "objective" observer, and because the client is the person who best knows 
how the client is actually doing, neither of the perspectives can easily be dismissed. There is some research which seriously questions the association between client satisfaction with services received and symptom reduction (Lunnen \& Ogles, 1998; Lambert, Salzer, \& Bickman, 1998). Conversely, Ankuta and Abeles (1993) did find a significant relationship between satisfaction indices and measures of client outcome.

Outcome Measures. Though each of the above mentioned sources can potentially provide important information, a primary focus of this dissertation was the utilization of outcome measures in assessing client improvement. The reason for this focus stems from the findings of Michael Lambert's research team (Lambert et al., 2001; Lambert et al., 2002; Whipple et al., 2003) in providing therapists with feedback generated by outcome measure data. A main purpose of this dissertation was to explore in a more systematic manner the supposed implications of using outcome measures in routine clinical practice, as suggested by the findings in the feedback studies. Before describing these studies in detail, it would be beneficial to comment on the current use of outcome measures in clinical practice today.

Psychotherapy researchers have, for the most part, been the people to both develop and use these outcome measures, and there have been many kinds of outcome measures developed (Froyd, Lambert, \& Froyd, 1996; Maruish, 2004; Ogles, Lambert, \& Masters, 1996; Sederer \& Dickey, 1996). Outcome measures are essential to the methodology of a majority of psychotherapy research studies. In order to study most aspects of therapeutic effectiveness, client change needs to be measured in some way. 
Psychotherapy researchers use outcome measures to examine the effects of an assortment of interventions in therapy.

Many of the outcome measures generated for research purposes, however, have been applied in actual clinical practice, while there are a few measures developed specifically for use by practicing clinicians in therapeutic settings. These outcome measures can be administered prior to treatment, any time during treatment, immediately following termination of treatment, and at a later time after treatment has ceased. There are several potential benefits of implementing such outcome assessment strategies in clinical practice.

In spite of the potential benefits, it appears that relatively few clinicians engage in standardized outcome assessment. In one of the few studies examining the use of outcome measures in routine practice, the American Psychological Association (APA) Committee for the Advancement of Professional Practice (CAPP) surveyed psychologists (members of the APA) about the effects of managed health care on their practices (Phelps, Eisman, \& Kohout, 1998). One of the items in the questionnaire asked whether or not the psychologist used an outcome measure. Twenty-nine percent of the sample reported using some form of outcome measurement in their clinical practice, with $60 \%$ of those using a standardized measure (e.g., BDI, SCL-90, MMPI, etc.) and $40 \%$ using an unstandardized outcome measurement method. This translates into roughly one out of five clinicians surveyed use a standardized measure. There was also a trend indicating that clinicians who received their licensure most recently were more likely to use outcome measures. 
Bickman et al. (2000) conducted a survey to assess the values and attitudes of clinicians who worked with children and adolescents in regards to outcome assessment (539 responded). Of the clinicians surveyed, 23\% reported that they used standardized outcome measures with their child or adolescent client cases. They also found that a large percentage of practitioners were interested in participating in outcome research and would like to receive outcome information about their clients at intake, during treatment, and after termination.

Hatfield and Ogles (2004) conducted a survey of independent psychologists in clinical practice to better understand who is using outcome measures and to assess factors (such as work setting, clientele, source of income, and others) that may influence whether or not clinicians use outcome measures in their practice. Another aim of this study was to elucidate the reasons that practitioners give for using and not using outcome measures. Respondents were members of the APA who were clinically active at the time of completing the survey. Of those receiving the survey, $50 \%$ responded. A total of $46 \%$ provided usable data. A majority of the respondents held a Ph.D. (10\% Psy.D.) and 60\% reported working a majority of their time in private practice.

In contrast to the earlier surveys, a surprising $37 \%$ of respondents reported gathering outcome data of one form or another. This is higher than the $29 \%$ of respondents in the CAPP (Phelps et al., 1998) study and the $23 \%$ who reported using standardized measures in the Bickman et al. (2000) study. With the spreading influence of managed care and other institutional pressures for accountability, plus an 
increase of training in the potential benefits of outcome assessment, this change might represent a shift in the field towards an increased use of outcome measures as part of clinical practice.

Clinicians working in institutional settings were more likely to use outcome measures than were clinicians in private practice (either group or solo practice). Whether this is due to external influences (i.e., agency or government requirements) or to enhanced resources (i.e., personnel, funding) to conduct outcome assessment is unknown. Not surprisingly, insight oriented therapists were less likely than cognitive or behavioral therapists to use outcome measures. This difference may reflect differences in training emphasis related to outcome assessment or to basic philosophical differences in the nature of assessment in general. In addition, it is possible that insight-oriented practitioners believe that the targets of treatment are not easily measured in the form of symptoms, behaviors, or other overt constructs.

When respondents were asked to rate the reasons why they use outcome measures as part of their practice, "tracking client progress" was rated quite high and was the most important reason given by outcome users. Related to tracking client progress, the second highest rated reason for using outcome measures was "to determine if there is a need to alter treatment." When tracking client progress using standardized measures, clinicians will have data available to help them know when new or different strategies may be needed to improve treatment. It appears from the Hatfield and Ogles study (2004) that some clinicians are using outcome measures as a tool in the process of judging client change, leading to potential decisions regarding 
treatment. Outcome measures represent one form of additional information as clinicians engage in the task of assessing client change.

Lambert, Strupp, and Horowitz (1997) state that "there is a need to develop a consensus about which measures most accurately reflect patient improvement." There have been efforts made to develop a core battery (Horowitz, Strupp, Lambert, \& Elkin, 1997), though this project has not yet produced a battery that is generally accepted. It is somewhat amazing that given the amount of years outcome measures have been used, there has not been a consensus of which measures are best suited for research and clinical purposes.

Addressing this issue, Shulte (1997) offers a paradigm from the medical model for measuring treatment success. In this paradigm, disease can be interpreted as the cause of the disorder, whether the cause is biological, psychological, or sociological. These causes then create (psycho)pathological changes or deficits in the person. The changes or deficits lead to the illness, which can be labeled as the symptoms and complaints. The consequence of the symptoms is impairment of normal behavior. The general concept of disease presumes this causal chain: causes - defect manifestation - consequences.

This paradigm addresses important aspects of psychotherapy outcome assessment. Shulte (1997) delineates how different psychotherapeutic schools offer different explanations for the manifestation of symptoms, or in other words, they attribute different causes to the symptoms. Treatment goals, in the sense of "healing" the pathological deficits or defects, will then be different for the various theoretical 
orientations. Due to this, outcome assessment will also differ between the schools. Schulte gives these examples: for psychodynamic therapies, changes in ego functions, defense mechanisms, and interpersonal conflicts can be measured; in Rogerian counseling, the theoretically postulated discrepancy between the perceived and ideal self can be measured; behavior therapists have mainly used measures of target behaviors on the level of illness; for cognitive therapists there are instruments to assess cognitive variables associated with maladaptive belief patterns; and psychiatric researchers look for markers of biochemical defects in mental disorders. Measures of treatment success will look quite different from each other considering the theoretical variability found in our field today.

Schulte finds some common ground, however, between the theoretical orientations. No matter what cause or combinations of causes are attributed to producing the symptoms, the fact remains that symptoms are present and Schulte suggests that there can be agreement about the description of symptoms and notes the efforts represented by the DSM and ICD. Despite the differences in treatment goals, the healing of pathological defects will most often lead to a reduction of symptoms. Outcome measures which focus on symptoms can therefore be used by most theoretical orientations as a usually direct, and sometimes less direct, method of assessing treatment success.

This paradigm offers a solution to a fundamental problem faced by researchers today. Though research tends to be conducted within the frameworks of specific models of therapy, Schulte's proposition that measures of symptom severity can 
generally assess treatment success has important implications for the use of outcome measures in clinical practice. Symptom based measures can be generally used in any setting and can provide most of the theoretical orientations the benefits of using outcome measures in clinical practice.

In making a judgment concerning client change (improvement or deterioration) clinicians often have several cues impacting the judgment. Client verbal report and clinicians' observations are perhaps the cues most typically available to make this judgment. Outcome measures are beginning to be used more frequently and provide one more cue in a clinician's attempt to determine the degree to which clients are improving or deteriorating. Outcome measures are not the only source of information pertinent to assessing client change. Most clinicians still do not use this information and many do not feel it is important. Newer research exists which systematically alters availability of information in the form of an outcome measure and have studied the influence this has on client change. This research is now described in more detail in the following section.

\section{Effects of Providing Outcome Measure Feedback to Therapists}

Traditionally, outcome assessment has been a research enterprise, but recently, there have been indications that outcome measures are being used by some independent practitioners to enhance their services. As found in the Hatfield and Ogles study (2004), the most important reason indicated by practitioners was to "track client progress." Creating dose-effect curves and therapist feedback systems are two 
tools that can be very beneficial to the therapist conducting psychotherapy and can actually aid the therapist in making treatment plan decisions.

In a qualitative study of fifty randomly selected clinicians in a large children's mental health service system, all of whom received scored assessment profiles for their clients, Garland, Kruse, and Aarons (2003) found that the vast majority reported not using the outcome measure information as part of treatment planning or monitoring. Despite the fact that most reported not using the information, there were other indicators that some of the clinicians found the process of treatment monitoring clinically useful. This study was conducted within the same service delivery system and does not necessarily represent clinicians across the country. It appears that these clinicians were either unaware of or unconvinced by studies in which using outcome measure information was clinically useful. The remainder of this section will demonstrate some methods used by others in which outcome measure information can be clinically useful.

One of the most important ways in which outcome assessment can be beneficial occurs when practitioners receive feedback concerning the current level of the client's functioning or the progress that has been obtained since therapy started. Recently, the Journal of Consulting and Clinical Psychology published a special section on this very topic (Lambert, 2001). When practitioners receive additional information in the form of feedback obtained from outcome measures, they can use the information to make decisions regarding the current treatment plan for the individual client. 
One way that this can be beneficial to clinicians is through the development of dose-effect curves. The dose-effect relationship predicts how well a particular client is expected to improve after a certain number of sessions. This is called patient profiling, and the benefits of this approach can be very important to the practicing clinician. Howard, Moras, Brill, Martinovich, and Lutz (1996) developed a patient profiling system that includes an estimated, expected course of treatment response for each patient based on his or her initial clinical characteristics.

As an example of how the creation of dose-effect expectancies can be helpful, imagine that the dose-effect curve for Clinician X predicts that Client Y will have improved by 20 units of the outcome measure after 4 sessions of Clinician X's therapy. Suppose that Client Y improved by only 5 units after the fourth session. The therapist might then reconsider this particular case to determine why Client $\mathrm{Y}$ is not progressing as might be expected. Similarly, if Client Y had actually deteriorated (demonstrated by a worse score on the outcome measure), Clinician X might then want to seriously consider changing the current therapeutic strategy and treatment plan.

There has been little research on client deterioration, with most findings in this area embedded as secondary results in research projects with other primary aims. The research that does exist suggests that approximately $5-10 \%$ of clients get worse, or deteriorate in therapy (Lambert \& Ogles, 2004; Mohr, 1995). The special section in the Journal of Consulting and Clinical Psychology (Lambert, 2001) summarized efforts to identify clients who might be at a higher risk of having a poor response to 
treatment. Being able to identify clients who are not improving or who are even getting worse is a crucial task if the clinician is to consider changing the treatment plan accordingly. However, it appears that clinicians might not be able to always differentiate between clients who are deteriorating from those who are simply not improving (Lunnen \& Ogles, 1998).

Receiving information from outcome measures during the course of treatment gives the practitioner the advantage of seeing from an additional perspective whether or not a particular client is improving as might be expected (Lueger, Howard, Martinovich, Lutz, Anderson, \& Grissom, 2001; Kazdin \& Wassell, 1998). If the client is not improving, then the therapist can be alerted to this and either begin a further assessment to investigate the reasons or perhaps alter the treatment if deemed necessary. "It is incumbent on practitioners to continually assess the outcome of their work with clients. If a therapist's clients are not improving, then the therapist must take responsibility to alter either his or her approach and interventions or the manner in which they are implemented" (Whiston \& Sexton, 1993).

Lambert's Feedback Studies. Often in psychotherapy research, pre- and posttreatment outcome assessments are required to detect changes resulting from manipulations of the independent variable being studied. However, Hatfield and Ogles (2004) found that "tracking client progress" was the most important reason that clinicians are using outcome measures in their clinical practices. Obtaining this type of information requires more than pre- and post-treatment measurements of change, rather continuous assessment of client change is needed to track therapeutic progress 
or a lack thereof. Is tracking client change beneficial and what are the effects of providing therapists with feedback concerning therapeutic progress?

An example of research exploring if and how measures can be beneficial to therapy outcome was demonstrated in a series of studies by Michael Lambert's research team. In their first study (Lambert, et al., 2001), these researchers wanted to investigate whether therapists who received feedback concerning client progress promoted more positive change in clients than did therapists who did not receive feedback. In this study, clients in a large university counseling center were given an easy-to-use, self-report outcome measure prior to each session of therapy. Therapists in the feedback condition received the score of this measure on a timely basis (during the following week), and information about how this client was progressing was compared to what would be expected for that particular client (as determined by algorithms created from dose-response expectancies, considering initial level of symptom severity).

After each completed session of treatment, decision rules were used to generate feedback using a progress graph and colored dot system. The dots were used to visually catch the attention of the therapist. The decision rules were based on patient intake score (initial level of disturbance), the number of treatment sessions completed, and the amount of change noted at the most recent session compared to the patient's initial.

For example, a client with an initial intake score of 90 and after 3 sessions of therapy improved by -10 units on the Outcome Questionnaire-45 (Lambert et al., 
1996), the therapist would be given a green dot (indicating that the client was progressing in the adequate range of what might be expected). Different colored dots indicated how the client was progressing (compared to expected progress) and was one potential source of information influencing judgment of client change and subsequent treatment plan decisions (e.g. possible termination due to successful change in the client, continuation of current treatment plan due to adequate change, possible alteration of treatment plan due to lack of change, or perhaps a serious alteration in the treatment plan due to negative change in the client during therapy indicating a possible dropout in therapy). Algorithms using patient profiling techniques were used to determine the cutoffs for each of the groups.

In this study, half of the clients were randomly assigned to either the experimental condition (therapists received feedback on client change) or the control condition (outcome measures were given, though feedback was not given to the therapist). The researchers hypothesized that the clients being treated by therapists who received feedback would progress better than the clients whose therapists did not receive feedback.

The results of the study indicated that there were no differences between the experimental and control conditions for those clients who were recovered or recovering in the adequate range. In other words, therapists receiving feedback did not help clients who were improving adequately to progress any better then did the therapists who were not receiving feedback. However, these researchers also found that even though clients with therapists in the feedback condition did not make more 
improvement overall than clients with therapists in the non-feedback condition, clients in the first group achieved their level of significant improvement sooner than did the others, resulting in fewer therapy sessions. This demonstrated the potential for outcome measures to improve therapeutic efficiency.

On the other hand, for those clients who were not improving as might be expected or were actually getting worse, the post-treatment outcomes were significantly different for the clients of feedback and non-feedback therapists. For these clients, therapists who received feedback and were alerted to the possibility of treatment failure were able to help their clients progress better than the therapists who were not provided with such feedback. Clients who were identified as not improving or getting worse and whose therapist was given feedback, stayed in therapy for more sessions than did clients whose therapist did not receive the feedback.

In an informal evaluation after data collection, none of the 29 interviewed therapists reported that they increased or decreased the number of sessions given to a client as a result of feedback. In fact there was considerable surprise expressed by the staff when informed of the finding that feedback cases had fewer sessions for improved clients and more sessions for clients not improving or getting worse. The researchers postulated that since the dose-effect literature demonstrates the correlation between client improvement and number of treatment sessions, feedback in this study may have had its greatest impact through improving the attendance of clients getting worse or not improving. It should be noted that it was unclear in this study what modifications to treatment interventions occurred following feedback, and Lambert et 
al. (2001) recommend that "the degree to which clinicians modify treatment behaviors following feedback should be a high priority for future research."

In a second study which aimed to replicate these findings, Lambert, et al. (2002) again found that for clients who were identified as not improving or getting worse, and whose therapist received feedback, had better post-treatment outcomes than similar clients whose therapist did not receive feedback. As in the first study, clients with a higher risk for treatment failure participated in more therapy sessions if their therapist received feedback. For clients whose were progressing as expected, the finding that clients in the feedback condition had fewer sessions of therapy failed to be replicated.

A difference in the second study was the inclusion of a tracking form in which the therapist briefly reported their actions following receiving a warning that their client presented an increased risk for treatment failure. Therapists reported that they "increased contemplation about the case" in $40 \%$ of the cases, "discussed the case in supervision, consulted with other professionals" in $37 \%$ of the cases, "became more directive with the client" in $28 \%$ of the cases, "discussed OQ feedback with the client during the session" in $18 \%$ of the cases, and "reconceptualized the case and/or altered the treatment plan" in $12 \%$ of the cases. Comparisons between patient outcomes of therapists endorsing and not endorsing these actions were not statistically significant. In contrast, clients whose therapist reported that they "referred for medication and/or referred for additional treatment/services" (in 19\% of the cases) had outcomes 
significantly worse when therapists reported taking these actions as compared to when therapists did not report such actions.

In a third study, Whipple, et al. (2003) added an additional component to the feedback condition. Clients who were identified as potential treatment failures were placed in one three 3 conditions: control-no feedback, experimental-feedback, and experimental-feedback + clinical support tools. In this study, when therapists received feedback that their client was not improving or getting worse, additional support tools were also made available. The clinical support tools were represented in a decision tree designed to systematically direct the therapist's attention to certain factors known to be important in psychotherapy outcome, such as: the quality of the therapeutic relationship, client motivation (readiness for change) and its match to treatment tactics, the client's social support network, reevaluation of diagnostic formulations, and an indication for medication referral. Brief measures of the therapeutic alliance, client motivation, and social support were available for use by the therapist as well as possible interventions based on these assessments.

The results indicated that client outcomes were better for therapists who received feedback and used the clinical support tools than for therapists who only received feedback or who received no feedback. Again, more treatment sessions were observed in the feedback + clinical support tool condition for clients whose therapist was warned of potential treatment failure than for those whose therapist received only feedback or no feedback. 
Whipple, et al., (2003) indicated that there was hesitancy on the part of many clinicians to increase paperwork with the use of the clinical support tools. Therapists were therefore allowed to decide for themselves whether to use the clinical support tools and consequently only $40 \%$ chose to do so. Further research is needed to eliminate any therapist effects, though the findings of this study are encouraging for the beneficial use of clinical support tools.

In addition to this primary finding, Whipple et al., (2003) replicated the finding of the previous two studies in which clients who improved as expected in the feedback and no feedback conditions both demonstrated comparable outcome gains at the completion of treatment. This study, however, found that clients of therapists who received feedback improved in fewer sessions than did clients in the control condition. Though they did not find this in the second study, the results of the Whipple et al., (2003) study add guarded confidence in the original finding. While feedback has been demonstrated to improve outcome for clients who are at risk for treatment failure, feedback might also aid in resource efficiency, helping therapists to allocate more therapy sessions to clients who are more distressed and fewer to those who improve in therapy.

In using a system similar to the one described above, practitioners can use an outcome assessment strategy to help guide them in their decision-making processes. Lambert, Okiishi, Finch, and Johnson (1998) suggests that using such a system aids in decision making in various ways. They postulate that if the therapist's outcome assessment strategy shows a patient has returned to normal functioning, termination 
might be considered or perhaps a spacing out of sessions. A lack of progress might result in increased contemplation of the case, leading to consultation and/or a revision of the treatment plan. Progress, but failure to achieve critical results, might indicate the need for continued treatment.

As is true of every phase of therapy, clinicians must make decisions. Choosing to continue treatment as it has been conducted or to alter the treatment plan in some way or to move towards termination is a decision that every practitioner must make in the course of therapy. The scores from an outcome measure would, of course, not be the only factor in treatment plan decisions, but might provide a valuable source of information that the therapist could consider in making those treatment plan decisions.

The researchers conducting the feedback studies utilized little control of the clinical behaviors of the therapists. In an attempt to not interfere with normal clinical practice, they also have little knowledge from observation of how the therapists used the information from outcome measures. It is uncertain to what degree the outcome measure influenced the therapists' judgment of client change and whether this led to actual alterations in the treatment being conducted. The provision of an additional source of information led to enhanced client outcomes for clients predicted as likely treatment failures; however, the mechanisms of this phenomenon are not clearly understood.

Studying Outcome Measures and Verbal Report as Additional Sources of Information

One of the purposes of this study was to investigate the effect that additional information, in the form of a standardized outcome measure and client verbal report, 
might have on clinicians' assessment of change and decisions regarding treatment. It is still uncertain what specific effect feedback had on clinicians' decision making processes in the Lambert et al. (2001 and 2002) studies. In the situations in which clinicians were warned of potential treatment failure, perhaps the additional information led the clinicians to become aware of alternatives that they had not previously considered (i.e., that this particular treatment is not helping this particular client).

To further investigate this on a more experimental level, clinicians were given a brief scenario of a continuing therapy case in the form of a two paragraph vignette. Much of the information was consistent across all of the vignettes to eliminate potential confounding variables introduced through differing information. Each of the vignettes contained information that was meant to be neutral, giving little to no hints as to whether the client was improving, not changing, or deteriorating. The first vignette condition contained only this information. It served as a control group and provided a baseline to compare the impact of giving other information in the vignettes. The remaining vignettes included a combination of information from outcome measures or client verbal report. The outcome measure and client verbal report had three versions each: 1) an indication that the client was getting better, 2) an indication that the client was getting worse or 3) the particular information was left out entirely. All potential combinations created the nine vignettes used in this study. Table 1 contains the names and associated acronyms of each condition, which will be used throughout the remainder of this manuscript. 
Table 1

Vignette Conditions

\begin{tabular}{|l|l|}
\hline Condition & Identifier \\
\hline No client verbal report - No outcome measure report & NVNO \\
\hline No client verbal report - Negative outcome measure report & NVO- \\
\hline No client verbal report - Positive outcome measure report & NVO+ \\
\hline Negative client verbal report - No outcome measure report & V-NO \\
\hline Negative client verbal report - Negative outcome measure report & V-O- \\
\hline Negative client verbal report - Positive outcome measure report & V-O+ \\
\hline Positive client verbal report - No outcome measure report & V+NO \\
\hline Positive client verbal report - Positive outcome measure report & V+O+ \\
\hline Positive client verbal report - Negative outcome measure report & V+O- \\
\hline
\end{tabular}

A more detailed description of the vignettes is contained in the methods section. The information from the outcome measure or client verbal report represented additional sources of information or cues which clinicians might use in making a judgment of client change.

Following the vignette, clinicians were asked to rate how much they think the client has changed and in what direction. Clinicians were then given the opportunity to make a decision about what to do: they could choose to continue therapy as it has been going, they could choose to consider taking steps towards termination, or they could choose to alter the treatment in some manner. Following this decision, clinicians were then asked how confident they were in their decision.

Though brief vignettes only simulate the rich detail and information that real life cases offer, it is hoped that these case studies represent to some degree the manner in which busy clinicians work. When clinicians have heavy case loads and several demands on their time, it is reasonable to assume that clinicians do not have much, if 
any, time to think about a client outside the session hour. Due to this constraint caused by the work environment, the clinician might have some difficulty in attuning to the complex patterns of information of a particular client from one session to the next. In some situations, perhaps it is rather easy to determine that the client is getting worse or better. The times when it is not a simple decision, however, are a different matter and led to the purposeful ambiguity in the vignettes. The control condition (no outcome measure and no client verbal report) would therefore represent situations in which the therapist is not necessarily alerted to potential treatment failure and has not noticed evidence that the client has made significant improvements. The mean judgment rating for the control condition was hypothesized to be statistically indistinguishable from 5 (indicating no change). This was the first hypothesis and will be identified in this manuscript as $\mathrm{H} 1$.

Due to the fact that there is a significant portion of clinicians who do not use outcome measures or feel that they are helpful (Hatfield \& Ogles, 2004), it was hypothesized that client verbal report would have a stronger impact on clinician judgment of client change than did outcome measure report $(\mathrm{H} 2)$. This was investigated in direct comparisons as well as by an investigation of the contradictory scenarios. In addition, it was hypothesized that additional confirmatory information (adding outcome measure indicating improvement to verbal report of improvement) will increase the judgment of client change, more than either type of information alone (H3). Due to a potential bias for clinicians to see pathology, it was hypothesized that 
reports of change in the negative direction (from either source) would have more impact than reports of client improvement (H4).

With no indication that the client in the vignette was getting better (perhaps leading to a move towards termination) or worse (indicating a need to alter treatment), it was anticipated that most clinicians in the control condition would choose to continue treatment as they have been (H5). Additionally, research has demonstrated that in some complex and uncertain situations people will often choose to defer their decision (Tversky \& Shafir, 1992). In the scenarios in which contradictory information was presented, it was hypothesized that clinicians would choose to maintain the status quo and continue treatment as usual in light of the conflicted information (H6).

Lambert, et al. (2001) and Whipple, et al. (2003) found that providing clinicians with outcome measure information led to a reduced amount of sessions for some clients who were progressing as expected. Therefore recognizing considerable client improvement and moving towards a possible termination might not be as easy as it seems. Additional information such as the positive outcome measure might lead clinicians to more deeply evaluate client progress and assess whether termination is warranted. It was hypothesized that client verbal report indicating client improvement would more likely lead to "considering steps towards termination" when corroborating outcome measure information was included, compared to client verbal report alone (H7). 
It can also be quite difficult for clinicians to recognize when their clients are getting worse. Clients typically present with some level of symptom distress and clinicians spend most of their working time with distressed individuals. In the situation where a therapist has a heavy caseload, it can be difficult to distinguish if a client is more distressed than they were previously in therapy. The negative outcome measure might direct the clinician to carefully reevaluate this client's lack of progress and perhaps make an alteration in treatment.

Oskamp (1965) found that confidence increased with the addition of similar information and it was hypothesized that confidence will increase with two sources indicating improvement or deterioration compared to either source alone (H8). Peterson and Pitz (1986) found that judges' confidence decreased with additional information even though accuracy improved. It was therefore hypothesized that when clinicians were presented with contradictory information (e.g., outcome measure indicated improvement and verbal report indicated deterioration) confidence would decrease (H9).

It was hypothesized that the confidence levels would be significantly higher when the outcome measure corroborates the client verbal report as compared to when it contradicts the client (H10). No matter what treatment decision the clinician makes, it was anticipated that it would be with lower confidence in the event of contradictory information. It was also hypothesized that the clinicians who received no information concerning client progress (control condition) would be least confident in whatever treatment decision they made (H11). 
One final question was asked of clinicians to explore the more general issue of how clinicians assess client progress. They were presented with a list of several sources of information such as client verbal report, clinician observations, service satisfaction survey, significant other report, outcome measure, etc. Clinicians were then asked to assign a percentage to each potential source of information, representing how much each one is a factor in the clinician's judgment of treatment progress. The ratings had to equal $100 \%$, thereby providing a subjective weighting of information from the clinician's perspective. It was anticipated that client report and clinician observations would be the highest rated sources of information (H12).

Each of these hypotheses will be addressed in the discussion section. A brief summary of all twelve are listed now. First, NVNO would be close to 5 . Client verbal report would have a stronger impact on clinician judgment of client change than did outcome measure report. Additional confirmatory information will increase the magnitude of client change more than either type of information alone. Reports of change in the negative direction (from either source) would have more impact than reports of client improvement. Most clinicians in the control condition would choose to continue treatment as they have been. Clinicians would choose to maintain the status quo and continue treatment as usual in the contradictory conditions. Client verbal report indicating client improvement would more likely lead to "considering steps towards termination" when corroborating outcome measure information was included, compared to client verbal report alone. Confidence will increase with two sources indicating improvement or deterioration compared to either source alone. 
When clinicians were presented with contradictory information confidence would decrease. Confidence levels would be significantly higher when the outcome measure corroborates the client verbal report as compared to when it contradicts the client. Clinicians who received no information concerning client progress (control condition) would be least confident in whatever treatment decision they made. Finally, client report and clinician observations would be the highest rated sources of information.

The overall findings of these various investigations were interesting in and of themselves. For additional analyses, however, clinicians completed a short demographic questionnaire allowing for several other comparisons. For example, did the additional information provided by an outcome measure have the same effect for clinicians with heavy caseloads compared to those with lighter caseloads? Clinicians were able to be compared on several other dimensions, such as: work setting, theoretical orientation, type of training, years of experience, etc.

Preliminary research is demonstrating the effect that additional information can have on clinical effectiveness and efficiency (Lambert, et al., 2001; Lambert, et al., 2002; Whipple, et al., 2003). More research is needed to better understand how feedback, from various sources of information, is affecting clinical decision making. An enhanced knowledge of this process can potentially lead to improved clinical practice and training. This dissertation begins to take a deeper look at the effect outcome measures and client verbal report can have on clinical decision making and represents only the beginning of potential research aimed to better understand this phenomenon. 
Methods

\section{Participants}

This study surveyed a national sample of psychologists. The random sample consists of members of the APA who are currently practicing therapy. A mailing list was obtained from the APA research office. In order to have only practicing therapists in the national sample, specific selection criteria were requested. Those included in the sample had to be licensed practitioners in the United Sates and must have paid the special assessment fee. The special assessment fee is a mandatory fee for all those who desire to practice therapy. Using this as a criterion excluded many of the people who do not currently practice from being part of the sample.

After the responses from two mailings were collected, a total of $894(50.0 \%)$ of the 1,800 practitioners in the sample responded. For the sample of usable data $(\mathrm{N}=$ $810), 50.6 \%$ of respondents were male, with $49.4 \%$ reporting being female. For the entire APA membership, 50.8\% are men with $49.2 \%$ women. A majority of the sample (83.1\%) indicated that a Ph.D. was their highest degree obtained. Eight and a half percent held a Psy.D., 4.2\% an Ed.D., and 1.5\% reporting a masters degree. In the general APA membership, 80\% hold a Ph.D., 8.3\% a Psy.D., and 4.7\% an Ed.D. Many practitioners in that study worked with adults (50.9\%), while $8.7 \%$ worked with children and/or adolescents. A sizable portion of the sample reported working with both (40.4\%). A large majority of the sample (94.0\%) indicated their race as White, with Hispanic at $1.4 \%$, Asian at $0.9 \%$, Black at $0.5 \%$, and American Indian at $0.3 \%$. The remaining respondents (3.1\%) choose either Multiracial/Multiethnic, Not 
Specified, or Other. General APA membership was as follows: White (76.7\%), Hispanic (2.2\%), Asian (1.8\%), Black (1.7\%), American Indian (0.2\%), and Not Specified (17.3\%).

Practitioners reported conducting therapy for an average of 22.9 hours per week $(s d=12.2)$ with 1 hour per week being the lowest and 60 hours being the highest reported. The average number of years since first licensure for the entire sample was $18.4(\mathrm{sd}=7.9)$, with the earliest date reported being 1960 and the most recent being 2001. The responses were grouped into three groups for reasons of data analysis. The groups are: pre-1980, 1980-1989, and 1990-to-present.

Respondents were asked to report the percentage of time that they worked in various settings. These results appear in Table 2. Those settings that were identified as being the only work place for the respondent are listed separately from those settings that we considered their primary work setting (51-99\% of their time). The settings are listed in order of their percentage of the total sample. There were 51 respondents who indicated that they worked in a setting 50 percent of their time. The remainder did not work in one setting more than half of their time (e.g., 40-40-20 split). 
Table 2

Work setting

\begin{tabular}{|l|l|l|l|l|}
\hline \multicolumn{1}{|c|}{ Setting } & $\begin{array}{l}\text { Single } \\
\text { setting } \\
(100 \%)\end{array}$ & $\begin{array}{l}\text { Primary } \\
\text { setting }(51- \\
99 \%)\end{array}$ & $\begin{array}{l}\text { Total primary } \\
\text { setting }(51 \%+)\end{array}$ & $\begin{array}{l}\text { Percentage } \\
\text { of total }\end{array}$ \\
\hline Private practice (solo) & 217 & 81 & 298 & 49.0 \\
\hline Private practice (group) & 66 & 23 & 89 & 14.6 \\
\hline Med center/hospital & 34 & 21 & 55 & 9.0 \\
\hline University/college & 14 & 34 & 48 & 7.9 \\
\hline Outpatient clinic & 10 & 12 & 22 & 3.6 \\
\hline Forensic/legal & 4 & 12 & 16 & 2.6 \\
\hline Community mhc & 6 & 8 & 14 & 2.3 \\
\hline Government & 8 & 6 & 14 & 2.3 \\
\hline School system & 2 & 10 & 12 & 2.0 \\
\hline $\begin{array}{l}\text { Residential/inpatient } \\
\text { psychiatric }\end{array}$ & 6 & 6 & 12 & 2.0 \\
\hline Medical school & 4 & 2 & 6 & 1.0 \\
\hline Other setting & 10 & 13 & 23 & 3.8 \\
\hline Total & 381 & 228 & 609 & 100.0 \\
\hline
\end{tabular}

For purposes of analysis, the work settings were combined into two groups:

private practice and institutional settings. There are a number of differences in work conditions between clinicians in private practice and those who work in some manner of institution. It is assumed that clinicians in private practice often have more autonomy and less oversight of their work. Approximately two thirds of this sample works in a private practice. For the general APA membership that matched the same selection criteria as this sample, $55.3 \%$ indicated that their primary employment setting was "Independent practice." Other work settings had similar percentages as this study's sample.

In considering the acknowledged theoretical orientation of each of the respondents, only those orientations that received a \#1 rank were counted. The 
numbers of clinicians who endorsed each theoretical orientation are included in Table

3.

Table 3

Theoretical Orientation

\begin{tabular}{|l|l|l|}
\hline \multicolumn{1}{|c|}{ Orientation } & Ranked \#1 & Percent of Sample \\
\hline Behavioral & 11 & 1.7 \\
\hline $\begin{array}{l}\text { Psychodynamic/ } \\
\text { Psychoanalytic }\end{array}$ & 115 & 17.3 \\
\hline Humanistic & 17 & 2.6 \\
\hline Eclectic or Integrative & 194 & 29.1 \\
\hline CBT & 259 & 38.9 \\
\hline Existential & 6 & 0.9 \\
\hline Interpersonal & 28 & 4.2 \\
\hline Other & 33 & 5.0 \\
\hline Total & 668 & 100.0 \\
\hline
\end{tabular}

Due to certain low frequencies, theoretical orientations were separated into three conceptually-based groups for purposes of the analyses. Cognitive Behavioral Therapy (CBT) was combined with Behavioral to form a new "CBT" group. Another group was termed "Insight oriented" and includes Psychodynamic/Psychoanalytic, Humanistic, Existential, and Interpersonal. The Eclectic or Integrative orientation remained alone and was labeled the "Eclectic" group.

\section{Instrument}

A simple and brief demographic questionnaire (Appendix A) was developed for the purpose of comparative analyses. Participants indicated their gender, race, highest degree held, average number of hours they conduct therapy per week, whether they work primarily with adults or children/adolescents, and their year of first 
licensure (as a gauge of how long they have been practicing). They also indicated on the demographic page their primary work setting, theoretical orientation, and a final question asking them if they use some form of outcome assessment in their clinical practice.

There were a total of nine different clinical vignettes (Appendix B). Information in the vignettes was exactly the same with the exception of two varying pieces of information (client verbal report and scores from an outcome measure). A third of the vignettes had the statement, "During your next session with Brian, he explains to you that he is feeling much worse than when he started therapy." Another third contained, "During your next session with Brian, he explains to you that he is feeling much better than when he started therapy." This statement of client verbal report was omitted from the remaining third of the surveys.

A similar pattern was followed in regards to information from an outcome measures. The negative conditions contained, "Scores from a routinely administered outcome measure completed by Brian before each therapy session indicate that the severity of his symptoms has significantly worsened." The positive conditions included, "Scores from a routinely administered outcome measure completed by Brian before each therapy session indicate that the severity of his symptoms has significantly improved." And again, a third of the vignettes omitted this statement. All potential combinations created the nine vignettes used in this study.

The other information in the vignette was intended to be neutral (not indicating client improvement or deterioration). It was assumed that the vignette with no client 
verbal report and no outcome measure information would provide clinicians with no information that would influence their judgment of client change and treatment decisions. This proved to be true for the judgment of client change, although there were indications that one piece of information might have influenced at least some of the participants in their treatment decisions. The statement "As of now, you have not observed significant changes in his affect and behavior" combined with a time frame of 3 months appeared to prompt some clinicians that treatment was not going well and needed to be changed. It is unknown what proportion of clinicians thought of this in the same manner. While this effect was unintended, the statement was consistent across the nine vignettes and whatever degree of bias was introduced by this statement was the same for all conditions.

While consulting with experienced clinicians about the vignettes, a common complaint was the unrealistic limitation of information about the client. Actual therapy would indeed provide tremendous amounts of more information and detail about the client that would be used to judge client change. Despite the obvious drawbacks in removing participants from "real-life decision making," there are some benefits to making artificial decision making scenarios. Carroll and Johnson (1990), in discussing decision research protocol state that at times, hypothetical decisions are preferable because they can give clearer answers to some questions. The Lambert feedback studies found an effect in real-life decision making situations, but did not fully investigate the actual processes involved in the decision making task. This dissertation by no means answered all of the questions raised by the feedback studies 
results, but does represent an initial attempt to dissect the phenomenon in a more controlled manner in order to better understand what happened in the feedback studies. As mentioned in the introduction, the lack of information was purposeful for two reasons. First, the vignettes were designed to represent situations of ambiguity in therapy. It is assumed that additional information from outcome measures indicating that a client is feeling worse will not much influence the decision making of a therapist whose client is suddenly actively suicidal. While this example might be extreme, there are definitely situations in which client progress or deterioration are quite obvious. However, those situations were not the focus of this study. Naturally, there are several sources of information (an important one being clinician's observations) that will influence the judgment of client change. In creating the vignettes, the attempt was to eliminate these variables in order to study only the effect that outcome measures and client verbal report might have on clinical decision making.

A secondary reason for the limited information was a matter of length. As the length of the vignettes increases, the response rate is likely to decrease. Clinicians are busy people and will likely not spend more than a few minutes on this study. If participants' first glance of the questionnaire gives them the impression that there is a good deal of reading involved, many will simply not complete it. In all survey research, there is the potential bias extending from the possibility that only those people who are invested in the subject will respond. This potentiality is increased if the vignettes are too long. 
Directly under the vignette, clinicians were asked to judge client change on a 9 point rating scale. They were then asked if they would choose to continue treatment in the same manner as they have been, altering the treatment, or considering moving towards termination. Under each of these options, several more specific treatment decisions were available for endorsement, along with space to write in their own specific course of action. The final question on the page asked clinicians to indicate how confident they are in their decision. A sample of a vignette with the questions that follow is contained in Appendix C.

A final question on the back page provided, in checklist format, an opportunity for clinicians to indicate what information is influential in assessing client change (Appendix D). Participants were asked to provide percentages, for the purpose of obtaining a "subjective weighting" of the sources of information. The items on the list included: client verbal report, scores from a routinely administered outcome measure, significant other, client satisfaction of services, clinician observations of client affect and behavior, and an "other" category letting the participants write in any sources of information not contained in the checklist.

Procedure

The mailing list from which the sample was composed of was bought directly from the APA. The research department of the APA were the people who created the sample and mailing labels. After taking into consideration the selection criteria previously mentioned, the APA research department conducted a random sampling of all members who met the selection criteria. The APA, upon approval of the request, 
sent the mailing address labels, along with an identical second set, which was used for a follow-up mailing.

A total of 1,800 addresses were ordered from the APA. Since there are nine total versions of the vignettes, this produced 200 mailed surveys for each one. Addresses were listed by zip code, with the first address assigned to the $1^{\text {st }}$ vignette condition, the second address the second condition; the tenth condition was assigned to the first condition and so forth. This assured random assignment of participants to each assignment. Each return envelope in the first mailing was assigned a subject number, for the sole purpose of identifying who to send a follow-up mailing to. There were no identification numbers included on the second mailing. The list identifying practitioners with subject numbers has been and will be kept confidential.

Included in the first mailing envelope was: a cover letter briefly describing the study (in Appendix E), a clinical vignette, and a pre-postage paid envelope. Research shows that certain factors will increase the response rate in survey research (Bruvold and Comer, 1988). This study utilized three such factors: multiple mailings, nonmetered stamp, and a personally signed cover letter. Approximately three to four weeks after mailing the original survey, a second survey was sent to all those who did not initially respond to the first mailed survey.

The demographic page was on the back side of the cover letter. The second sheet of paper had the vignette on the front side along with corresponding questions. On the back of the vignette page was the source of information question. 
The entire study fit nicely onto two sheets of paper, which hopefully helped the participants realize that this study only takes a few minutes to complete.

Response Rates. Of 1,800 surveys mailed, approximately 698 surveys were returned after the first mailing. The remaining 1,100 subjects were mailed a second survey. After the responses from the second mailing were collected (196), a total of $894(50.0 \%)$ of the 1,800 practitioners in the sample responded. Not all of the 894 were included in the data analysis, however. Forty-seven reported 0 hours of therapy per week, and since this study was looking at clinically active practitioners, these were excluded from any analyses. Thirty-seven surveys were returned by practitioners who did not participate in the study (rejected participation, retired, deceased, etc.).

Of the remaining 810 surveys, 628 (77.5\%) were complete and had no problems. Approximately 143 (17.7\%) surveys did not have a completed demographic page. This was unfortunate and likely occurred because clinicians did not notice it on the back side of the cover letter. These surveys were included in the sample, but in the event that demographic information was necessary for a particular analysis, the case was excluded for the specified analysis. Another $39(4.8 \%)$ of the surveys either did not have a completed treatment decision section or failed to follow instructions and endorsed more than one of the three options. In this case, the responses were entered as missing data. The total number of surveys included in the data analysis was 810 . This number was $45.0 \%$ of the original 1,800 surveys mailed and $47.2 \%$ of the 1716 potential surveys (excluding those conducting 0 hours of therapy, retired, deceased, or refused to participate). Table 4 contains the number of 
surveys returned for each condition. A Chi-Square analysis was conducted and the response rates did not differ between conditions, $\chi^{2}(8, \mathrm{n}=1800)=8.872, \mathrm{p}=.353$.

Table 4

Responses per Condition

\begin{tabular}{|l|l|}
\hline Condition & N \\
\hline NVNO & 98 \\
\hline NVO- & 87 \\
\hline NVO+ & 95 \\
\hline V-NO & 94 \\
\hline V-O- & 99 \\
\hline V-O+ & 81 \\
\hline V+NO & 87 \\
\hline V $+O+$ & 98 \\
\hline V $+O-$ & 80 \\
\hline
\end{tabular}

Data Analysis

Since the vignettes vary on two specific dimensions, client verbal report and outcome measure report, this study utilized a 3 x 3 design (see Table 5). 
Table 5

3 x3 Design

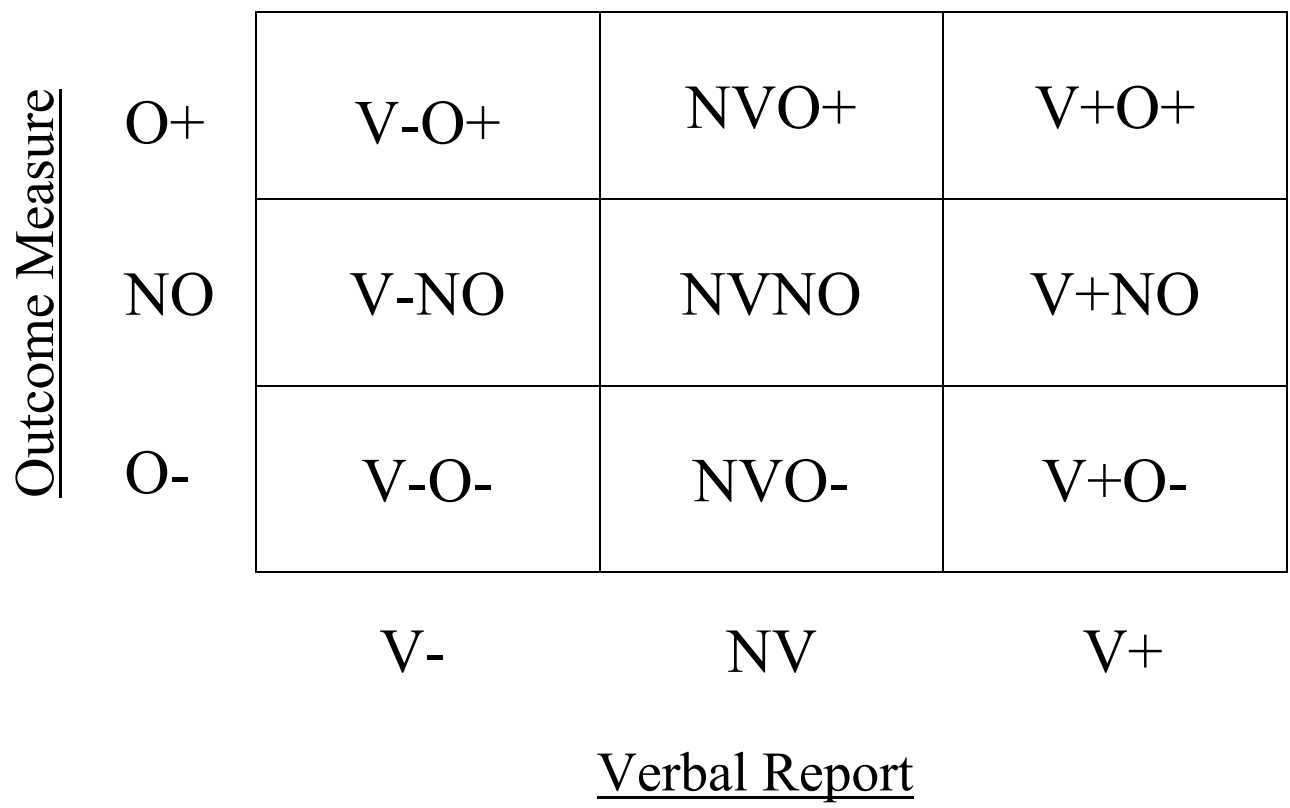

This design was the basis for the judgment analyses. A two-way analysis of variance was conducted to examine the influence of client verbal report and outcome measure report on clinician judgment of client change. Several post hoc comparisons were conducted to determine the source of significant differences. Three-way ANOVAs were conducted to investigate potential clinician differences (gender, theoretical orientation, work setting, years since licensure, number of hours per week they conduct psychotherapy, and whether they conduct some form of outcome assessment in their clinical practice). Relative influence of various sources of information (last page of the survey) was described descriptively, with several followup comparisons investigating clinician differences. 
Treatment decisions were analyzed using logistic regression methods for both the primary analysis and clinician differences. In an investigation of the effect that additional information has on treatment decisions, positive and negative client report were compared to no client report, with positive and negative outcome measure report similarly compared to no outcome measure report. The additional sources of information served as predictor variables in the logistic regression. For the clinician differences analyses, specific clinician demographic variables were added as additional predictors in the logistic regression model. The sub-choices for each treatment decision were described descriptively.

For the confidence ratings, a two-way analysis of variance was conducted to examine the influence of client verbal report and outcome measure. A three-way analysis of variance added treatment decision as another variable to the previous analysis. Finally, several four-way analyses of variance were utilized to investigate clinician differences. 


\section{Results}

Analyses will be grouped based on the dependent variable of interest: judgment of client change, treatment decision, and confidence ratings. First, analyses involving clinician judgments of client change will be reported. Specifically, the influence of information (in the form of client verbal report and scores from an outcome measure) on the degree of client change will be explored. This will be followed by a description of specific clinician characteristics that had an affect on judgments of client change. Finally, a description of the "source of information" question (asking "how much influence each potential source of information has for you when judging client change") will be reported.

The second section will contain the analyses of treatment decisions. The effects that client verbal report and outcome measure report, as well as clinician characteristics, have on the clinicians' treatment decisions will be reported. The third and final section will describe results of analyses concerning clinician confidence in the treatment decisions.

\section{Judgment of Client Change}

Verbal Report vs. Outcome Measure Report. Clinician judgment of client change was rated on a 9-point scale, with lower numbers representing client deterioration and higher numbers client improvement. The midpoint on the scale was five and indicated no change. It was hypothesized that the NVNO condition would be near the midpoint, or no change. Indeed, the mean for the NVNO condition was 5.19 and can therefore serve as a "baseline" comparison to gauge whether additional 
information had an effect on the judgment of client change (compared to no information).

A two-way analysis of variance (verbal report by outcome measure report) was conducted to determine the influence that information in the form of client verbal report and outcome measure report had on clinician judgment of client change. The interaction was significant, $F(4,711)=12.74, p<.001$. Table 6 contains the mean ratings for each of the nine conditions separately, as well as means for the main effect investigations. Figure 1 graphically demonstrates the relationship between the verbal and outcome measure factors.

Table 6

Judgment of Client Change by Condition

\begin{tabular}{|c|c|c|c|c|}
\hline & V- & NV & V+ & $\begin{array}{c}\text { Outcome } \\
\text { Measure } \\
\text { Means }\end{array}$ \\
\hline $\mathrm{O}+$ & $4.21(1.76)$ & $6.55(1.17)$ & $6.83(0.90)$ & $5.93(1.73)$ \\
\hline $\mathrm{NO}$ & $3.51(1.45)$ & $5.19(0.69)$ & $6.09(1.24)$ & $4.93(1.56)$ \\
\hline O- & $2.32(1.06)$ & $2.78(1.21)$ & $3.72(1.81)$ & $2.87(1.47)$ \\
\hline $\begin{array}{c}\text { Verbal Report } \\
\text { Means }\end{array}$ & $3.29(1.63)$ & $4.90(1.84)$ & $5.68(1.84)$ & \\
\hline
\end{tabular}

Notes. $\mathrm{V}+=$ positive client verbal, $\mathrm{NV}=$ no client verbal, $\mathrm{V}-\mathrm{=}$ negative client verbal, $\mathrm{O}+=$ positive outcome measure, $\mathrm{NO}=$ no outcome measure, $\mathrm{O}-=$ negative outcome measure.

Verbal Report Means and Outcome Measure Means represent the investigation of main effects in the analysis. 
Figure 1

Client Verbal Report and Outcome Measure Report for Judgment of Client Change

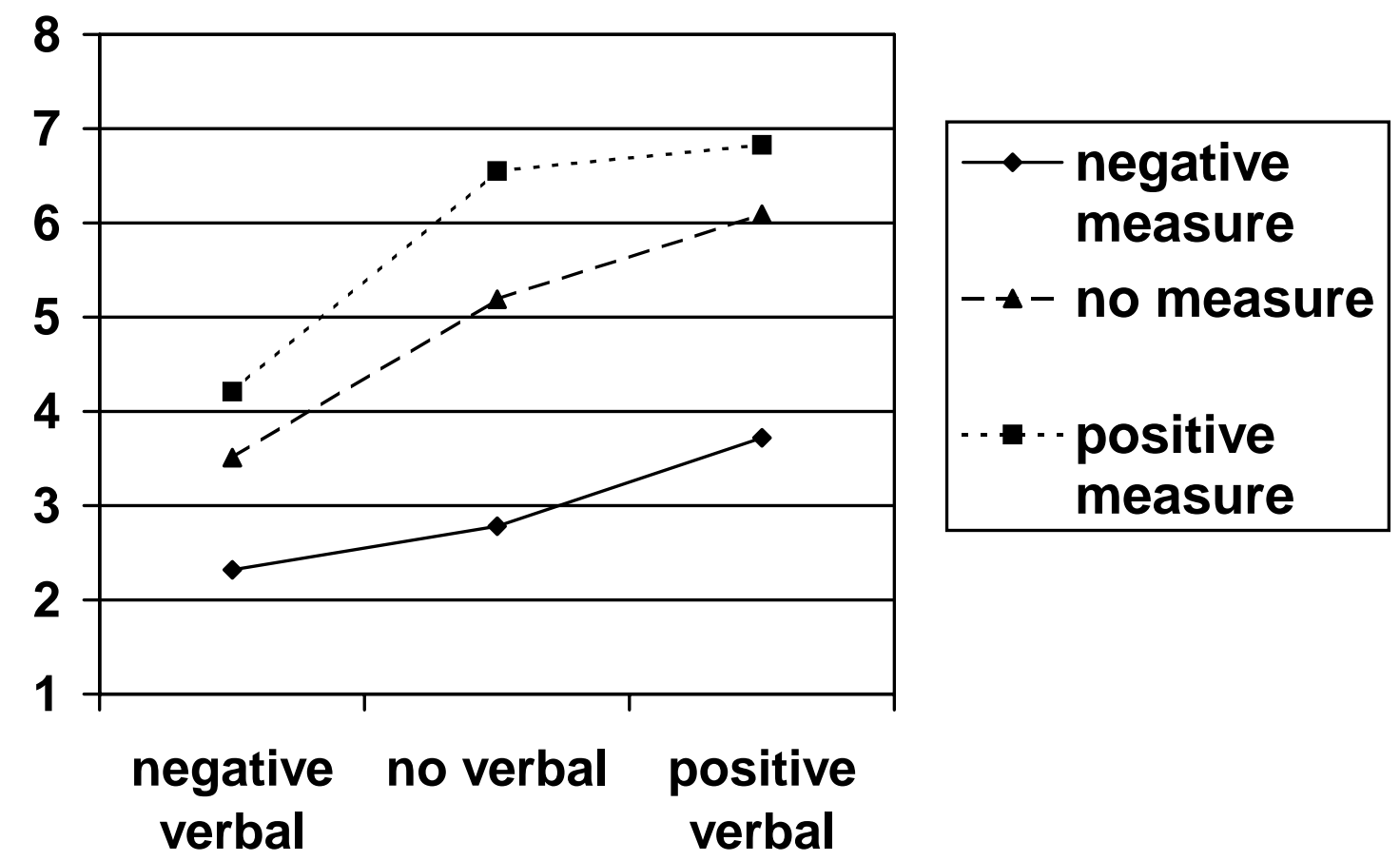

In order to understand the specific interactions in an intuitive manner, an oneway analysis of variance was conducted comparing the mean judgment ratings for each of the nine vignette conditions, $F(8,711)=139.45, p<.001$, followed by several post hoc comparisons (using Tukey's HSD). Of the 36 possible post hoc comparisons, 28 were significantly different. Using a Bonferroni correction, significance was determined by values of $p<.001$. Due to a large $\mathrm{N}$ for each of the nine vignette conditions, effect sizes were calculated to determine the magnitude of difference. Table 7 displays each of the effect sizes for all 28 significant comparisons. The eight 
comparisons which were not significantly different are also identified. Using Cohen's three levels of effect size (Cohen, 1988), most of the comparisons in this analysis can be considered large differences. Due to the specific hypotheses of this study, Sheffe testes were conducted to verify that NVO- and V-NO were different when measured by their distance from NVNO, as well as NVO+ and V+NO. Neither set of differences were statistically significant $(p>.05)$.

Table 7

Effect Sizes of Judgment Differences

\begin{tabular}{|l|c|c|c|c|c|c|c|c|c|}
\hline & V-O- & NVO- & $\begin{array}{l}\text { V- } \\
\text { NO }\end{array}$ & V+O- & V-O+ & NVNO & V+NO & NVO+ & V+O+ \\
\hline V-O- & - & & & & & & & & \\
\hline NVO- & ns & - & & & & & & & \\
\hline V-NO & 0.94 & ns & - & & & & & & \\
\hline V+O- & 0.94 & 0.61 & ns & - & & & & & \\
\hline V-O+ & 1.30 & 0.95 & ns & ns & - & & & & \\
\hline NVNO & 3.21 & 2.45 & 1.48 & 1.07 & 0.73 & - & & & \\
\hline V+NO & 3.27 & 2.70 & 1.91 & 1.53 & 1.23 & 0.90 & - & & \\
\hline NVO+ & 3.79 & 3.17 & 2.31 & 1.86 & 1.57 & 1.42 & ns & - & \\
\hline V+O+ & 4.59 & 3.80 & 2.75 & 2.18 & 1.87 & 2.05 & ns & ns & - \\
\hline
\end{tabular}

In the two-way analysis of variance, main effects were statistically significant for verbal report, $F(2,711)=182.59, p<.001$, and outcome measure report, $F(2,711)=$ $318.40, p<.001$. Table 6 reports the mean ratings of client change for the three levels of client verbal report (collapsed across outcome measure levels). Table 6 contains the same information for the three levels of outcome measure report (collapsed across client verbal report levels). For the main effects, each level of the verbal report 
variable differed significantly from all others, as did each level of the outcome measure report variable (all at $p<.001$ ). This suggests that both the negative verbal report and negative outcome measure report led clinicians to rate the client as doing worse than when the information was not present. The same was true for the positive conditions of verbal report and outcome measure report in that clinicians in both conditions rated clients as doing better than when the information was not present.

Negative Change vs. Positive Change. In testing the specific hypothesis that report of change would be more influential in the negative direction, $[\mathrm{V}+\mathrm{O}+$ minus NVNO $]<[$ NVNO minus V-O-], a Scheffe Test found that negative information did alter the judgment of client change more than positive information $(p<.05)$. Scheffe tests were similarly performed on the differences between single pieces of information, $[\mathrm{NVO}+$ minus $\mathrm{NVNO})]<[\mathrm{NVNO}$ minus NVO- $]$ and $[\mathrm{V}+\mathrm{NO}$ minus $\mathrm{NVNO})]<[\mathrm{NVNO}$ minus V-NO]. The negative outcome measure was significantly further from the no information condition than the positive measure condition $(p<$ $.05)$. The negative verbal report was not significantly further from the no information condition than the positive verbal report condition. For a reminder of the mean ratings and standard deviations for each condition in these analyses, please refer to Table 6 .

Clinician Differences. Several three-way analyses of variance (verbal report by outcome measure report by clinician characteristic) were conducted to investigate the effect that certain clinician characteristics had on judgment of client change. The three independent variables were the selected demographic factor, client verbal report, and outcome measure report. In all six three-way ANOVA's performed, main effects 
were found for client verbal report and outcome measure report, along with their twoway interaction. Since the F values for each of these were quite similar to those reported earlier (for the two-way ANOVA), they will not be described again here. Rather, only the main effects for the clinician variable and any interactions involving the clinician variable will be reported in this section.

To begin with, there was not a significant interaction effect for gender, nor a main effect for gender. The same was true for theoretical orientation.

Clinicians were asked whether they used some form of outcome assessment in their practice. Responses were divided into two groups, users and non-users. Somewhat surprisingly, there were no significant interactions between clinicians conducting some form of outcome assessment and any of the other independent variables, including outcome measure report. There was a significant main effect for outcome assessment in practice, $F(1,571)=4.57, p=.033$, with users rating clients an average 0.22 units lower (getting worse) on the 9 point scale than did non-users. This difference was small with an effect size of 0.11 .

Work setting was divided into two groups: private practice and institutional settings. The three-way interaction was not significant. The two way interaction of verbal report and work setting was significant, $F(2,508)=3.74, p=.024$. In post hoc comparisons, work setting did not significantly alter judgment scores for any given level of verbal report (negative, none, or positive). There was not a significant effect for the outcome measure report by work setting interaction. There was also not a significant main effect for work setting. 
The number of hours per week that clinicians conducted psychotherapy was divided into three groups: less than 20 hours, 20-29 hours, and 30 hours or above. There was not a significant three-way interaction or a two-way interaction between hours/week and outcome measure report. There was a significant interaction between hours/week and client verbal report, $F(4,565)=2.54, p=.039$. Post hoc analyses indicate that for verbal reports of negative client change, hours/week did not significantly alter clinician judgment. The same was true for no verbal report and positive verbal report. Although each of these levels were statistically the same, there were small differences within each cluster with the high and low hour/week group altering between verbal report conditions. It is likely that the interaction is a result of this ordering difference, despite the fact that there was not a significant difference within each level of verbal report. There was also not a significant main effect for hours/week.

Years since licensure, which served as a rough estimate of clinical experience, was divided into three categories: pre-1980, 1980-1989, and 1990- present. There was a significant three-way interaction between verbal report, outcome measure report, and years since licensure, $F(8,560)=2.22, p=.024$. Within the three-way interaction, there was one difference that stood out. When the outcome measure provided negative information and the verbal report was positive (contradictory information), more recently licensed clinicians tended to rate the client as having "no change," whereas the older clinicians rated them as getting much worse. There was not a difference with the other contradictory scenario (negative verbal and positive outcome 
measure) in that all clinicians rated the clients the same. The effect size for this one difference was 1.76 , although with N's of 15 and 12, a cautious interpretation of this finding would be prudent.

The two-way interaction between outcome measure report and years since licensure was not significant. There was, however, a significant two-way interaction between client verbal report and years since licensure, $F(4,560)=3.84, p<.004$. Post hoc analyses indicated that for negative verbal report and no verbal report, all three levels of years since licensure were almost identical. There was an interesting trend (just missing significance at $p=.10$ ) between pre-1980 and 1990-present within the positive verbal condition. More recently licensed clinicians tended to rate clients as more improved when positive verbal report information was present than did the oldest cohort of clinicians in the presence of the same information.

There was a significant main effect for years since licensure, $F(2,560)=4.97$, $p=.007$. Post hoc analysis revealed that only pre-1980 and 1990-to-present were statistically different $(p=.013)$, with pre-1980 clinicians giving a lower rating of 0.38 units on the judgment scale than 1990 to present clinicians. The effect size of this difference was 0.19 . The middle group was not significantly different from either of the other two groups.

Source of Information. Clinicians were asked to rate the importance of various sources of information by indicating the relative influence each source of information has in judging client change. They were to divide $100 \%$ however they desired to 
designate the relative importance of each item. The average percentages assigned to each of the sources of information for the sample $(\mathrm{N}=753)$ are contained in Table 8.

It should be noted that there was approximately a five to six percent increase on the item "scores on a routinely administered outcome measure" for clinicians who received one of the six vignettes containing outcome measure information compared to clinicians who received one of the three vignettes with no mention of outcome measures. This difference is illustrated in Table 8 and was significant, $t=6.21, p<$ $.001(\mathrm{~d}=0.49)$. It appears that the task of using outcome measure information slightly altered clinician's perceptions of how much influence outcome measures have in their normal judgment of client change.

Table 8

Self Reported Relative Influence of Each Source of Information

\begin{tabular}{|l|c|c|}
\hline Source of Information & $\begin{array}{c}\text { Percent of } \\
\text { Influence - Did not } \\
\text { receive outcome } \\
\text { measure (Std. } \\
\text { Dev.) }\end{array}$ & $\begin{array}{c}\text { Percent of Influence - } \\
\text { Received outcome } \\
\text { measure (Std. Dev.) }\end{array}$ \\
\hline Client verbal report of progress & $38.08(16.99)$ & $35.31(16.50)$ \\
\hline $\begin{array}{l}\text { Scores from a routinely administered } \\
\text { outcome measure }\end{array}$ & $7.38(10.81)$ & $13.10(12.63)$ \\
\hline Significant other report & $12.88(10.08)$ & $12.97(9.97)$ \\
\hline $\begin{array}{l}\text { Client satisfaction with services } \\
\text { questionnaire }\end{array}$ & $2.62(5.76)$ & $3.85(6.26)$ \\
\hline $\begin{array}{l}\text { Clinician's observations of client affect } \\
\text { and behavior }\end{array}$ & $36.15(14.86)$ & $31.32(15.13)$ \\
\hline Other (N = 125) & $17.58(13.78)$ & $18.98(14.26)$ \\
\hline
\end{tabular}


As can be seen in Table 8, client verbal report and clinician observations were the two most influential sources of information. Clinicians indicated that scores from an outcome measure and significant other reports are less important in their judgment of client change. Almost $70 \%$ of clinicians indicated that information from a satisfaction questionnaire had zero influence on their judgment of client change. For those who gave a response greater than zero for satisfaction questionnaire, the mean percentage was $10.35 \%($ std dev $=6.44)$. A list of clinicians' responses to "other" are contained in Appendix F.

Several separate analyses were conducted to explore specific clinician differences and how they might be related to the subjective weighting of the various sources of information. The means for each clinician characteristic are displayed in Tables 9 through 14. These tables also identify the significant differences and the associated effect sizes of those differences.

Table 9

Gender by Source of Information

\begin{tabular}{|l|c|c|}
\hline \multirow{2}{*}{ Client verbal } & Male & Female \\
\cline { 2 - 3 } & Mean (Std Dev) & Mean (Std Dev) \\
\hline Measure & $36.56(17.4)$ & $37.18(16.5)$ \\
\hline Significant other & $12.34(13.6)^{\mathrm{a}}$ & $9.04(10.4)^{\mathrm{a}}$ \\
\hline Satisfaction & $14.09(10.5)^{\mathrm{b}}$ & $11.76(9.7)^{\mathrm{b}}$ \\
\hline Observation & $3.18(6.1)$ & $3.23(6.0)$ \\
\hline
\end{tabular}

Notes. Significant comparisons and effect sizes: (a) $p=.001$, es $=0.27$; (b) $p=.004$, es $=0.23$ 
Table 10

Outcome Measure Use by Source of Information

\begin{tabular}{|l|c|c|}
\hline \multirow{2}{*}{ Client verbal } & User & Non-user \\
\cline { 2 - 3 } & Mean (Std Dev) & Mean (Std Dev) \\
\hline Measure & $33.36(17.4)^{\mathrm{a}}$ & $39.13(16.4)^{\mathrm{a}}$ \\
\hline Significant other & $15.67(12.9)^{\mathrm{b}}$ & $7.63(10.8)^{\mathrm{b}}$ \\
\hline Satisfaction & $13.54(9.6)$ & $12.53(10.5)$ \\
\hline Observation & $4.12(6.9)^{\mathrm{c}}$ & $2.53(5.2)^{\mathrm{c}}$ \\
\hline
\end{tabular}

Notes. Significant comparisons and effect sizes: (a) $p<.001$, es $=0.34$; (b) $p<.001$, es $=0.68$; (c) $p=.001$, es $=0.26$; (d) $p<.001$, es $=0.35$

Table 11

Work Setting by Source of Information

\begin{tabular}{|l|c|c|}
\hline \multirow{2}{*}{ Client verbal } & Private Practice & Institution \\
\cline { 2 - 3 } & Mean (Std Dev) & Mean (Std Dev) \\
\hline Measure & $37.09(16.5)$ & $36.83(17.8)$ \\
\hline Significant other & $9.05(11.6)^{\mathrm{a}}$ & $13.30(12.6)^{\mathrm{a}}$ \\
\hline Satisfaction & $12.57(10.2)$ & $13.67(10.2)$ \\
\hline Observation & $2.73(6.0)$ & $3.80(6.0)$ \\
\hline
\end{tabular}

Notes. Significant comparisons and effect sizes: (a) $p<.001$, es $=0.35$; (b) $p<.001$, es $=0.34$ 
Table 12

Theoretical Orientation by Source of Information

\begin{tabular}{|l|c|c|c|}
\hline \multirow{2}{*}{ Client verbal } & CBT & Insight Oriented & Eclectic \\
\cline { 2 - 4 } & Mean (Std Dev) & Mean (Std Dev) & Mean (Std Dev) \\
\hline Measure & $35.53(17.1)$ & $39.28(17.3)$ & $37.06(16.4)$ \\
\hline Significant other & $13.08(13.8)^{\mathrm{a}}$ & $8.74(10.6)^{\mathrm{a}}$ & $9.68(10.9)$ \\
\hline Satisfaction & $14.14(10.4)^{\mathrm{b}}$ & $10.39(9.7)^{\mathrm{b}}$ & $12.67(9.6)$ \\
\hline Observation & $3.69(6.5)$ & $2.65(5.6)$ & $2.75(5.5)$ \\
\hline
\end{tabular}

Notes. Significant comparisons and effect sizes: (a) $p=.002$, es $=0.35$; (b) $p=.001$, es $=0.37$

Table 13

Therapy Hours per Week by Source of Information

\begin{tabular}{|l|c|c|c|}
\hline \multirow{2}{*}{ Client verbal } & $<20$ & $20-29$ & $30+$ \\
\cline { 2 - 4 } & Mean (Std Dev) & Mean (Std Dev) & Mean (Std Dev) \\
\hline Measure & $37.06(17.5)$ & $35.79(16.4)$ & $37.60(17.1)$ \\
\hline Significant other & $13.23(13.0)^{\mathrm{a}}$ & $9.14(12.1)^{\mathrm{a}}$ & $9.67(11.2)$ \\
\hline Satisfaction & $12.24(9.6)$ & $13.36(10.7)$ & $13.14(10.1)$ \\
\hline Observation & $3.93(6.0)$ & $2.86(6.3)$ & $2.61(5.5)$ \\
\hline
\end{tabular}

Notes. Significant comparisons and effect sizes: (a) $p=.002$, es $=0.33$

Table 14

Years Since Licensure by Source of Information

\begin{tabular}{|l|c|c|c|}
\hline \multirow{2}{*}{ Client verbal } & 1990 to present & $1980-1989$ & Pre- 1980 \\
\cline { 2 - 4 } & Mean (Std Dev) & Mean (Std Dev) & Mean (Std Dev) \\
\hline Measure & $37.36(17.3)$ & $36.98(16.6)$ & $36.22(17.3)$ \\
\hline Significant other & $12.15(12.6)$ & $10.21(12.4)$ & $9.57(11.4)$ \\
\hline Satisfaction & $12.55(9.6)$ & $13.01(10.4)$ & $13.26(10.5)$ \\
\hline Observation & $3.17(6.2)$ & $2.86(5.9)$ & $3.67(6.1)$ \\
\hline
\end{tabular}

Note. No significant comparisons. 
All of the significant differences produced small effect sizes, with one exception. Clinicians who use some form of outcome assessment in their clinical practice placed more weight on information from an outcome measure than did clinicians who did not conduct regular outcome assessment. Other than this one difference, it appears that the subjective weighting of sources of information remained relatively constant across clinician differences.

Treatment Decisions

Additional Information. Cell frequencies for each treatment decision by vignette condition are displayed in Table 15. The percentage of clinicians who chose each treatment decision within the particular condition was also included. 
Table 15

Treatment Decision by Condition

\begin{tabular}{|c|c|c|c|}
\hline & $\begin{array}{c}\text { Continue } \\
\text { Treatment }\end{array}$ & Alter Treatment & $\begin{array}{c}\text { Consider } \\
\text { Termination }\end{array}$ \\
\hline \multirow{2}{*}{ NVNO } & 19 & 76 & 1 \\
& $19.8 \%$ & $79.2 \%$ & $1.0 \%$ \\
\hline \multirow{2}{*}{ NVO+ } & 33 & 49 & 4 \\
& $38.4 \%$ & $57.0 \%$ & $4.7 \%$ \\
\hline \multirow{2}{*}{ NVO- } & 10 & 78 & 0 \\
& $11.4 \%$ & $88.6 \%$ & $0.0 \%$ \\
\hline V-NO & 14 & 72 & 2 \\
& $15.9 \%$ & $81.8 \%$ & $2.3 \%$ \\
\hline \multirow{2}{*}{ V-O- } & 14 & 83 & 0 \\
& $14.4 \%$ & $85.6 \%$ & $0.0 \%$ \\
\hline V-O+ & 20 & 53 & 2 \\
& $26.7 \%$ & $70.7 \%$ & $2.7 \%$ \\
\hline V+NO & 35 & 40 & 9 \\
& $41.7 \%$ & $47.6 \%$ & $10.7 \%$ \\
\hline V+O+ & 31 & 34 & 17 \\
\hline V+O- & $37.8 \%$ & $41.5 \%$ & $20.7 \%$ \\
\hline \multirow{2}{*}{ Total } & 15 & 59 & 1 \\
& $20.0 \%$ & $78.7 \%$ & $1.3 \%$ \\
\hline
\end{tabular}

For purpose of treatment decision analyses, Consider Termination responses were eliminated due to low cell frequencies. A logistic regression analysis was performed on treatment decision (continue and alter treatment) as the dependant variable with client verbal report and outcome measure report as predictors. For both client verbal report and outcome measure report, variables were coded in such a way that the specific conditions no verbal report and no outcome report were used as the reference categories, leaving two predictor variables each for a total of four predictors. 
A test of the full model with all four predictors against a constant-only model was statistically reliable, $\chi^{2}(4,810)=54.82, p<.001$, indicating that the predictors, as a set, reliably distinguished between clinician decisions to alter treatment or continue treatment in the same manner. The variance in treatment decision accounted for is small, however, with Nagelkerke R Square $=.106$. Individual predictors, logit coefficients, odds ratios, odds ratios confidence intervals (95\%) are displayed in Table 16.

Table 16

Logistic Regression Analysis for Client Verbal Report and Outcome Measure Report

\begin{tabular}{|l|l|l|l|}
\hline Predictor & $\mathrm{B}$ & Odds Ratio (OR) & Confidence Interval \\
\hline Negative client report & 0.265 & 1.304 & 0.846 to 2.010 \\
\hline Positive client report & -0.720 & 0.487 & 0.324 to 0.732 \\
\hline $\begin{array}{l}\text { Negative outcome } \\
\text { measure report }\end{array}$ & 0.695 & 2.004 & 1.282 to 3.132 \\
\hline $\begin{array}{l}\text { Positive outcome } \\
\text { measure report }\end{array}$ & -0.552 & 0.576 & 0.387 to 0.855 \\
\hline Constant & 1.175 & & \\
\hline
\end{tabular}

It needs to be remembered that both client report odds ratios are a comparison between the predictor and the reference category (no client report). The same is true of outcome measure report, both are compared to no outcome measure report.

Given this analysis, it appears that negative client verbal report does not increase the odds that a clinician will choose to alter treatment more than no client verbal report. On the other hand, positive client report changes the odds of altering treatment 0.49 times compared to no client report, meaning that the odds of clinicians 
deciding to alter treatment when receiving a positive client report are less then when they receive no client report. Compared to receiving no outcome measure report, the odds of choosing to alter treatment is two times greater when receiving negative outcome measure report and 0.58 times greater when receiving positive outcome measure report (they are more likely to choose continuing treatment).

Clinician Differences. Similar logistic regression analyses were conducted for several clinician characteristic variables. In each analysis, client verbal report and outcome measure report were retained in the full model. The odds ratios for each of those can be interpreted in the same manner as before. Table 17 contains the percentage of clinicians who chose to alter or continue treatment for each of the clinician variables considered. 
Table 17

Clinician Differences in Treatment Decisions

\begin{tabular}{|l|c|c|}
\hline Clinician Variable & $\begin{array}{l}\text { Percent Continue } \\
\text { Treatment }\end{array}$ & Percent Alter Treatment \\
\hline \hline Male & 28.9 & 71.1 \\
\hline Female & 21.8 & 78.2 \\
\hline \hline Private Practice & 27.5 & 72.5 \\
\hline Institutional Setting & 22.7 & 77.3 \\
\hline Use Outcome Measures & 21.7 & 78.3 \\
\hline Do Not Use Measures & 28.1 & 71.9 \\
\hline \hline CBT & 19.1 & 80.9 \\
\hline Insight Oriented & 40.5 & 59.5 \\
\hline \hline 1990-present & 22.9 & 77.1 \\
\hline $1980-1989$ & 22.4 & 77.6 \\
\hline Pre 1980 & 35.4 & 64.6 \\
\hline 30 or more hours/week & 23.6 & 76.4 \\
\hline 20-29 hours/week & 23.9 & 76.1 \\
\hline Less than 20 hours/week & 29.6 & 70.4 \\
\hline
\end{tabular}

The first clinician difference investigated was gender. Table 18 contains the individual predictors, logit coefficients, odds ratios, and odds ratios confidence intervals $(95 \%)$. Based on this sample of clinicians, the odds of men deciding to alter treatment is 0.65 times greater than women choosing to alter treatment (women are more likely to alter treatment than men). In reporting this gender difference, it should be mentioned that men and women did not differ in their judgments of the amount of change. 
Table 18

Logistic Regression Analysis for Gender

\begin{tabular}{|l|l|l|l|}
\hline Predictor & B & Odds Ratio (OR) & Confidence Interval \\
\hline Negative client report & 0.419 & 1.521 & 0.933 to 2.481 \\
\hline Positive client report & -0.552 & 0.576 & 0.368 to 0.901 \\
\hline $\begin{array}{l}\text { Negative outcome } \\
\text { measure report }\end{array}$ & 0.585 & 1.796 & 1.102 to 2.926 \\
\hline $\begin{array}{l}\text { Positive outcome } \\
\text { measure report }\end{array}$ & -0.446 & 0.640 & 0.410 to 0.999 \\
\hline Gender & -.436 & 0.647 & 0.440 to 0.950 \\
\hline Constant & 1.346 & & \\
\hline
\end{tabular}

The logistic regression analysis containing theoretical orientation is depicted in Table 19. Based on this sample of clinicians, the odds of CBT therapists deciding to alter treatment is three times greater than insight oriented therapists choosing to alter treatment (insight oriented therapists are more likely to continue treatment than CBT therapists). Of note is that when theoretical orientation is in the model, only positive outcome measure report remains a meaningful predictor, with positive client report and negative outcome measure report becoming no longer significant. 
Table 19

Logistic Regression Analysis for Theoretical Orientation

\begin{tabular}{|l|l|l|l|}
\hline Predictor & B & Odds Ratio (OR) & Confidence Interval \\
\hline Negative client report & 0.333 & 1.395 & 0.782 to 2.486 \\
\hline Positive client report & -0.215 & 0.806 & 0.456 to 1.425 \\
\hline $\begin{array}{l}\text { Negative outcome } \\
\text { measure report }\end{array}$ & 0.547 & 1.729 & 0.956 to 3.125 \\
\hline $\begin{array}{l}\text { Positive outcome } \\
\text { measure report }\end{array}$ & -0.622 & 0.537 & 0.307 to 0.937 \\
\hline Theoretical Orientation & 1.160 & 3.190 & 1.979 to 5.143 \\
\hline Constant & 0.311 & & \\
\hline
\end{tabular}

Table 20 contains the results of the logistic regression analysis for years since licensure. In this analysis, both predictors of 1990-present and 1980-1989 are a comparison between the predictor and the reference category (in this case pre 1980). Based on this sample of clinicians, the odds of therapists who have received their license since 1980 deciding to alter treatment is just under two times greater than therapists who received their license prior to 1980 (older therapists are more likely to continue treatment than newer therapists). Of note is that when years since licensure is in the model, positive client report and negative outcome measure report are meaningful predictors, with negative client report and positive outcome measure report not significant. 
Table 20

Logistic Regression Analysis for Years Since Licensure

\begin{tabular}{|l|l|l|l|}
\hline Predictor & B & Odds Ratio (OR) & Confidence Interval \\
\hline Negative client report & 0.413 & 1.511 & 0.925 to 2.469 \\
\hline Positive client report & -0.538 & 0.584 & 0.373 to 0.914 \\
\hline $\begin{array}{l}\text { Negative outcome } \\
\text { measure report }\end{array}$ & 0.613 & 1.846 & 1.130 to 3.016 \\
\hline $\begin{array}{l}\text { Positive outcome } \\
\text { measure report }\end{array}$ & -0.414 & 0.661 & 0.423 to 1.033 \\
\hline $\begin{array}{l}\text { 1990-present } \\
1980-1989\end{array}$ & 0.633 & 1.882 & 1.156 to 3.066 \\
\hline Constant & 0.673 & 1.961 & 1.226 to 3.136 \\
\hline
\end{tabular}

When the variables work setting, outcome measure use, and number of hours per week of conducting psychotherapy were added to models with client verbal and outcome measure report, these three clinician variables were not meaningful predictors of treatment decision. In two cases, the clinician variables did change the significance of other variables in the model. In the original model, positive client report, negative outcome measure report and positive outcome measure report were meaningful predictors, while negative client report did not significantly predict treatment decision. When work setting was included in the model, positive outcome measure report was no longer a significant predictor. When clinician use of outcome measures was inserted in the model as a variable, positive outcome measure report was again no longer significant. With hours per week in the model, the other predictors were the same as the original model.

It is possible that the three clinician variables which were meaningful predictors are related and therefore these findings are repetitive. For example, there 
has been a recent increase in the number of women in the field of psychology. For this sample, there were significantly more men than women who received their license pre-1980, with an equal gender split in 1980-1989, and significantly more women than men in 1990-present. This cohort effect might represent a single factor rather than two. A likely explanation is that the era in which clinicians were trained and licensed has more to do with the decision to alter treatment than does an innate gender difference. Conversely, there were a higher proportion of CBT men than CBT women. Considering that men were more likely to continue treatment and CBT therapists were least likely to do so, these findings are somewhat contradictory. Perhaps the most probable repetition in these findings might be that theoretical orientation and years since licensure are essentially part of another cohort effect. However, there are equal proportions of insight oriented therapists and CBT therapists for each of the years since licensure categories.

Sub-Choices Decision Analyses. Under each treatment option on the survey (continue treatment, alter treatment, terminate treatment) were four slightly more specific treatment decisions. Respondents were instructed that they could choose any of the sub-choices that were applicable. Table 21 contains the frequencies that each of the sub-choices were endorsed. A complete list of the content of "other" responses are contained in Appendices G, H, and I. 
Table 21

Treatment Decision Sub-Choices

\begin{tabular}{|l|c|c|}
\hline Treatment Decision & $\mathrm{N}$ & $\begin{array}{c}\text { Percent within } \\
\text { treatment decision }\end{array}$ \\
\hline \hline Continue Treatment & $\mathbf{1 9 1}$ & \\
\hline by making no changes in the treatment plan & 17 & $8.9 \%$ \\
\hline by continuing for now, reevaluating in the future & 104 & $54.5 \%$ \\
\hline by continuing for now and seeking peer consultation & 67 & $35.1 \%$ \\
\hline Other & 61 & $31.9 \%$ \\
\hline Alter Treatment & 538 & \\
\hline by altering the treatment plan & 320 & $59.5 \%$ \\
\hline by altering the implementation of current treatment plan & 235 & $43.7 \%$ \\
\hline by reevaluating diagnostic formulation & 378 & $70.2 \%$ \\
\hline Other & 283 & $52.6 \%$ \\
\hline Terminate Treatment & 36 & \\
\hline by terminate with scheduled booster sessions & 3 & $8.3 \%$ \\
\hline by moving towards termination in the next few sessions & 8 & $22.2 \%$ \\
\hline by discussing possible termination with client & 30 & $83.3 \%$ \\
\hline Other & 14 & $38.9 \%$ \\
\hline
\end{tabular}

\section{Confidence Ratings}

Treatment Decisions. A one-way ANOVA was conducted to determine whether clinicians' confidence differed by treatment decision alone. The result was significant, $F(2,744)=6.88, p=.001$. Post hoc analyses indicated that clinicians who decided to alter treatment were statistically more likely to have higher confidence in their decision than clinicians who chose to either continue treatment or consider termination. Mean confidence ratings and associated effect sizes are contained in Table 22 . 
Table 22

Confidence in Treatment Decision

\begin{tabular}{|l|c|c|}
\hline & Mean & Std Deviation \\
\hline Continue Treatment & 80.04 & 15.5 \\
\hline Alter Treatment & $83.20^{\mathrm{a}}$ & 12.9 \\
\hline Consider Termination & $76.38^{\mathrm{a}}$ & 15.9 \\
\hline
\end{tabular}

Notes. Significant comparisons and effect sizes: (a) $p=.011$, es $=0.51$

Verbal Report vs. Outcome Measure Report. A two-way analysis of variance was conducted to determine the influence that information in the form of client verbal report and outcome measure report had on clinician confidence in their treatment decision. The interaction was significant, $F(4,738)=3.04, p=.017$. Main effects were also statistically significant for verbal report, $F(2,738)=4.00, p=.019$, and outcome measure report, $F(2,738)=4.58, p=.011$.

Table 23 reports the mean ratings of confidence for the three client verbal report variables (collapsed across outcome measure variables). Significant differences and associated effect sizes are also included. Table 23 also contains the same information for the three outcome measure variables (collapsed across client verbal report variables).

In order to explore the interaction, an one-way analysis of variance was conducted comparing the mean confidence ratings for each of the nine vignette conditions, $F(8,738)=3.72, p<.001$, followed by several post hoc comparisons (using Tukey's HSD). Table 23 contains the mean confidence ratings for each of the nine conditions separately. 
Table 23

Confidence of Treatment Decision by Condition

\begin{tabular}{|c|c|c|c|c|}
\hline & $\mathrm{V}-$ & $\mathrm{NV}$ & $\mathrm{V}+$ & $\begin{array}{c}\text { Outcome } \\
\text { Measure } \\
\text { Means }\end{array}$ \\
\hline $\mathrm{O}+$ & $79.92(14.7)$ & $82.10(12.2)$ & $78.96(14.2)$ & $80.36(13.7)^{\mathrm{a}}$ \\
\hline $\mathrm{NO}$ & $83.08(12.3)$ & $85.30(13.3)$ & $76.64(17.5)$ & $81.91(14.8)$ \\
\hline O- & $83.69(13.3)$ & $83.53(12.4)$ & $84.88(12.3)$ & $83.99(12.7)^{\mathrm{a}}$ \\
\hline $\begin{array}{c}\text { Verbal Report } \\
\text { Means }\end{array}$ & $82.39(13.4)$ & $83.71(12.7)^{\mathrm{b}}$ & $80.00(15.2)^{\mathrm{b}}$ & \\
\hline
\end{tabular}

Note. Significant main effect comparisons and effect sizes: (a) $p=.010$, es $=0.27$;

(b) $p=.008$, es $=0.26$

All but one of the post hoc comparisons revealed no significant differences between condition means. The one significant difference involved the $\mathrm{V}+\mathrm{NO}$ condition, which had the lowest confidence rating, and the NVNO condition, which had the highest confidence rating. The effect size for the difference was 0.56

To investigate the combined effects of vignette condition and treatment decision on clinician confidence, a three-way ANOVA was conducted with client verbal report, outcome measure report, and treatment decision as the independent variables. For this analysis, the treatment decision of considering termination was eliminated due to low cell counts. There were seven cells in the considering termination condition which had fewer than 5 responses (including 2 with no responses). In this three-way analysis, there were no significant interactions or main effects.

Clinician Differences. Several four-way analyses of variance were conducted investigate clinician differences in confidence ratings. Each analysis included as 
independent variables: treatment decision (without termination), client verbal report, outcome measure report, and the particular clinician variable being examined.

There were no significant interactions or main effects for outcome assessment in practice (users vs. non-users). In the gender analysis, only a main effect for treatment decision was significant, $F(1,542)=4.32, p=.038$, which difference was described earlier. The same was true for theoretical orientation in that only a main effect for treatment decision was significant, $F(1,494)=4.52, p=.034$. In the analysis of therapy hours per week, significant main effects were found for treatment decision, $F(1,520)=4.96, p=.026$; client verbal report, $F(2,520)=4.41, p=.013$ (also described earlier); and therapy hours per week, $F(2,520)=9.73, p<.001$. Post hoc analyses found that clinicians conducting less than 20 hours per week had less confidence than those conducting between 20 and 29 therapy hours per week $(p=$ .014 , es $=0.28)$ and those doing 30 or more therapy hours per week $(p=.001$, es $=$ $0.36)$.

A significant interaction was found for work setting and outcome measure report, $F(1,469)=3.42, p=.034$. Post hoc analyses revealed no specific differences that were significant. A significant main effect was found for work setting (private practice vs. institutional setting), $F(1,469)=6.96, p=.009$, with clinicians in private practice being more confident than those working in institutional settings $(e s=0.25)$.

The final clinician difference investigated was years since licensure. The four way interaction (years since licensure, verbal report, outcome measure report, and treatment decision) was significant, $F(6,520)=2.44, p=.025$. Post hoc analyses 
revealed no individual comparison that was significant. A three way interaction effect between years since licensure, verbal report, and measure report was significant, $F(8,520)=2.18, p=.028$. Of all the post hoc comparisons, none were significantly different. A significant main effect was found for verbal report, $F(1,520)=4.96, p=$ .026 (described earlier). 


\section{Discussion}

The discussion segment of this dissertation is divided into four sections. First, the results from analyses of clinicians' judgment of client change will be discussed, including a comparison between outcome measure report and client verbal report. The strength of negative and positive information, getting worse and getting better respectively, will also be explored. Several investigations of clinician differences are examined, and comments on the source of information question are given here as well. The next section is a consideration of treatment decisions, including factors influencing the decisions made by clinicians. This is followed by a discussion of clinician confidence ratings and then a description of limitations for this study. The final section provides a summary of the dissertation, limitations, and potential future research directions.

\section{Judgment of Client Change}

Before clinicians consider whether there needs to be an alteration in the treatment plan, or that therapy is sufficiently effective, they must make a judgment regarding the degree of progress (or lack thereof) that the client is making. In lens model terminology, clinicians must interpret several cues concerning the actual progress made by that client. While several potential cues or sources of information exist, two were empirically manipulated in this study to investigate their influence on the clinicians' judgment of client change. The first issue to be discussed in this section is a comparison between these two sources of information - client verbal report and outcome measure report. 
A second issue to be considered is the relative strength of negative information compared to positive information (e.g., did information which indicated client deterioration have more impact on judgment of client change than information indicating client improvement?). This is followed by a discussion of clinician differences and how much impact they had on the judgment process. The final issue discussed in this section is a consideration of clinician's subjective weighting of various sources of information.

Verbal Report vs. Outcome Measure Report. The condition that served as the control (no verbal or outcome measure report) was indeed close to five (5.19), which was labeled "About The Same" on the survey $(\mathrm{H} 1)$. This provides some confidence that other than the two sources of information acting as independent variables, the vignettes did not bias clinicians on the judgment task. This "control" vignette was statistically different from all other vignettes for how much therapists judged clients to have improved or worsened. In essence, each of the eight vignettes with additional information (from the client, outcome measure, or both) influenced clinician judgments concerning the amount of client change.

In order to improve the readability of the discussion section, acronyms will be used to identify the different vignette conditions. These are the same acronyms used previously, but as a reminder the full terms are included in Table 24. 
Table 24

Vignette Conditions

\begin{tabular}{|l|l|}
\hline Condition & Identifier \\
\hline No client verbal report - No outcome measure report & NVNO \\
\hline No client verbal report - Negative outcome measure report & NVO- \\
\hline No client verbal report - Positive outcome measure report & NVO+ \\
\hline Negative client verbal report - No outcome measure report & V-NO \\
\hline Negative client verbal report - Negative outcome measure report & V-O- \\
\hline Negative client verbal report - Positive outcome measure report & V-O+ \\
\hline Positive client verbal report - No outcome measure report & V+NO \\
\hline Positive client verbal report - Positive outcome measure report & V+O+ \\
\hline Positive client verbal report - Negative outcome measure report & V+O- \\
\hline
\end{tabular}

The original hypothesis was that client verbal report would be a stronger indicator of client change than outcome measure report (H2). This hypothesis was based on the assumption that most clinicians do not use outcome measures in practice and would therefore be more likely to rely on client verbal report when making judgments of client change. In other words, verbal report by the client would influence clinician ratings of client change more than information from an outcome measure. Based on the results of this study, however, this hypothesis was not supported. Clinician judgments of change for the vignettes with only one of the two sources highlighted (e.g., negative outcome measure (NVO-) versus negative verbal report ( $\mathrm{V}-\mathrm{NO})$, and positive outcome measure $(\mathrm{NVO}+)$ versus positive verbal report $(\mathrm{V}+\mathrm{NO}))$ were not statistically different. Whether the vignette included information from the client's verbal report or from an outcome measure, clinicians judged the amount of change similarly. Also, if clinicians were to place more weight on verbal 
report, it would be expected that they would rate clients in the $\mathrm{V}-\mathrm{O}+$ condition worse than clients in the $\mathrm{V}+\mathrm{O}$ - condition. Again, this was not the case.

Two possible explanations exist for this finding. First, these results might indicate that in practice, clinicians use the information provided by outcome measures and client verbal report equally as they assess client progress. If therapists are using an outcome measure that is both valid and reliable, then they might view the information contained in both to be ultimately from the same source. Both verbal report and outcome measures are forms of client self-report. Although a majority of clinicians are not currently using outcome measures as part of their clinical practice, if available many (if not most) clinicians might use them in a similar fashion to the way they use client verbal report.

Another possible explanation for the finding that client verbal report and outcome measure report were equally influential in the task of judging client change lies in the methodology itself. The vignettes were short and purposively contained little relevant information regarding the client's progress. Faced with the task of judging the client's change and given the dearth of cues available, any information might have the same impact. The demand characteristics of the judgment task might have led clinicians to more directly use the outcome measure information.

Even if these findings resulted from the methodology, there are still potential clinical implications. The vignettes were designed, in part, to represent a busy clinician's work environment. With several clients everyday, and little time to think about each case outside of the therapy hour, noticing all of the cues of deterioration or 
improvement can be a difficult task. Clients typically present with depressed mood, feelings of anxiety, or other symptomatic complaints. Determining when one individual client is reporting more or less severe symptoms from one session to the next might be extremely challenging given the clinician's particular work environment. In such circumstances, clinicians might be missing cues related to progress (or lack thereof) and therefore information from an outcome measure might not be quickly dismissed and could potentially have as great an impact as the client's verbal report.

The methodology of Lambert's feedback studies (Lambert, et al. 2001; Lambert, et al. 2002; and Whipple, et al. 2003) made the outcome measure information as readily noticeable as this study's methodology. In the feedback studies, the scores and interpretation of information from the outcome measure were delivered in a noticeable manner in order to draw the clinician's attention. The researchers did not control what the clinicians did with the information, but the outcome measure report was readily available. Although it is unknown the precise impact the outcome measures had on judging client change in the feedback studies, it is possible that they were given approximately equal weight in the process of assessing client progress for each therapist.

In two separate studies, Bastardi and Shafir (1998) and Redelmeier, Shafir, and Aujla (2001) found that when information is singled out, it tends to have a greater impact on decision making than when it is simply included with other information. They found that the pursuit of information itself had an impact on decision making. 
Outcome measure information in both the Lambert feedback studies and this dissertation were readily and easily detectable. Perhaps this phenomenon contributed to verbal report and outcome measure report having a similar influence on judgment of client change. If so, then this dissertation adds support to these other two studies' (Bastardi \& Shafir, 1998; Redelmeier, Shafir, \& Aujla, 2001) findings that making certain information more noticeable or seemingly more salient can impact individual's judgments and decision making. Various methods likely can serve to highlight certain information regarding client change in clinical practice other than the methodology utilized in the feedback studies (i.e., Lambert, et al., 2001) and this dissertation.

If both client verbal report and outcome measures influence clinicians equally, there is some evidence that they are not aware of it or perhaps choose to not acknowledge it. As will be discussed later in a section detailing clinician's self report of how various sources of information influence their judgments, clinicians in this study assigned approximately three to five times more importance to client verbal report than outcome measure report. In a smaller study, Garland, et al. (2003) found that clinicians rated scores from an outcome measure as the least influential of several possible types of information in determining client progress. There is a considerable portion of therapists who feel that outcome measures are not helpful and do not adequately reflect therapeutic effectiveness (Hatfield \& Ogles, 2004). Outcome measures, though used in psychotherapy research, are not necessarily considered the gold standard in assessing client improvement in clinical practice. If clinicians object to using outcome measures, then they would likely also object to using a feedback 
protocol similar to Lambert's studies based on the possibility that doing so could unknowingly influence the judgment process. More research is needed to better understand how much influence outcome measures can have compared to client verbal report in actual clinical practice.

Another hypothesis was that two corroborating sources of information would lead clinicians to rate more client change than either piece of information alone (H3). Interestingly, of the four possible comparisons, three failed to support this hypothesis. The condition in which both verbal report and outcome measure report were positive $(\mathrm{V}+\mathrm{O}+)$ did not lead to a higher rating of client change than either verbal report $(\mathrm{V}+\mathrm{NO})$ or outcome measure report (NVO+) alone. Similarly, when both outcome measure and client verbal report were negative (V-O-), it did not lead to a lower rating than a negative outcome measure by itself (NVO-). However, the negative verbal report alone (V-NO) condition led clinicians to rate clients as deteriorating less than when both negative sources of information were present (V-O-).

When assessing client deterioration, outcome measure information adds something to client verbal report while client verbal report does not significantly add to outcome measure report. In other words, if an outcome measure indicates a client is getting worse, the clinician is not likely to judge the client as being any more deteriorated if the client also verbally reports it. Conversely, if a client verbally reports feeling worse the clinician will judge him or her to have deteriorated, but then if an outcome measure also indicates deterioration the clinician will then judge the client as being worse than when there was only the verbal report. 
This is a striking finding when considering the Lambert feedback studies. The feedback had its greatest impact when the outcome measure indicated that the client was not progressing as expected or was actually getting worse. It is possible that the outcome measure was most helpful (and salient) in situations in which the clinician was missing verbal (and other) cues of deterioration (whether the cues were present or not!). It is unknown if this was in fact the situation in the feedback studies, but the present finding raises the possibility that outcome measures are most helpful when they act as a meaningful cue of client deterioration (in the absence of other noticeable cues or even in the presence of verbal cues).

Negative Change vs. Positive Change. It was hypothesized that negative information (from either source) would have a larger impact on clinician judgment of client change than information indicating client improvement (H4). The Scheffe test comparing the differences between positive information $(\mathrm{V}+\mathrm{O}+)$ and negative information (V-O-) in their relative distance from "no change" (NVNO) supported this hypothesis. It appears that on this judgment task, when information from both sources agree, negative change indicators have a stronger impact on clinician judgments than positive indicators. Clinicians might be more guarded in their willingness to accept information suggesting client improvement. Perhaps they have reasons for not fully believing the client's positive self-report in either form. Another possibility arises from the statement in the vignette that therapy had been occurring for 3 months. Information suggesting deterioration could be surprising if the clinician expected 
improvement in that time and therefore the negative information might have had a greater effect on the judgment task.

A final possible explanation is that clinicians are not more guarded in response to positive information, but rather, more sensitized to negative information because of the potential consequences of client lack of progress (or deterioration). A well supported concept in the judgment and decision making literature is loss aversion (Kahneman \& Tversky, 1982). According to loss aversion theory, a loss of \$X (negative outcome) is more aversive than a gain of $\$ \mathrm{X}$ (positive outcome) is attractive. Kahneman and Tversky (1982) demonstrated that several studies have found this effect in various contexts. The tendency for people to avoid potentially negative outcomes is stronger than their tendency to choose decisions that might result in positive outcomes. Clinicians in this study might have been more sensitive to information related to client deterioration (negative outcome) than information indicating client improvement (positive outcome), based upon loss aversion principles. In this sense, the negative verbal report and negative outcome measure report was more salient.

A comparison of the two contradictory vignette conditions ( $\mathrm{V}-\mathrm{O}+$ and $\mathrm{V}+\mathrm{O}-)$ is interesting and supports the notion that negative information is more influential in judging client change than positive information. It was originally thought that the source of information would be the most influential factor involved, specifically that the verbal report would impact the judgment rating the most. This was not the case. Regardless of whether the information was from the client's verbal report or from an 
outcome measure, clinicians rated the client as getting worse in both contradictory vignette conditions. Both conditions were significantly lower than the no information condition (NVNO).

Clinical practice is quite complex and therapists often find themselves dealing with large amounts of information. It is common for clinicians to have mixed signals concerning actual client change. The results of this study are important in that the question is now raised as to whether clinicians are biased to place more weight on negative information, even if contradictory information is present. Is there an anchoring effect occurring arising from clients initially presenting in a state of distress? Are therapists trained to see client improvements as well as they are to recognize problematic client thoughts and behaviors? Additional research needs to be conducted to assess the robustness of this finding and to better understand this important factor in judging client change.

In further analyses using Scheffe tests, it was found that negative information was stronger than positive when only outcome measure information was presented (NVO- versus $\mathrm{NVO}+$ ), but this did not hold true for when only client verbal report was presented $(\mathrm{V}-\mathrm{NO}$ versus $\mathrm{V}+\mathrm{NO})$. It is interesting that outcome measures are more influential when indicating client deterioration than when they suggest client improvement. Once again, this matches with the findings of the Lambert feedback studies in that outcome measures indicating that clients were getting better did not have as great an effect as did the outcome measures that indicated a client was getting 
worse. This finding also suggests that the outcome measure used in the feedback studies had its strongest impact when alerting the therapist of client deterioration.

The most striking findings of the past two sections is that negative information is more salient in judging client change and that the source of information potentially matters in only limited situations. More research is needed to better understand why negative information is more influential in clinicians' judgment of client change than information indicating client improvement. And does the source of the information matter greatly when clinicians make the judgments in actual clinical practice, as they report it does? Again, additional research would help clarify this issue.

Clinician Differences. After considering issues related to the source of information and direction of change, the discussion now turns to clinician variables and the impact these variables had on judgments of client change. Gender was not a factor in client judgment of client change. Men and women made similar judgments of client change across the conditions presented in this study. Another factor that was not influential was theoretical orientation, specifically an interaction between orientation and outcome measure report. This was somewhat surprising since Hatfield and Ogles (2004) found that insight-oriented therapists were less likely to use outcome measures in their clinical practice. As will be discussed in more detail in the next section, insight oriented therapists also indicated that outcome measures are less influential in their assessment of client change than did other therapists. Despite their view that outcome measures are less important or influential, insight oriented therapists used outcome measure information provided in the vignette in the same 
manner as did the other respondents. It is possible that the reason for this is related to, if not the same, as the reasons discussed earlier for no difference between client verbal report and outcome measure report. That is, when information is available clinicians are likely to use it regardless of their orientation, especially in situations where limited information is available.

Another interesting non-significant finding was clinicians who routinely conduct outcome assessment in their clinical practice did not use the outcome measure report in the vignettes differently than other therapists. For those who are engaged in the process of routinely assessing client outcome, often with some form of outcome measure, one would think that outcome measure information would be more salient and therefore influential in their judgment of client change. This was not the case. Clinicians who use outcome measures were similar to clinicians who do use outcome measures in terms of their use of client verbal report when making judgments of change. This, too, might be attributed to the nature of the vignette and the limited information provided regarding client progress. It is possible in a scenario in which there is much information from which to make a judgment that those clinicians who regularly administer outcome measures might use the outcome measure information more than other clinicians. On the other hand, clinicians who routinely use outcome measures may be attuned to all sources of information that are available and do not place any special emphasis on the standardized measure.

There was a small main effect $(d=0.11)$ for outcome measure users in that they tended to rate the client in the vignette 0.22 scale points lower regardless of the 
information presented. Although statistically significant, the difference is small enough to question whether it is practically significant. Perhaps these clinicians are more focused on client levels of symptomatology and are therefore a little more likely to assume that clients are presenting worse than other clinicians who are not as focused on tracking client symptom levels. Again, this was a small effect and difficult to interpret.

Another small difference that is difficult to apply practical significance to was the main effect for years since licensure $(d=0.19)$. Regardless of the information in the vignette, clinicians who received their license before 1980 rated the client 0.38 scale points lower than therapists licensed since 1990. Older therapists might view clients as more distressed than do therapists of more recent generations. This is perhaps related to different training models more predominately occurring before 1980, perhaps leading these clinicians to view clients as more clinically impaired. In the past two decades, some of the social stigma regarding the utilization of psychotherapeutic services has diminished and perhaps there are some less disturbed individuals who participate in therapy.

In the three-way interaction, older therapists rated the client as getting worse and newer therapists rated the client as not changing when presented with an outcome measure indicating deterioration and the client stating he was getting better ( + +O-). Perhaps this shows a tendency for older clinicians to not believe client report of getting better when other information contradicts it or for newer clinicians to not believe other information when the client states improvement. However, this 
difference was not replicated in the other vignette condition which offered contradictory information $(\mathrm{V}-\mathrm{O}+)$.

Source of Information. Clinicians were asked to rate the importance of various sources of information by indicating the relative influence each source of information has in judging client change. They were to divide $100 \%$ however they desired to designate the relative importance of each item. This represented clinicians own subjective reporting of the importance they assign each source of information and does not necessarily represent how much influence each source of information actually has in their clinical practice.

The priming effect found outcome measure information was in the vignette is interesting. Those clinicians who had just used information from an outcome measure to make a judgment of client change indicated that in their normal clinical practice, outcome measures play a somewhat larger role in their assessment than did clinicians who had not just used or seen that information for the survey. Perhaps if outcome measures, or any other source of information, are made available or made more pertinent in everyday clinical practice, clinicians might view them as more important than they currently do.

It was hypothesized that client verbal report and clinician observations would be the two most influential sources of information (H12). Not only was this true, but they were almost equally influential. Although significant other report is often difficult to obtain, clinicians rated it as less than half as influential as client verbal report. This raises the question of how much clinicians believe or use significant other 
reports when it is available. Satisfaction questionnaires were broadly rejected as having little to no influence in assessing client progress. This demonstrates a different perspective that clinicians hold contrary to the consumer focused model held by various agencies and companies. Some agencies use client satisfaction questionnaires as a method of evaluating services provided by an agency, sometimes in conjunction with outcome measures or as the sole method of service evaluation. Clinicians in this study indicated, however, that this information has little to no influence when assessing client progress.

Both client verbal report and clinician observation were at least twice as influential as outcome measure report. This contradicts the finding discussed earlier that client verbal report and outcome measure report were used equally in the judgment task of this study. Since the question in this study asked clinicians to provide a subjective "weighting" of sources of information that they felt were important and did not observe actual clinician practice in using these sources of information, additional research is needed to understand how clinicians use information to assess client change. Other methodologies exist which can better examine the precise influence various sources of information have on clinician judgment. The results of this study can provide a starting point in these investigations. Are client verbal report and clinician observations equally influential in clinician judgments of client change, or do clinicians act differently in real clinical practice? When outcome measure information is available in combination with client verbal report, do they have equal influence or does client verbal report have twice the 
influence as outcome measures? Are certain clinician observations more important than others? For now, it is important to note that there was a discrepancy between clinicians' stated weighting of and preference for sources of information and the actual influence of those sources in their judgments of client change for the vignette. Future research is needed to better understand how clinicians perceive and use various cues in assessing client change.

Most of the significant clinician differences were found in how influential in their judgments they felt outcome measures were. The biggest difference (and most obvious) was that clinicians who routinely conduct outcome assessment in their clinical practice were more likely to endorse a higher percentage for outcome measures than clinicians who do not do this in clinical practice. Other clinicians who ascribed a higher influence to outcome measures were cognitive-behavioral therapists, newer clinicians, those working in an institutional setting, and males. With the exception of gender, each of those would have been predicted based on the findings of the Hatfield and Ogles (2004) study since these are the groups of clinicians more likely to conduct routine outcome assessment in their clinical practice. In this sense, most of the clinician differences can be explained by the fact that those clinicians who conduct outcome assessment are more likely to report using outcome measures in assessing client change. It is uncertain why men tended to rate a higher influence for outcome measures than women.

Although it appears that there were not many clinician differences in how much impact the two sources of information had on the judgment of client change, 
clinicians' perception of how much influence each source of information has on their actual clinical judgments did differ. While most clinicians reported that client verbal report and clinician observations were the most influential, the level of importance assigned to an outcome measure varied. Those clinicians who tend to more often use outcome measures in their clinical practice (Hatfield \& Ogles, 2004) found them to be more important than those who do not routinely use them. The results of this study challenge the congruence between clinicians' perceptions of how much influence varying sources of information have and how they might actually use the information. Additional research is needed to further determine the actual impact these sources of information have on clinician judgment of client change and whether clinicians are accurate in their perceptions of how they use available information. A separate question is whether indications of client change lead to any action taken by therapists, which is the focus of the next section.

\section{Treatment Decisions}

The "treatment decision" portion of the study was based upon the Lambert feedback studies (Lambert, et al., 2001; Lambert, et al., 2002; and Whipple, et al., 2003). In the first two feedback studies, the only manipulation was the provision of a single piece of information - an indication of client progress (or lack thereof) based upon the administration of a standardized outcome measure completed by the client. It is unclear what exactly occurred in the therapists' mind or the therapy room as a result of this intervention. For clients who were predicted to be treatment failures, giving information from a client-completed outcome measure ultimately improved 
client outcomes. In some of the studies, outcome measure information also shortened the number of sessions required to reach satisfactory client improvement. Somehow, the extra information either led the therapists to alter the treatment they were providing or at least think about the case differently (or more thoroughly).

In order to better understand what might have occurred in the feedback studies, treatment decision was included as a primary matter for investigation in this dissertation. With a more controlled and simple circumstance, in the form of a clinical vignette, does the addition of outcome information lead therapists to a decision to alter the treatment they are providing or will they continue to conduct "therapy as usual?" Following a consideration of the impact additional information had on treatment decisions will be a discussion of clinician variables. Finally the specific sub-choices of clinicians will be explored.

Additional Information. Close to $80 \%$ of the therapists in the NVNO condition chose to alter treatment. It was presumed that clinicians would decide to not alter treatment in response to the vignette containing no information concerning client improvement or deterioration (H5). The basis for this assumption was that in absence of any information suggesting that the client is getting worse, clinicians would choose to maintain the status quo and deliver their normal therapeutic services. In other words, clinicians would only choose to alter treatment if therapy was going drastically wrong, as indicated by information suggesting that the client has deteriorated since beginning therapy. This basic assumption, however, proved to be false. 
Hints at why so many therapists chose to alter treatment began to emerge in some of the responses that clinicians wrote in the "Other" space provided. A few clinicians in the NVO+ and $\mathrm{V}+\mathrm{NO}$ conditions wrote something similar to, "I would discuss this discrepancy with the client." Such a comment suggests that the therapist found a discrepancy between the report of positive change (either from the client or an outcome measure) contrasted with statements in the vignette. Since these were not the contradictory conditions, there was a consideration of what this "discrepancy" might be.

The most likely explanation lies in the following sentence from the vignette, "As of now, you have not observed significant changes in his affect and behavior." This sentence was intended to provide neutral information for the clinician's first task in the study - assessing client change. Based on the results described earlier, the information does appear to be effectively neutral for the judgment task (i.e., vignettes with no outcome or verbal information were rated close to the mid point - "about the same"; see previous section). For the treatment decision task, however, this sentence likely conveyed more information than was originally intended. Couple the sentence stating no observable changes with the statement "Brian...has seen you for approximately 3 months of therapy" and a probable explanation becomes apparent. In an era of managed care and cost containment, brief modalities of therapy have emerged. In today's clinical world, three months of therapy can be a long time. It is quite possible that for many clinicians and clients, if improvement has not been observed during three months of treatment, then something is assumed to be amiss. It 
is possible that many clinicians in the NVNO condition decided to alter treatment because the vignette indicated no observable client improvement during the 3 months of therapy. Again, when contrasted with reports of positive change (either through the client verbal report $(\mathrm{V}+\mathrm{NO})$ or outcome measure $(\mathrm{NVO}+)$, some clinicians indicated they would discuss the discrepancy.

Fortunately, the vignette statements of no observable change and three months of therapy were consistent across all nine vignette conditions. The NVNO condition can therefore still serve as a base rate (or control) indicator, with $80 \%$ of therapists choosing to alter treatment and $20 \%$ choosing to continue treatment as usual. This view of change and treatment still provides an opportunity for comparison with other scenarios. For example, it is still possible to examine the influence that the additional information (verbal or outcome) had on treatment decisions (e.g., under certain circumstances did clinicians choose to alter treatment less than the base rate of $80 \%$ of the time?).

When outcome measure information indicating client deterioration was presented, the odds of therapists choosing to alter treatment was two times greater. "Altering treatment" is a general term, but it does suggest that the clinician would purposely change the treatment plan, the manner in which the current treatment plan was being conducted, and/or reevaluate the diagnostic formulation when negative outcome measure information is presented. This study supports the notion that many therapists would consider changing their delivery of services when they obtain information from an outcome measure suggesting client deterioration that is added to a 
scenario where the client has made no perceivable change over a 3 month period. Outcome measure information might help focus the therapist's attention on cues indicating client deterioration and possible treatment failure, and then potentially lead to an alteration in the treatment.

Conversely, when therapists are given similar information suggesting client deterioration by means of the client's verbal report, they are not more or less likely to alter treatment compared to not having this verbal indicator of client change. There appears to be at least a portion of clinicians for whom a client's verbal reporting of getting worse does not increase the likelihood of changing treatment in some manner. Theoretical rationales might explain the reluctance of some therapists to change treatment following a client's reporting of deterioration (as will be discussed later).

More generally, the lack of influence that negative verbal report had on treatment decisions offers a potential explanation for why the feedback system in the Lambert studies was effective. It is possible that some of the clients in the studies verbally informed their therapist that they were doing worse, though this did not necessarily lead to a change in the treatment. The change in treatment came following an outcome measure indicating that the client was not progressing as expected. The results of this dissertation suggest that information from outcome measures is instrumental in leading to a change in the treatment being provided. This can be true either in the absence or presence of a client verbally reporting deterioration. Future research can further investigate the significance and robustness of this finding. 
If clinicians received information from the client's verbal report or an outcome measures report suggesting that the client has improved since the beginning of therapy, more clinicians chose to continue treatment in the same manner they had been. If clients are indicating improvement, then therapy is likely effective and more of the same effective therapy would logically lead to further improvement. It must be remembered that the vignette also contained the statement regarding no observable change and $40-57 \%$ of the clinicians still chose to alter treatment. Despite that statement, however, there was a group of clinicians who were sufficiently persuaded by client's self report (in either form) to confidently continue their current treatment. A visual inspection of the data presented in Table 15 of the results section suggests that information suggesting client improvement (in absence of contradictory information) had the largest impact on how many clinicians would choose to continue treatment in the same manner.

In two of the three feedback studies (Lambert, et al. 2001, Whipple, et al. 2003), clients whose therapists received feedback that their clients were progressing as expected were able to achieve the same level of improvement in fewer sessions. Therefore, it was assumed that information indicating client improvement would lead clinicians to at least consider taking steps towards termination. As it turned out, relatively few clinicians chose to do so. The sentence in the vignette stating that the therapist has not noticed any change might have made most therapists hesitant to decide to terminate therapy (even when the vignette included other indicators of improvement). Again, despite this statement there were a small number of clinicians 
who nonetheless chose to take steps towards termination (refer to Table 15 in the Results section).

It was hypothesized that the addition of positive outcome measure information to positive verbal report would increase the percentage of clinicians choosing to take steps towards termination $(\mathrm{V}+\mathrm{NO}$ versus $\mathrm{V}+\mathrm{O}+)(\mathrm{H} 7)$. In making this hypothesis, it was assumed that some of the clients in the Lambert feedback studies verbally expressed some form of symptom reduction and the therapist either was unconvinced or did not notice the cue. The outcome measure then either served to make the therapist more aware that the client was improving or added additional evidence of the same. Through either of these means, therapists might consider the possibility of termination and choose to move in that direction. Despite the small numbers and the statement in the vignettes regarding no observable change, the percentage of clinicians choosing to terminate did double from $10 \%$ to $20 \%(\mathrm{~V}+\mathrm{NO}$ and $\mathrm{V}+\mathrm{O}+$ respectively). In context of the no change statement, this might represent a significant increase in the likelihood of clinicians to consider taking steps towards termination when outcome measure information suggesting client improvement is presented. Further research is needed to better investigate the significance of this finding.

It was also hypothesized that in the two contradictory conditions clinicians would choose to continue treatment as usual (H6). In complex or uncertain situations, people will sometimes choose to defer their decision (Redelmeier \& Shafir, 1995; Tversky \& Shafir, 1992) or maintain the status quo. It was anticipated that the contradictory information would create a situation of uncertainty for the clinicians, 
therefore leading them to defer their decision by maintaining the status quo of treatment as usual. As has been demonstrated previously, there was a problem for this data in assuming that the status quo is analogous to continuing treatment as usual. The status quo that the contradictory conditions must be compared to is the control condition with no verbal or outcome measure information (NVNO).

The $\mathrm{V}+\mathrm{O}$ - condition had $20 \%$ of clinicians choosing to continue treatment as usual, precisely the same number as the NVNO condition. The V-O+ condition demonstrated an increase with $27 \%$ choosing to continue treatment as usual. The hypothesis was correct for the $\mathrm{V}+\mathrm{O}$ - condition in that clinicians appeared to make treatment decisions in a similar manner as those who received no verbal report or outcome measure report, suggesting the possibility that in complex situations with contradictory information, clinicians might maintain the status quo of treatment. This adds some support to the findings of the Redelmeier and Shafir (1995) studies, clinicians were hesitant to change their behavior in complex situations from what they were doing in the absence of the additional (contradictory) information. The other contradictory condition ( $\mathrm{V}-\mathrm{O}+$ ) was interesting because there were a few clinicians who were more persuaded by the positive outcome measure than the negative client report. Additional research is necessary to determine if this finding would be replicated.

The most important finding in the primary treatment decision analysis was how outcome measure information indicating client deterioration might lead more clinicians to alter the treatment they are providing than does information from a 
client's verbal report. This study did not empirically investigate why one source of information might lead to more changes in the treatment than another source, although this would be an important issue to understand. A consideration of clinician characteristics might offer a few clues.

Clinician Differences. Several clinician characteristics were studied in order to ascertain their influence on treatment decision making. The theoretical orientation of the clinician had the largest influence on the treatment decision. Insight oriented therapists chose to continue treatment $40 \%$ of the time compared to $20 \%$ for CBT therapists. There are philosophical differences between these two treatment modalities that might explain this finding. For example, one respondent wrote this comment on the survey, "After 3 months, therapy is just beginning." Some insight oriented therapists do not expect symptom reduction to occur rapidly and a lack of quick improvement does not necessarily indicate that treatment is not working. Within the combination of modalities that make up the insight oriented group for this study are several long-term therapies in which symptomatic improvement might not be expected in the early stages of therapy.

The finding that clinicians licensed before 1980 were more likely to decide to continue treatment as usual probably has its roots in the same explanation. More therapists were trained in longer-term therapies during that era, and therefore were more likely to not alter treatment. Although this relationship is not clear-cut since there were as many CBT therapists as insight oriented therapists in the older group, there has been a movement in the past 20 years toward briefer therapy models. 
A relationship that is more easily decipherable is the finding that men were more likely than women to continue treatment. More men were licensed prior to 1980 than women and the opposite was true for the most recently licensed therapists. The gender effect is probably a duplication of the other finding that older clinicians were more likely to continue treatment as usual rather than a true gender difference. On the other hand, it is possible that this could be reversed and the years since licensure finding is a by-product of an actual gender difference. However, it is difficult to imagine the underlying cause for a gender difference in tendency to alter treatment.

Work setting failed to be an influential factor in treatment decisions. This is somewhat interesting since it might be expected that therapists working in an institutional setting are more commonly under pressure to provide briefer therapy. Many agencies conduct some form of quality assurance program that might dictate a change in the treatment plan if a client is not progressing. This effect was not observed in this study, possibly indicating that private practice therapists are just as willing as therapists in institutional settings to alter treatment when clients fail to progress.

Based on the clinician differences found in this study, it is possible that feedback systems similar to those used in the Lambert studies might not be as effective with therapists who utilize longer treatment modalities or who do not expect quick symptom reduction. Information in the form of outcome measure feedback might not be useful information for these therapists. More research is needed to better understand how information from any source of information regarding client change is 
used with insight oriented therapists. Does direct client verbal feedback concerning deterioration (or improvement) influence their decisions in how they are conducting therapy? Perhaps they would alter treatment in some manner but the methodology utilized in this study was unable to access that kind of information. Likewise, would the feedback study protocol be as effective for older therapists (or men) than younger therapists (or women)? Does work setting not influence the likelihood of clinicians choosing to alter therapy, as the findings of this study suggest? Future research is need to further investigate these questions.

Sub-Choices for Treatment Decisions. Under each treatment decision that therapists could choose from were three more specific treatment decisions. Participants were instructed that they could endorse as many as they would like. Space was provided for clinicians to write in their own responses if they desired. Many of the participants chose to write something, as can be seen in Appendices G, H, and I.

Of the 191 clinicians who chose to continue treatment as usual, few endorsed doing so with no changes in the treatment plan. A majority indicated that they would continue for now and then reevaluate in the future. A third of these clinicians stated that they would continue for now and seek peer consultation. Peer consultation could eventually lead to a change in the treatment being offered, as could a future reevaluation. Therefore, almost all of the clinicians who decided to continue treatment in the usual manner were presumably open to future changes in treatment. 
Each of the sub-choices under the alter treatment option were frequently endorsed. Of the 538 clinicians who indicated that they would alter treatment, $70 \%$ indicated that they would reevaluate the diagnostic formulation. Garb (1998) has reviewed several studies concerning the errors some clinicians can make when conducting psychodiagnostic tasks. One of the reasons clients do not get better or the treatment is not working might stem from an inaccurate conceptualization of the client's problems. If the diagnostic formulation changes, it is possible the treatment will also change. An inaccurate case conceptualization remains only one possible explanation why treatment is not working, there are likely other factors involved. This study found that a majority of clinicians feel that reevaluating the diagnosis is an important step in the process, either alone or in conjunction with other changes in the treatment being provided.

Half of the 538 clinicians who chose to alter treatment took the time to write something in the space provided by the "other category." Most of these statements can be grouped into one of four broad categories. Several clinicians indicated that they would discuss the discrepancy with the client (presumably in the contradictory conditions or positive conditions coupled with the statement that the clinician has not noticed any changes) or explore with the client the self-report of deterioration/improvement. Discussing things with the client was also a popular "other" comment under the continue treatment decision. Of the 36 clinicians in the study who chose to terminate, 30 indicated that they would discuss possible termination with the client. Generally, discussing progress (or lack thereof) with the 
client might lead to an enhanced therapeutic alliance, more accurate case conceptualization, additional cues to be used in the assessment of actual client change, a discussion of potential changes in the treatment plan, and/or several other clinical possibilities.

Another popular "other" comment under the alter treatment decision was medications or psychiatric evaluation. It was somewhat surprising that this many clinical psychologists would refer for medications after three months of therapy. In the Whipple, et al. (2003) feedback study, various clinical support tools were offered to clinicians when outcome measure scores indicated that the client was a potential treatment failure. Therapists were given a list of options that they might try with this client. Referring for medication was one of the therapeutic decisions on the list given to the therapists. In comparing the overall outcome of the clients who were in the clinical support tool conditions, the only intervention that led to clients actually getting worse following implementation was referral for medication. There are several possible explanations for this, but it is an interesting finding in light of how many clinical psychologists in this dissertation indicated that they would make such a referral.

Several of the "other" comments indicated a decision for further evaluation or assessment of various sorts. Some clinicians expressed a desire for more information that would presumably help them more clearly understand the degree of change in the client and possibly inform better treatment decisions. Finally, although peer consultation was one of the listed options under the continue treatment decision, it was 
not specifically mentioned under the alter treatment decision and some clinicians expressed that this would be one of their actions.

The variety found in the responses provided by clinicians concerning their treatment decisions represents the variety that can be found in actual clinical practice. Several studies found that clinicians (some of whom were very similar in theoretical background) that clinicians frequently disagreed when choosing treatment options after reviewing the same information (Felton \& Nelson, 1984; Keller et al., 1986; Nierenberg, 1991; Bickman, Karver, \& Schut, 1997). The diversity of responses in this dissertation adds support to the notion that clinicians also do not agree on treatment decisions later in therapy.

Although there are similarities, many clinicians provide treatment in an idiosyncratic manner. How one clinician might respond to a cue of client deterioration might not be the same to how another clinician would respond. One treatment option that was frequently written under the broader treatment options suggested a discussion with the client about the client's progress. Another popular response was the gathering of more information. Both of these two "types" of intervention potentially lead to better communication between client and therapist. Improved communication can lead to a higher frequency, and potentially a higher quality, of cues representing actual client progress (or lack thereof).

\section{Confidence Ratings}

After clinicians judged the degree of client change and then made a decision regarding treatment, they answered a question regarding their confidence in the 
decision they made. The question assessing clinician confidence read, "How confident are you that your decision is appropriate?" In all, the clinicians in this sample indicated high confidence in their treatment decision. The question remains whether this was an artifact of the study's design or if clinicians truly are this confident. The answer is probably both. Remember that a sizable portion of clinicians chose to alter treatment even in conditions indicating the client was getting better, although to a lesser extent than those in conditions indicating client deterioration.

Clinicians were given an opportunity to write their own specific course of action, which half chose to do and it is not surprising that many clinicians were confident in their treatment decision. The design of the study allowed clinicians flexibility in their treatment decisions and they would naturally choose that with which they were most confident would be the best course of action. It seems reasonable to assume that clinicians would not choose a treatment option that they were not confident in, especially if alternatives existed that they found more appropriate. It is possible that removing the ability of respondents to write in their own treatment options might have decreased, to a small degree, their confidence rating since some of them would no longer be allowed to write in their best treatment ideas. It is also possible that clinicians would be highly confident in their decision to alter treatment without necessarily being confident in how they would actually do it.

Clinicians were a little less confident in decisions to terminate treatment. In most work settings, clinicians initiate few case terminations. Clients will often stop 
coming without prior notification to the therapist. Sometimes third-party payment sources influence the timing of termination. Clinicians who received a vignette with only positive verbal report or outcome measure report or both made most of the termination decisions. As found in the judgment of client change results, positive information was less influential than negative information in the judgment task. This could possibly lead to less confidence in any decisions based on that information. Also, because there was so little information in the vignette, clinicians might not have been as confident that termination was the best option.

The information presented in the vignette had almost no impact on clinician confidence in their treatment decision. It was hypothesized that the control condition NVNO would have the lowest confidence rating due to the difficulty of making a treatment decision with little information on which to base it (H11). Although statistically the same as seven of the other conditions, therapists in this condition reported the highest confidence of all. The only significant difference between the vignette conditions was between the highest (NVNO) and lowest (V+NO).

It was also hypothesized that confidence would increase when two sources of information were present compared to either one alone (i.e., $\mathrm{V}+\mathrm{O}+$ greater than either $\mathrm{V}+\mathrm{NO}$ or $\mathrm{NVO}+$ ), based upon the classic study by Oskamp (1965) in which additional, similar information increased participant confidence in their judgments (H8). It was also hypothesized that confidence would decrease in contradictory information conditions, due to the finding by Peterson and Pitz (1986) that additional information which was not confirmatory led to a decrease in participant confidence 
(H9). Due to the lack of differences between almost all of the vignette conditions, neither one of these hypotheses were supported. Similarly, the hypothesis that confidence levels would be significantly higher when the outcome measure corroborates the client verbal report as compared to when it contradicts the client (H10) was disconfirmed due to virtually no differences between the conditions on clinician confidence.

It is possible that clinicians are, as a whole, a confident group of people. Research has demonstrated that professionals in several fields are highly confident in their decisions (Torngren \& Montgomory, 2004), as are people who merely perceive themselves as experts (Bradley, 1981). It has to be questioned, however, whether clinicians truly are this confident across conditions or if the methodology used in this study even allows the confidence ratings to be adequately interpreted. In particular, the flexibility in the treatment decision task might have served to limit the variability in the confidence ratings. Clinicians were able to choose the treatment option they were most confident in, possibly creating a ceiling effect. Future research can address this limitation and be better able to comment on clinician confidence in treatment decisions.

Despite the methodological shortcomings of this study's investigation of clinician confidence in treatment decisions, two clinician differences were still observed. Clinicians in private practice had a little more confidence in their treatment decisions than did clinicians who work in institutional settings. A possible explanation for this finding is that private practice offers less oversight of clinical 
work and clinicians who are naturally more confident in their own work seek working environments that diminish the possibility of someone offering differing suggestions. Also, clinicians who conduct psychotherapy less than 20 hours per week were a little less confident than those doing more therapy per week. Perhaps clinicians working full time gain more confidence with increased experience. Another possibility is that clinicians who are less confident in their own clinical work will seek out other types of job opportunities and only do psychotherapy part time.

\section{Summary of Hypotheses}

Table 25 contains the original hypotheses from the introduction along with the conclusions from the results of this study. 
Table 25

Summary of Hypotheses

\begin{tabular}{|l|l|}
\hline Hypothesis & Conclusion \\
\hline H1: NVNO close to 5 & Confirmed \\
\hline $\begin{array}{l}\text { H2: client verbal report would have a stronger impact on } \\
\text { clinician judgment of client change than did outcome } \\
\text { measure report }\end{array}$ & Disconfirmed \\
\hline $\begin{array}{l}\text { H3: additional confirmatory information will increase the } \\
\text { magnitude of client change more than either type of } \\
\text { information alone }\end{array}$ & $\begin{array}{l}\text { 3 Comparisons } \\
\text { Disconfirmed, } \\
\text { Confirmed }\end{array}$ \\
\hline $\begin{array}{l}\text { H4: reports of change in the negative direction (from either } \\
\text { source) would have more impact than reports of client } \\
\text { improvement }\end{array}$ & Confirmed \\
\hline $\begin{array}{l}\text { H5: } \text { most clinicians in the control condition would choose to } \\
\text { continue treatment as they have been }\end{array}$ & Disconfirmed \\
\hline $\begin{array}{l}\text { H6: clinicians would choose to maintain the status quo and } \\
\text { continue treatment as usual in the contradictory conditions }\end{array}$ & Disconfirmed \\
\hline $\begin{array}{l}\text { H7: client verbal report indicating client improvement would } \\
\text { more likely lead to considering steps towards termination" } \\
\text { when corroborating outcome measure information was } \\
\text { included, compared to client verbal report alone }\end{array}$ & Cautiously \\
\hline $\begin{array}{l}\text { H8: confidence will increase with two sources indicating } \\
\text { improvement or deterioration compared to either source } \\
\text { alone }\end{array}$ & Disconfirmed \\
\hline \begin{tabular}{l} 
H9: $\begin{array}{l}\text { when clinicians were presented with contradictory } \\
\text { information confidence would decrease }\end{array}$ \\
\hline $\begin{array}{l}\text { H10: confidence levels would be significantly higher when the } \\
\text { outcome measure corroborates the client verbal report as } \\
\text { compared to when it contradicts the client } \\
\text { progress (control condition) would be least confident in } \\
\text { highest rated sources of information }\end{array}$
\end{tabular} & Disconfirmed \\
\hline $\begin{array}{l}\text { H12: client report and clinian observations would be the } \\
\text { clinicians who received no information concerning client }\end{array}$ & Disconfirmed \\
\hline
\end{tabular}

Many of the hypotheses (H8, H9, H10, H11) were disconfirmed due to the high degree of clinician confidence, disallowing direct comparisons between conditions. The 
confirmation or disconfirmation of the other hypotheses were discussed in previous sections.

\section{Methodological Considerations}

While interpreting the results from this study, it is prudent to discuss its methodological limitations and strengths. First of all, there is a question of how well this sample represents all independent practitioners in this country. Certainly not $83 \%$ of professionals delivering therapeutic or counseling services hold a Ph.D. Compared to the general population of all psychologists, there might not be $64 \%$ in private practice (solo or group). While this might limit generalizability to all mental health providers, the sample does have some representative strength, however. The random assignment method used to mail the surveys provided a geographically diverse sample. Each of the conditions had similar numbers of participants. The average number of hours conducting therapy per week is just under 23 , which represents a typical clinician's schedule. Considering the grouping of theoretical orientations utilized for the comparative analyses, there is a good division of eclectic, insightoriented, and cognitive-behavioral therapists. There is also an even gender split. The findings of this study must be considered, however, in the context of its limitations in generalizability. More research will be needed to gain a better perspective on outcome measure use for all mental health professionals.

As described in previous sections, the methodology utilized for this study has both advantages and drawbacks. The experimental control in this study was something lacking in the Lambert feedback studies. On the other hand, it is 
acknowledged that brief vignettes do not provide the depth of information available to clinicians in actual clinical practice. The complexity involved in real practice is not always captured in methodologies similar to the one used in this study. All results of this study need to therefore be considered in light of this difference. Rather than discounting the results as too far removed from actual clinical practice, they can be interpreted as new hypotheses derived from empirical study needing further investigation. It would be beneficial for each of these results to be replicated in studies that more closely match actual clinical practice. The results of this study therefore create many of the hypotheses to be tested in other, more clinically representative research investigations.

While the vignette worked well for the judgment of client change task, it did not prove to be completely neutral for the treatment decision task. Although this potentially created a bias towards choosing to alter treatment, comparative analyses were still possible. It would be helpful for the treatment decision findings to be replicated with more completely neutral clinical information to better understand the decisions that therapists would make in similar situations. Additionally, the reliability of the questionnaire has not been established and it is unknown if the same results would occur if the same clinicians were to take the questionnaire another time.

Finally, the question assessing clinician confidence read, "How confident are you that your decision is appropriate?" It should be noted that the question asked for confidence concerning the treatment decision (continue, alter, terminate) and not their confidence in their judgment of client change. It would have been informative to 
assess these separately and future research should investigate clinician confidence in judgments of client change. For this study, however, only confidence in the treatment decision was asked of the respondents. Additionally, less flexibility in the treatment decision task might allow for a more rigorous investigation of clinician confidence.

\section{Conclusion}

Available research suggests that between 5-10\% of psychotherapy clients deteriorate after beginning therapy (Lambert \& Ogles, 2004; Mohr, 1995). The Lambert feedback studies (Lambert, et al., 2001; Lambert, et al., 2002; Whipple, et al., 2003) found that providing therapists with information concerning client progress obtained from a routinely administered outcome measure led to better outcomes for clients who were predicted to be treatment failures. If outcomes are improved through providing a single piece of information, it is important to understand how it works if we are to continue efforts to help the portion of clients who are not progressing in therapy.

Little research has been conducted investigating how clinicians use information when judging client change and what effect additional information has on this judgment task. Additionally, there is little empirical investigation of how the outcome measure in the feedback studies actually impacted the therapeutic process. This dissertation represents an initial attempt to better understand the processes behind the feedback study findings.

Although the methodology used in this study was a step removed from actual clinical practice, the results raise several interesting hypotheses that can be 
investigated in more clinically representative studies. First, despite the fact that many clinicians indicated that outcome measures were less influential in their judgment of client change than other sources of information, both outcome measure information and client verbal report had an equal impact on the judgment of client change. Clinicians were also more influenced by information (from either source) that indicated client deterioration than by information suggesting that the client was improving.

Judging client change is only one part of the process, however. Clinicians will make decisions concerning their delivery of services following their judgment of change (whether the decision is to alter the treatment or to continue in the same manner). Even though outcome measures and client verbal report impacted clinician judgment equally, client verbal report of deterioration did not significantly influence clinician treatment decisions, while outcome measure information indicating deterioration did influence clinician treatment decisions.

Research exists that explores clinician tasks related to the earlier stages of therapy, such as psychodiagnostic accuracy and initial treatment decisions (Garb, 1998). Similar tasks in the later stages of therapy, such as judgment of client progress and decisions related to possible changes in the delivery of treatment, are arguably just as important. The better we understand how clinicians perform these tasks, the better able we will be to effectively train clinicians in how to conduct their own outcome assessment and make appropriate treatment decisions. Ultimately, this knowledge can 
hopefully lead to an improvement in therapeutic services and help those people we are trying to serve. 


\section{References}

Ankuta, G.Y., \& Abeles, N. (1993). Client satisfaction, clinical significance, and meaningful change in psychotherapy. Professional Psychology: Research \& Practice, 24(1), 70-74.

Arkes, H.R., \& Harkness, A.R. (1980). Effect of making a diagnosis on subsequent recognition of symptoms. Journal of Experimental Psychology: Human Learning \& Memory, 6(5), 568-575.

Bastardi, A., \& Shafir, E. (1998). On the pursuit and misuse of useless information. Journal of Personality and Social Psychology, 75, 19-32.

Bickman, L., Karver, M.S., Schut, L.J. (1997). Clinician reliability and accuracy in judging appropriate level of care. Journal of Consulting \& Clinical Psychology, 65(3), 515-520.

Bickman, L., Rosof-Williams, J., Salzer, M. S., Summerfelt, W. T., Noser, K. Wilson, S. J., \& Karver, M. S. (2000). What information do clinicians value for monitoring adolescent client progress and outcomes? Professional Psychology: Research and Practice, 31, 70-74.

Bradley, J. V. (1981). Overconfidence in ignorant experts. Bulletin of the Psychonomic Society, 17(2), 82-84.

Bruvold, N. T., \& Comer, J. M. (1988). A model for estimating the response rate to a mailed survey. Journal of Business Research, 16(2), 101-116.

Carroll, J.S., \& Johnson, E.J. (1990). Decision Research: A Field Guide. Newbury Park: Sage Publications.

Cohen, J. (1988). Statistical power analysis for the behavioral sciences (2nd ed.). Hillsdale, NJ: Erlbaum.

Dawes, R.M. (1994). House of cards: Psychology and psychotherapy built on myth. New York, NY: Free Press.

Dowie, J., \& Elstein, A.S. (Eds.). (1988). Professional judgment: A reader in clinical decision making. New York, NY: Cambridge University Press.

Dumont, F. (1993). Inferential heuristics in clinical problem formulation: Selective review of their strengths and weaknesses. Professional Psychology: Research \&Practice, 24(2), 196-205. 
Ellis, M.V., Robbins, E.S., Schult, D., Ladany, N., et al. (1990). Anchoring errors in clinical judgments: Type I error, adjustment, or mitigation? Journal of Counseling Psychology, 37(3), 343-351.

Felton, J.L., \& Nelson, R.O. (1984). Inter-assessor agreement on hypothesized controlling variables and treatment proposals. Behavioral Assessment, 6(3), 199-208.

Friendlander, M.L., \& Phillips, S.D. (1984). Preventing anchoring errors in clinical judgment. Journal of Consulting and Clinical Psychology, 52, 366-371.

Friendlander, M.L., \& Stockman, S.J. (1983). Anchoring and publicity effects in clinical judgment. Journal of Clinical Psychology, 39, 637-643.

Froyd, J.E., Lambert, M.J., \& Froyd, J.D. (1996). A review of practices of psychotherapy outcome measurement. Journal of Mental Health (UK), 5(1), $11-15$.

Garb, H.N. (1998). Studying the clinician: Judgment research and psychological assessment. Washington, DC: American Psychological Association.

Garland, A.F., Kruse, M., \& Aarons, G.A. (2003). Clinicians and outcomes measurement: What's the use? The Journal of Behavioral Health Services and Research, 30(4), 393-405.

Goldstein, W.M., \& Hogarth, R.M. (1997). Judgment and decision research: Some historical context. In W.M. Goldstein \& R.M. Hogarth (Eds.). Research on judgment and decision making: Currents, connections, and controversies. New York, NY:Cambridge University Press.

Hastie, R., \& Dawes, R.M. (2001). Rational Choice in an Uncertain World. Thousand Oaks: Sage Publications.

Hatfield, D.R., \& Ogles, B.M. (2004). The Use of Outcome Measures by Psychologists in Clinical Practice. Professional Psychology: Research and Practice, 35(5), 485-491.

Horowitz, L.M., Strupp, H.H., Lambert, M.J., \& Elkin, I. (1997). Overview and summary of the Core Battery Conference. In H.H. Strupp., L.M. Horowitz, \& M.J. Lambert (Eds.) Measuring patient changes in mood, anxiety, and personality disorders: Toward a core battery. (pp. 491-502). Washington, D.C.: American Psychological Association Press. 
Horvath, A.O., \& Symonds, B.D. (1991). Relation between working alliance and outcome in psychotherapy: A meta-analysis. Journal of Counseling Psychology, 38(2), 139-149.

Howard, K. I., Moras, K., Brill, P. L., Martinovich, Z., \& Lutz, W. (1996). Evaluation of psychotherapy: Efficacy, effectiveness, and patient progress. American Psychologist, 51, 1059-1064.

Kahneman, D. \& Tversky, A. (1982). Choices, values, and frames. In H.R. Arkes \& K.R. Hammond (Eds.) Judgment and Decision Making: An Interdisciplinary Reader. (pp. 194-210). New York: Cambridge University Press.

Kazdin, A. E., \& Wassell, G. (1998). Treatment completion and therapeutic change among children referred for outpatient therapy. Professional Psychology: Research and Practice, 29, 332-348.

Keller, M.B., Lavori, P.W., Klerman, G.L., Andreasen, N.C., Endicott, J., Coryell, W., et al. (1986). Low levels and lack of predictors of somatotherapy and psychotherapy received by depressed patients. Archives of General Psychiatry, 43, 458-466.

Lambert, M. J. (2001). Psychotherapy outcome and quality improvement: Introduction to the special section on patient-focused research. Journal of Consulting and Clinical Psychology, 69(2), 147-149.

Lambert, M. J., Hansen, N. B., Umphress, V., Lunnen, K., Okiishi, J., Burlingame, G., Huefner, J. C., \& Reisinger, C. W. (1996). Administration and scoring manual for the Outcome Questionnaire (OQ_45.2). Wilmington, DL: American Professional Credentialing Services.

Lambert, M.J., Horowitz, L.M., \& Strupp, H.H.(1997). Conclusions and recommendations. In H.H. Strupp., L.M. Horowitz, \& M.J. Lambert (Eds.) Measuring patient changes in mood, anxiety, and personality disorders: Toward a core battery. (pp. 491-502). Washington, D.C.: American Psychological Association Press.

Lambert, M.J., \& Ogles, B.M. (2004). The efficacy and effectiveness of psychotherapy. In Lambert, M.J. (Ed.). Bergin and Garfield's Handbook of Psychotherapy and Behavior Change. (5 ${ }^{\text {th }}$ Ed., pp. 139-193). New York: Wiley. 
Lambert, M. J., Okiishi, J. C. Finch, A. E., \& Johnson, L. D. (1998). Outcome assessment: From conceptualization to implementation. Professional Psychology: Research and Practice, 29, 63-70.

Lambert, W., Salzer, M.S., \& Bickman, L. (1998). Clinical outcome, consumer satisfaction, and ad hoc ratings of improvement in children's mental health. Journal of Consulting \& Clinical Psychology, 66(2), 270-279.

Lambert, M.J., Whipple, J.L., Smart, D.W., Vermeersch, D.A., Nielsen, S.L., \& Hawkins, E.J. (2001). The effects of providing therapists with feedback on patient progress during psychotherapy: Are outcomes enhanced? Psychotherapy Research, 11(1), 49-68.

Lambert, M.J., Whipple, J.L., Vermeersch, D.A., Smart, D.W., Hawkins, E.J., Nielson, S.L., et al. (2002). Enhancing psychotherapy outcomes via providing feedback on client treatment response: A replication. Clinical Psychology and Psychotherapy, 9, 91-109.

Lee, D.Y., Barak, A., Uhlemann, M.R., \& Patsula, P. (1995). Effects of preinterview suggestion on counselor memory, clinical impression, and confidence in judgments. Journal of Clinical Psychology, 51, 666-675.

Lueger, R. J., Howard, K. I., Martinovich, Z., Lutz, W., Anderson, E. E., \& Grissom, G. (2001). Assessing treatment progress of individual patients using expected treatment response models. Journal of Consulting and Clinical Psychology, 69(2), 150-158.

Lunnen, K.M., \& Ogles, B.M. (1998). A multiperspective, multivariable evaluation of reliable change. Journal of Consulting \& Clinical Psychology, 66(2), 400-410.

Maruish, M.E. (Ed.). (2004). The use of psychological testing for treatment planning and outcomes assessment (3rd ed.). Mahwah, NJ: Lawrence Erlbaum Associates.

Mohr, D.C. (1995). Negative outcome in psychotherapy: A critical review. Clinical Psychology: Science \& Practice, 2(1), 1-27.

Mumma, G.H. (2002). Effects of three types of potentially biasing information on symptom severity judgments for major depressive episode. Journal of Clinical Psychology, 58(10), 1327-1345.

Murdock, N.L. (1988). Category-based effects in clinical judgment. Counselling Psychology Quarterly, 1(4), 341-355. 
Nierenberg, A.A. (1991). Treatment choice after one antidepressant fails: A survey of northeastern psychiatrists. Journal of Clinical Psychiatry, 52(9), 383-385.

Ogles, B. M., Lambert, M. J., \& Masters, K. S. (1996). Assessing outcome in clinical practice. Boston: Allyn and Bacon.

Oskamp, S. (1965). Overconfidence in case-study judgments. Journal of Counseling Psychology, 29(3), 261-265.

Pain, M.D., \& Sharpley, C.F. (1989). Varying the order in which positive and negative information is presented: Effects on counselors' judgments of clients' mental health. Journal of Counseling Psychology, 36(1), 3-7.

Phelps, R., Eisman, E. J., \& Kohout, J. (1998). Psychological practice and managed care: Results of the CAPP practitioner survey. Professional Psychology: Research and Practice, 29, 31-36.

Peterson, D.K., \& Pitz, G.F. (1986). Effects of amount of information on predictions of uncertain quantities. Acta Psychologica, 61, 229-241.

Pitz, G.F. (1969). An inertia effect (resistance to change) in the revision of opinion. Canadian Journal of Psychology, 23(1), 24-33.

Rabinowitz, J. (1993). Diagnostic reasoning and reliability: A review of the literature and a model of decision-making. Journal of Mind \& Behavior,14(4), 297-315.

Redelmeier, D.A., \& Shafir, E. (1995). Medical decision making in situations that offer multiple alternatives. Journal of the American Medical Association, 273(4), 302-305.

Redelmeier, D.A., Shafir, E., \& Aujla, P.S. (2001). The beguiling pursuit of more information. Medical Decision Making, 21(5), 376-387.

Rock, D.L. (1994). Clinical judgment survey of mental-health professionals: I. An assessment of opinions, ratings, and knowledge. Journal of Clinical Psychology, 50(6), 941-950

Sederer, L. I., \& Dickey, B. (Eds.). (1996). Outcome assessment in clinical practice. Baltimore: Williams \& Wilkins.

Shemberg, K.M., \& Doherty, M.E. (1999). Is diagnostic judgment influenced by a bias to see pathology? Journal of Clinical Psychology, 55(4), 513-518. 
Schoen, D.A. (1988). From technical rationality to reflection-in-action. In J. Dowie, \& A.S. Elstein (Eds.). Professional judgment: A reader in clinical decision making. New York, NY: Cambridge University Press.

Shulte (1997). Dimensions of outcome measurement. In H.H. Strupp., L.M. Horowitz, \& M.J. Lambert (Eds.) Measuring patient changes in mood, anxiety, and personality disorders: Toward a core battery. (pp. 57-80). Washington, D.C.: American Psychological Association Press.

Smith, D., \& Dumont, F. (2002). Confidence in psychodiagnosis: What makes us so sure? Clinical Psychology and Psychotherapy, 9, 292-298.

Strohmer, D.C., Shivy, V.A., \& Chiodo, A.L. (1990). Information processing strategies in counselor hypothesis testing: The role of selective memory and expectancy. Journal of Counseling Psychology, 37(4), 465-472.

Torngren, G. \& Montgomery, H. (2004). Worse than chance? Performance and confidence among professionals and laypeople in the stock market. The Journal of Behavioral Finance, 5(3), 148-153.

Turk, D.C., \& Salovey, P. (1985). Cognitive structures, cognitive processes, and cognitive-behavioral intervention: II. Judgments and inferences of the clinician. Cognitive Therapy and Research, 9, 19-33.

Turk, D.C., Salovey, P., \& Prentice, D. (1988). Psychotherapy: An informationprocessing perspective. In Turk, D.C. \& Salovey, P. (Eds.), Reasoning, inference, and judgment in clinical psychology (pp. 1-16). New York, NY: Free Press.

Tversky, A. \& Kahneman, D. (1982). Judgment under uncertainty: Heuristics and biases. In H.R. Arkes \& K.R. Hammond (Eds.) Judgment and Decision Making: An Interdisciplinary Reader. (pp. 194-210). New York: Cambridge University Press.

Tversky, A., \& Shafir, E. (1992). Choice under conflict: The dynamics of deferred decision. Psychological Science, 3, 358-361.

Ward, T. (1999). Method, judgement, and clinical reasoning. Behaviour Change, 16(1), 4-9.

Weiss, I., Rabinowitz, J., \& Spiro, S. (1996). Agreement between therapists and clients in evaluating therapy and its outcomes: Literature review. Administration \& Policy in Mental Health, 23(6), 493-511. 
Whipple, J.L., Lambert, M.J., Vermeersch, D.A., Smart, D.W., Nielsen, S.L., \& Hawkins, E.J. (2003). Improving the effects of psychotherapy: The use of early identification of treatment and problem-solving strategies in routine practice. Journal of Counseling Psychology, 50(1), 59-68

Whiston, S. C., \& Sexton, T. L. (1993). An overview of psychotherapy outcome research: Implications for practice. Professional Psychology: Research and Practice, 24, 43-51.

Wilson, F.E., \& Evans, I.M. (1983). The reliability of target-behavior selection in behavioral assessment. Behavioral Assessment, 5(1), 15-32. 
Appendix A 
What is your highest degree obtained? (Please check one)

Ph.D.

Psy.D.

M.S./ M.A.

MSW

B.A./B.S.

M.D.

Ed.D.

How many hours per week do you conduct psychotherapy?

What is your year of first licensure?

Do you work primarily with: __ Children/Adolescents, __ Adults, _ _ or Both

Are you:

Male_Female

Race:

_ American Indian __Asian _ Hispanic __Black __ White __ Other Multi-racial/Multi-ethnic _ Not specified

What percent of your time do you work in each of these settings?

Private practice (solo)

Medical center/hospital

School system

Medical school

Forensic/legal

Government

Private practice (group)

University/college

Outpatient clinic

Community mental health clinic

Residential/Inpatient psychiatric

Other

Please indicate which of these theoretical orientations best describes you.

(If more than one applies, please rank order your selections)

Behavioral

Psychoanalytic or Psychodynamic

Humanistic

Eclectic or Integrative

Cognitive-behavioral or Cognitive

Existential

Interpersonal

Other

Do you use some form of outcome assessment in your practice?

(Outcome assessment is defined as routinely collecting data regarding client progress)

Yes _ No 
Appendix B 


\section{$\underline{\mathrm{NVNO}}$}

Brian is a 28 -year-old client who has seen you for approximately 3 months of therapy. He initially presented with moderately severe depressive symptoms and it was collaboratively agreed upon that you would provide the therapeutic services. Since that time, you have conducted therapy in a usual manner because Brian presents as quite similar to many of your other clients. He has reported depressed mood and related interpersonal problems, which represent the content of your therapeutic discussions. Up to this point, you have not given Brian's case any more thought than your typical clients' cases, but you currently find yourself thinking about how therapy might proceed with Brian.

As of now, you have not observed significant changes in his affect and behavior. It seems as if Brian has been somewhat satisfied with the services you are providing. He has offered no substantial information about what significant others think about how he is doing.

\section{$\underline{\mathrm{NVO}+}$}

Brian is a 28-year-old client who has seen you for approximately 3 months of therapy. He initially presented with moderately severe depressive symptoms and it was collaboratively agreed upon that you would provide the therapeutic services. Since that time, you have conducted therapy in a usual manner because Brian presents as quite similar to many of your other clients. He has reported depressed mood and related interpersonal problems, which represent the content of your therapeutic discussions. Up to this point, you have not given Brian's case any more thought than your typical clients' cases, but you currently find yourself thinking about how therapy might proceed with Brian.

Scores from a routinely administered outcome measure completed by Brian before each therapy session indicate that the severity of his symptoms has significantly improved. As of now, you have not observed significant changes in his affect and behavior. It seems as if Brian has been somewhat satisfied with the services you are providing. He has offered no substantial information about what significant others think about how he is doing. 
NVO-

Brian is a 28 -year-old client who has seen you for approximately 3 months of therapy. He initially presented with moderately severe depressive symptoms and it was collaboratively agreed upon that you would provide the therapeutic services. Since that time, you have conducted therapy in a usual manner because Brian presents as quite similar to many of your other clients. He has reported depressed mood and related interpersonal problems, which represent the content of your therapeutic discussions. Up to this point, you have not given Brian's case any more thought than your typical clients' cases, but you currently find yourself thinking about how therapy might proceed with Brian.

Scores from a routinely administered outcome measure completed by Brian before each therapy session indicate that the severity of his symptoms has significantly worsened. As of now, you have not observed significant changes in his affect and behavior. It seems as if Brian has been somewhat satisfied with the services you are providing. He has offered no substantial information about what significant others think about how he is doing.

$\underline{\mathrm{V}+\mathrm{NO}}$

Brian is a 28-year-old client who has seen you for approximately 3 months of therapy. He initially presented with moderately severe depressive symptoms and it was collaboratively agreed upon that you would provide the therapeutic services. Since that time, you have conducted therapy in a usual manner because Brian presents as quite similar to many of your other clients. He has reported depressed mood and related interpersonal problems, which represent the content of your therapeutic discussions. Up to this point, you have not given Brian's case any more thought than your typical clients' cases, but you currently find yourself thinking about how therapy might proceed with Brian.

As of now, you have not observed significant changes in his affect and behavior. During your next session with Brian, he explains to you that he is feeling much better than when he started therapy. It seems as if Brian has been somewhat satisfied with the services you are providing. He has offered no substantial information about what significant others think about how he is doing. 
$\underline{\mathrm{V}+\mathrm{O}+}$

Brian is a 28-year-old client who has seen you for approximately 3 months of therapy. He initially presented with moderately severe depressive symptoms and it was collaboratively agreed upon that you would provide the therapeutic services. Since that time, you have conducted therapy in a usual manner because Brian presents as quite similar to many of your other clients. He has reported depressed mood and related interpersonal problems, which represent the content of your therapeutic discussions. Up to this point, you have not given Brian's case any more thought than your typical clients' cases, but you currently find yourself thinking about how therapy might proceed with Brian.

Scores from a routinely administered outcome measure completed by Brian before each therapy session indicate that the severity of his symptoms has significantly improved. As of now, you have not observed significant changes in his affect and behavior. During your next session with Brian, he explains to you that he is feeling much better than when he started therapy. It seems as if Brian has been somewhat satisfied with the services you are providing. He has offered no substantial information about what significant others think about how he is doing.

$\underline{\mathrm{V}+\mathrm{O}-}$

Brian is a 28-year-old client who has seen you for approximately 3 months of therapy. He initially presented with moderately severe depressive symptoms and it was collaboratively agreed upon that you would provide the therapeutic services. Since that time, you have conducted therapy in a usual manner because Brian presents as quite similar to many of your other clients. He has reported depressed mood and related interpersonal problems, which represent the content of your therapeutic discussions. Up to this point, you have not given Brian's case any more thought than your typical clients' cases, but you currently find yourself thinking about how therapy might proceed with Brian.

Scores from a routinely administered outcome measure completed by Brian before each therapy session indicate that the severity of his symptoms has significantly worsened. As of now, you have not observed significant changes in his affect and behavior. During your next session with Brian, he explains to you that he is feeling much better than when he started therapy. It seems as if Brian has been somewhat satisfied with the services you are providing. He has offered no substantial information about what significant others think about how he is doing. 
$\underline{\mathrm{V}-\mathrm{NO}}$

Brian is a 28-year-old client who has seen you for approximately 3 months of therapy. He initially presented with moderately severe depressive symptoms and it was collaboratively agreed upon that you would provide the therapeutic services. Since that time, you have conducted therapy in a usual manner because Brian presents as quite similar to many of your other clients. He has reported depressed mood and related interpersonal problems, which represent the content of your therapeutic discussions. Up to this point, you have not given Brian's case any more thought than your typical clients' cases, but you currently find yourself thinking about how therapy might proceed with Brian.

As of now, you have not observed significant changes in his affect and behavior. During your next session with Brian, he explains to you that he is feeling much worse than when he started therapy. It seems as if Brian has been somewhat satisfied with the services you are providing. He has offered no substantial information about what significant others think about how he is doing.

$\underline{\mathrm{V}-\mathrm{O}-}$

Brian is a 28-year-old client who has seen you for approximately 3 months of therapy. He initially presented with moderately severe depressive symptoms and it was collaboratively agreed upon that you would provide the therapeutic services. Since that time, you have conducted therapy in a usual manner because Brian presents as quite similar to many of your other clients. He has reported depressed mood and related interpersonal problems, which represent the content of your therapeutic discussions. Up to this point, you have not given Brian's case any more thought than your typical clients' cases, but you currently find yourself thinking about how therapy might proceed with Brian.

Scores from a routinely administered outcome measure completed by Brian before each therapy session indicate that the severity of his symptoms has significantly worsened. As of now, you have not observed significant changes in his affect and behavior. During your next session with Brian, he explains to you that he is feeling much worse than when he started therapy. It seems as if Brian has been somewhat satisfied with the services you are providing. He has offered no substantial information about what significant others think about how he is doing. 
$\underline{\mathrm{V}-\mathrm{O}+}$

Brian is a 28 -year-old client who has seen you for approximately 3 months of therapy. He initially presented with moderately severe depressive symptoms and it was collaboratively agreed upon that you would provide the therapeutic services. Since that time, you have conducted therapy in a usual manner because Brian presents as quite similar to many of your other clients. He has reported depressed mood and related interpersonal problems, which represent the content of your therapeutic discussions. Up to this point, you have not given Brian's case any more thought than your typical clients' cases, but you currently find yourself thinking about how therapy might proceed with Brian.

Scores from a routinely administered outcome measure completed by Brian before each therapy session indicate that the severity of his symptoms has significantly improved. As of now, you have not observed significant changes in his affect and behavior. During your next session with Brian, he explains to you that he is feeling much worse than when he started therapy. It seems as if Brian has been somewhat satisfied with the services you are providing. He has offered no substantial information about what significant others think about how he is doing. 
Appendix C 
Brian is a 28-year-old client who has seen you for approximately 3 months of therapy. He initially presented with moderately severe depressive symptoms and it was collaboratively agreed upon that you would provide the therapeutic services. Since that time, you have conducted therapy in a usual manner because Brian presents as quite similar to many of your other clients. He has reported depressed mood and related interpersonal problems, which represent the content of your therapeutic discussions. Up to this point, you have not given Brian's case any more thought than your typical clients' cases, but you currently find yourself thinking about how therapy might proceed with Brian.

Scores from a routinely administered outcome measure completed by Brian before each therapy session indicate that the severity of his symptoms has significantly worsened. As of now, you have not observed significant changes in his affect and behavior. During your next session with Brian, he explains to you that he is feeling much better than when he started therapy. It seems as if Brian has been somewhat satisfied with the services you are providing. He has offered no substantial information about what significant others think about how he is doing.

1. Would you judge that your client is...

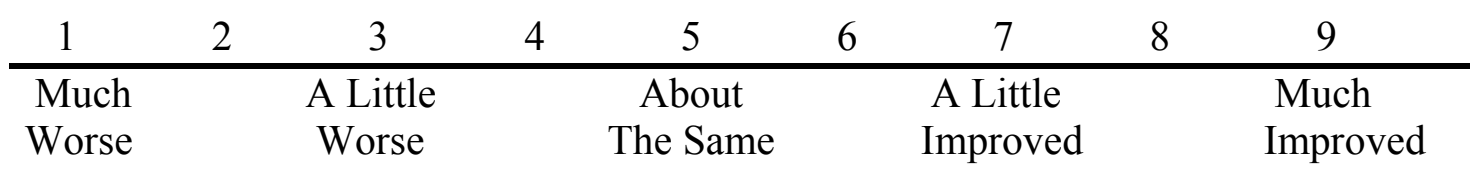

2. Would you...(select one of A, B, or C)

A) continue treatment in the same manner as you have been by: (select all that apply)

making no changes in the treatment plan. continuing for now, reevaluating in the future. continuing for now and seeking peer consultation. other

B) alter the treatment being provided

by: (select all that apply) altering the treatment plan. altering the implementation of current treatment plan. reevaluating diagnostic formulation. other

C) consider taking steps towards termination by: (select all that apply) terminate with scheduled booster sessions. moving towards termination in the next few sessions. discussing possible termination with client. other

3. How confident are you that your decision is appropriate?

(Use a scale of 0 to $100 ; 0=$ complete uncertainty as to whether this decision is appropriate, $100=$ absolute certainty that this decision is appropriate) 
Appendix D 
Please indicate how much influence each potential source of information has for you when judging client change. Please treat these as percentages, with the total necessarily being $100 \%$.

(If an item does not influence your judgment of client change, please enter a " 0 ")

Client verbal report of progress

Scores on a routinely administered outcome measure

Significant other report

Client satisfaction with services questionnaire

Clinician's observations of client affect and behavior

Other

Other

Other 
Appendix E 
Dear Practitioner,

For my Doctoral Dissertation at Ohio University, I am conducting a study regarding clinical judgment and decision making and am asking you for your assistance with this. I understand that you are very busy, and would therefore be greatly appreciative if you would please take the few minutes necessary to complete the survey and return it to me in the postage paid envelope included with this letter. All information from the survey will be strictly confidential.

I am asking you to please read a brief clinical vignette and then answer three short questions about it. I understand that the vignette contains only a limited amount of clinical information and that in real therapy more information would naturally be available; however I would like to ask you to do the best you can with the information that is provided. You will notice that there is a short set of demographic questions on the reverse of this page. On the reverse side of the vignette is one follow-up question. Again, only a few minutes should be required to complete the entire study. I am optimistic that the information gained in this study will be important for the practice of professional psychology. If you would like to receive a summary of the results of this study, please include a mailing address or an email address in the return envelop. It will then be separated from your responses to assure confidentiality.

Thank you very much for your time in completing this survey and best of wishes to you and your clients.

Sincerely,

Derek R. Hatfield

Benjamin M. Ogles, Ph.D.

Supervisor 
April 15, 2004

Dear Practitioner,

A couple of weeks ago I sent you a short survey regarding clinical judgment and decision making. As of yet, I have not received the survey from you. Since I am not sure of the reason that I have not yet received it, I am mailing the survey to you again in case it was misplaced. I understand that you are very busy, and would therefore be greatly appreciative if you would please take the few minutes necessary to complete the survey and return it to me in the postage paid envelope included with this letter. All information from the survey will be strictly confidential.

I am asking you to please read a brief clinical vignette and then answer three short questions about it. I understand that the vignette contains only a limited amount of clinical information and that in real therapy more information would naturally be available; however I would like to ask you to do the best you can with the information that is provided. You will notice that there is a short set of demographic questions on the reverse of this page. On the reverse side of the vignette is one follow-up question. Again, only a few minutes should be required to complete the entire study. I am optimistic that the information gained in this study will be important for the practice of professional psychology. If you would like to receive a summary of the results of this study, please include a mailing address or an email address in the return envelop. It will then be separated from your responses to assure confidentiality.

Thank you very much for your time in completing this survey and best of wishes to you and your clients.

Sincerely,

Derek R. Hatfield

Benjamin M. Ogles, Ph.D.

Supervisor 


\section{Appendix F}

Answers to the "Other" category of "Source of Information" question. (copied directly as written, __ indicates illegibility).

Clinician's interpretation of client behavior

Discussion and reconciliation of all the above

Psych testing; checklists

GAF score

Period administration of diagnostic measures

Report from psychiatrist and other MD

Information from a coordinating provider (e.g. the patient's psychiatrist or social worker) on the case.

feedback from school, physician, or any other source of observations

maintenance of change by report and observation

GAF; level of functioning

Client's ability to be honest

Log of behavioral changes

Cognitions: increased positive, decreased self-defeating

Case manager, another social service professional

Peer Consultation

Positive change in targeted symptoms

Colleague opinion

Feedback from work, family, friends

Consultant's thoughts

Misc other input varies with specific client situations

Observations of others on treatment

Follow thru in between session of agreed upon strategies

Objective measures (such as wt., when working with individual with eating disorders) testing

Input from another professional who sees brian such as a psychiatrist. Input from referral source

observation/reports of activities, resumption of pre-morbid behaviors etc.

objective data from personality test

discussions re: work and other activities

client's observations re: his symptoms and behaviors

other treztars opinion

change in medical status; change in environment, e.g., work status; change in relationships

sense of humor increases 
routine written assessment inst.

other staffs obserbations of pt. on the ward; past history; medical records

my observations of their thought process

longterm psychoanalytic threatment has an ebb and flow which cannot be measured during the process...outcome determined by (ideally) clients and therapists acknowledgement of shifts and progress in affected areas

level of functioning in work and relationships

content of sessions

nature of client/clinician relationship and changes over time

family members; psychiatrist

adjustment

report of specific sxs e.g. sleep, appetite etc.

peer or medical colleage

that he is more on my mind

consultation with other providers

consultation

referral source feedback

indicators like school/work performance on attendance

initial diagnosis and presentation which includes style and personality issues (e.g. amplifier vs izer)

clinician's observation of client lang use - words he/she uses as a reflection of their thinking patterns

outside psychiatrist; job performance report; pmd; etc.

client's reported interactions with friend and family

long diatribe about "meatball mental health in the era of managed care"

peer consultation

outside sources, significant others, etc.

other clinicians evaluation if also concurrently treating (i.e. couples therapist, group, psychiatrist)

mental status exam; reports of day to day functioning; also a long commentary about why "client" is not as good a term as "patient"

frank discussion of progress toward goals; parent report of minor

clinician's interpretation of client's reports

at risk factors - drug and alcohol abuse? Recent death/separation, cit depression history, family or origin $\mathrm{c}$ , good habits/bad habits, exercise, friends

legal, physician, other report

feedback from consultants/colleagues with whom I've staffed the client

peer supervision

H-T-P drawings

Client description of school/occupational adjustments

Client's ongoing narrative - tone, illustrations of coping, quality of relationships, etc.

Time factor - observation over time 
Work or social performance

Achieving targeted goals

Treating psychiatrist' opinion (most of my pts are on meds)

Response to meds

My own "gut" feeling

Scores on pre-post testing

Clients report of progress in areas outside of therapy (work, home, etc). Case

formulation is critical! If character of personality disorder presents, client's self-report becomes more questionable

personality testing on objective outcome e.g. return to work or school

my own test battery defined on other side [mmpi and Rorschach]; opinion of peer supervision group (includes psychiatrist and internal medicine specialist)

all of the above used as part of re-evaluation

changes in relationship problems; client feels different internally; client has achieved collaboratively agreed upon goals

other professionals treating this patient (such as psychiatrists, etc) assessment of progress and recovery

psych testing

comparing progress related to specific treatment goals

evidence of secondary gain issues

personality evaluation - more indepth eval

feedback from client 6 months to a year after termination

content of thought; level of discouragement

theoretic understanding/integration of above

collateral reports

client's report of behavior change; client's report of increased insight/understanding/broader perspective; client's report of symptom reduction; client's report of interpersonal/social change as told to them by others

objective changes in functioning (absences, etc.)

achievement of identified target goals for tx plan

knowledge re history of family, history of alc and mental illness, of his early life; how he presents his problem and himself; mo own feelings about him

progress towards stated goals

would have sought significant others observations which are not reported in the scenario

report of behavioral changes per initial assessment

data from client homework assignments

my assessment of client's compliance with treatment and homework commitment

psychiatrist/family worker/couples counselor/therapist i.e., any other treating clinician

discrepancy client verbal report/ written report or congruence of all source of data; intuition behavior changes

report on whether symptoms have improved 
past psych history self report of engagement and enjoyment in daily activities independent aspects of functioning session theme/contrast 


\section{Appendix G}

Answers to the "Other" category of "Would you continue treatment in the same manner as you have been?" (copied directly written, ___ indicates illegibility).

Explore what he means by "feeling much worse", why this is what he feels?

Discussing the discrepancy between objective scores, my observation, and his verbal report with him to try to understand why the discrepancy exists. Make any change, if needed, only after clarification through the dialogue with the patient. Question him as to "why" he is better: i.e., changes in life, occup., relationship, and by what criteria he is using to measure/assess his progress. Then after treatment plan based on his current infor. because the therapists hasn't seen a difference/improvement!

Continue, but do a "quarterly treatment update plan"

Be attentive and inquiring, to determine if I might have missed something in our sessions to date, and/or if something had occurred to increase his resistance in therapy. If so, then I would focus on those areas in therapy. I am assuming that the individual is also on an anti-depressant and that this is being monitored by me and the prescribing physician.

I would be talking with Brian about the discrepancy between how he presents and how he rates himself. There is often initial improvement from relief of getting help, but deeper issues may continue.

assess his occupational, social, emotional functioning directly and specifically reevaluate, find out why he is worse then change of ne explore referral for medication evaluation assess why he thinks he's better and talk about how he looks less changed to me Enquire about relations with others and level of functioning at work/peers/family etc. monitor specific sxs: sleep, appetite, exercise, pleasure, sexual functioning share the results of testing with him

I would want to evaluate the discrepancy between his perception of change and mine of little change. Evaluate more thoroughly with patient his perception/report of progress and achievement of treatment goals; evaluate need for ongoing treatment vs. need to move toward termination

discuss pt's views/thoughts re: progress use this info to refine tx and consider other options

Note the discrepancy between report and presentation and find out why we differ...have a long and thorough discussion because you do not have enough information to make decisions B and C.

speak to patient about discrepancy between his response to outcome measure and your observations and hi self observation

assess for possible cycling or consider a psychopharmacological consultation 
assessing the nature of his perceived improvement psychiatric consultation

talk to brian about worsening symptoms; consult peers; change treatment if app to the new information

as always, on-going consideration of changes in treatment get a medical and psychiatric consult.

talk to client about what he wants

investigate the meaning and reality of brian's self-assessment

I would have referred him for anti-depressant medication immediately upon evaluating him

confront inconsistency between my observations and outcome measure; get more info. try to assess what has changed with client and with environment exploring nature of worsened symptoms and potential sources of change

process the discrepancy between outcome data and his statement that he feels worse, if necessary depending on what we learn

discuss with pt his report of worsening symptoms and explore reason/perception symptom relief is often the time treatment really begins

enlist brian's help in designing a treatment plan - to include info. From him re what is helping

explore with him possible causes for his "feeling better" until this info is available it is impossible to decide on $\mathrm{A}, \mathrm{B}$, or $\mathrm{C}$ - although " $\mathrm{A}$ " is most likely

ask for collateral views how he is doing (work, love, play, generosity)

ask the patient for his opinions/thoughts

seek input form s.o.'s

discuss treatment issues with client, especially with regard to differences between selfreport and therapist observations

reevaluate with client

refer to psychiatrist for eval

consider anti depressants, ask about triggering events

no rush to judgment but engage client in his self-determinism

seek more ongoing evaluation

determine if sx severity is due normal progression of treatment, a recent stressor, or some other issues about which I have no or little information. If sx being worse is due to new stressor or unknown issue, I'd probably consider altering treatment

discuss with the client about his feeling worse and alternatives such as including significant others in the therapy, transfer to a different therapist, etc.

ask the client what he wanted in regards to treatment. Did he want to continue or terminate?

discuss with client the discrepancy

explore brian's feelings about tx; what's working for him, what isn't. after tx on info given 
consult with the psychiatrist with whom I am collaborating and be alert for any suicidal ideation

discuss discrepancy between reported improvement on measure and what he reports during sessions. Ask client to evaluate current tx

I would consult with brian, talk thim about the discrepancy between the outcome measure, his statement he's feeling much better and my observation that there's no change - figure out best course of action collaboratively

confronting the inconsistencies; reevaluating treatment process and goals with pt. reevaluate treatment plan and its implementations, but until reevaluation is complete, continue talk with him re what he means, what he expects and what about medication? Maybe the tx needs to be altered/maybe not discuss symptom changes as indicated in outcome measures with client assess basis of his present state of mind ask him how he is doing on his goals possibly suggest psychopharmacology evaluation confront his reported improvement in contrast to his apparent lack of progress 


\section{Appendix H}

Answers to the "Other" category of "Would you alter the treatment being provided?" (copied directly as written, indicates illegibility).

Refocus on other goals where client has not made progress

Referral for psychiatric eval

Discuss contradictory findings with brian

Discuss with client his perception about utility of therapy, what has helped or

hindered; I would also see his report of feeling $\mathrm{w}$ as potentially _ p_ning the working relationship if he begins to reveal more about deeper issues. I also would be likely to bring up the case in supervision.

peer consultation

referral to MD for possible meds

refer for med assessment and get her data from collaterols (if consent given) i.e. family, partner, etc. physician.

refer for antidepressant medication and schedule family session

seek peer consultation

gather more information through interview and other measures

assess medical

medication evaluation

consider behavioral interventions and medication

medical consult

? of meds eval

ask brian what "is much better", what is the same or worse, what goals he has for himself, what he wants in terms of treatment (cont. alter goals, termination) Discuss my observations and his and try to determine what is most appropriate. inquiring into the discrepancy with the client; consulting with other health care providers involved with this client.

consult of MD providing meds and others in regular consultation group for their insight and feedback

seek peer consultation

psychiatric consultation

multimodal assessment

seek consultation

discuss the incongruency; get releases signed to receive input from significant others medication referral and include number of sessions. I would discuss discrepancy

between what he says and what he writes on outcome measure

peer consultation and psychiatric referral

request medication evaluation

review concerns with client 
seek peer consultation; evaluation for suicidal risk, discuss referral for meds, discuss

pt's view of treatment relationship

consider formal evaluation; seek peer consultation

discuss outcome ratings vs. your observations of limited change to clarify disparate information and clarify amount of progress, refine treatment goals and process

Take case to consultation

Obtain some psychometric data - discuss possibility of medications

Seek peer consultation

Psychiatric consult for medication

Discussing treatment objectives (and their measurability) and client's degree of compliance

ask questions, pay more attention to our relationship dynamics/ask what he thinks about our work style, review treatment goals and ask his current feeling about them

insist on another medical eval

confront brian about why he is reporting one result to me and another on the outcome measure and make future treatment plan based on the outcome

discuss observations/data with client - evaluate discrepancies together

gather information from other treaters and, with pt's permission, from family members or significant others

evaluate for suicide potential

medication (re)evaluation

consultation on the case

discuss contradictions, concerns directly with client

openly discuss issue with client

discuss with the client his progress and feelings about therapy. Discuss possibility of referral for meds consult. Discuss alternative approaches

exploring the discrepancy between self-report and observed affect and behavior

discuss potential referral for other services or to another provider

consult re:

refer for medical evaluation

consider referral to psychiatrist and possibly psychometric testing

discuss it with him - share disparity in my observations vis-à-vis self-reported data.

What does he think? Where is he in regard to his goals?

Peer consultation

Engaging signif. others in tx and client monitoring/assessment

Add testing (mmpi, pai), obtain info from significant others if client agrees, articulate and explore lack of change in affect and behavior despite positive changes in self report

asking about his relationship others _ his context and how their discussing contradictions I am noticing to see what it means to him

consider discrepancy between outcome measure and patient's self report and change treatment if necessary 
coordinate with prescriber of meds/other love s__ /family

recommend a medication consultation with a psychiatrist and urge him to have the consultation

gather objective data such as MMMPI-2

consider psychiatric consultation

get more assessment data - get input from family members and/or

partner/spouse/romantic interest

review of meds/stressors/support and altering if needed

re-eval suicidality speak to family

consider moer intensive treatment modality

medication evaluation

medication reevaluations, consult with significant others with permission

discuss outcome measure with patient

reevaluate treatment plan

perhaps another opinion - psychiatry or review case with peer/partner

discuss the discrepancy between observations clinically and the results of the outcome measurement

discuss with him the discrepancy between outcome measure and my observation want to look at more objective measures, i.e. behavior and perhaps hear what others might say re: client

Seek peer consultation; psychiatric consult/med eval

Present discrepancy to client and explore how it is that outcome measure and self report in sessions are so different

medical eval. f/intervention with antidep. medic.

focus on discrepancy between his reporting of outcome measures

obtain further diagnostic information (pertinent to all 5 areas) followed by reformulation of treatment plan

ask him why paper and pencil report is so different than self-report; give him a bdi; ask how others perceive how he is doing

seek peer consultation

consider some psychological testing to rule out personality issues/disorder

consider referral for medication

consider medications

processing with brian HIS perceptions of the past 3 months of therapy and clarifying with him his goals and ideas about how to proceed

maybe alter my approach a little, more heavy handed or more homework

careful assessment of suicidality, homicidal thoughts, fantasy, seeking permission to obtain corroborative input form third party

more assessment

discuss possibility of anti-depressant medication

evaluate for suicide risk; reevaluate drug/alcohol abuse; sleep disturbance; refer for medication evaluations; possibly include one or more significant others 
need a check on validity of self-report measure; with pt's permission, seek input form significant other re: his progress; do a current mental status exam and compare to intake mental status

do some objective testing (eg bdi, bsi)

do psychological testing to help clarify what I'm missing

determine likely cause of deterioration

psychiatric/med eval

determine if tx gains reported have real world correlates, exp. in relationships and selfview. Discuss tx plan with him, and proceed accordingly. If not, consider altering tx plan; if real world correlates apparent then track to see if changes are holding for next few sessions

refer for medication eval. (if the client agrees with rec.)

reevaluate tx goals/discuss observations

address disparity between outcome measure and presentation

name discrepancy bet his and my view of his progress, maybe. Try to elicit more

feelings abt me, therapy and wr relationship - definitely

discussing with pt.

possible referral for meds

possibly psychiatry referral

probably seek medication evaluation

process contradiction between affect and outcome measure

peer consultation

re-specify goals, maybe discuss meds

questioning why his affect and behavior don't match ratings

discuss goals and plan w/client (work through and understand the contradictory info)

consider meds if not already on them

reevaluate condition, therapy goals, inconsistency between outcome measure and appearance/report

try to bring in significant others

consult with peer; consult with medical/ psychiatric prof. re medication evaluation

having a frank discussion with pt. re: lack of change

assessing diff between outcome measure and self report

psychiatric eval if not yet done

psychiatric consultation

consider medication consultation

refer for med-eval; assess suicidality; assess sources of support at home/work

consultation with peer, possible assessment, refer for physical

begin to focus on disparity between his report and my observations and explore how others are viewing him and improvements in outside life. Please note - I do interpersonal psychotherapy so I would be focusing on how significant others view him from the outset of treatment. (within my practice, if I had full info. From working with patient; i.e. I'm pretending I have more info than can be provided in this format) 
discuss with client - explore Q, Rx, peer consultation, what do his significant others think, etc.

explore discrepancy in reports and alter according to new goals

conduct more in depth assessment of the discrepancy between the verbal self-report of sx and the outcome measure

refer for medication eval by psychiatrist for depression

focusing more on the tra on syx.

bring in family member

discuss med eval with $\mathrm{pt}$

referral for medication

determine source/factors contributing to worsening of feelings

discuss with brian the tx plan and his sx's

seek peer consultation

address directly with brian discrepancy between assessment and report

discuss referral

consider medication; reconceptualize patient: see if patient has beliefs that interfere

with treatment; seek peer consultation; identify what I might be doing wrong

try other techniques - consider medication or change in medication

refer for medication evaluation

increasing feedback from brian and re-evaluating treatment more frequently; exploring reasons for worsening symptoms

discuss with him the disconnect between my observations and his self-report. I would also gather more information regarding his day to day functioning and relationships

as on the original intake, ask "what would you like to see happen as a result of therapy and how would we know if it is working?"

peer consultation/ and referral for psychiatric consultation

consider referral to group or another practitioner

refer for medical intervention; seek consultation

discuss difference betw self report and outcome measures

actively discuss goals of therapy and approach with patient. If patient is worse, the clinical formulation should account largely for this. This ma be the "required" course of treatment, but it should be actively addressed with dept.

admit to not observing continuing dec in self report of symptom and affect; $p_{\text {_ _ for }}$ self disclosure re: disappointment with tx; examine patterns of responses in other settings

refer for medication evaluation

Referral for eval of psychotropic meds

Obtain more detailed information re: pt.. experience and alter plan accordingl as needed; if on meds, discuss which prescriber intensification of sx if not on meds, discuss with patient referral for evaluation for psychotropics

agree on treatment goals

seek a medical consult 
ask brian to record daily "mood and affects" log and seek peer consultation based on myperceived lack of progress

talk with bryan abou my observations, etc. to decide on next therapeutic steps give pt. a session evaluation scale to measure tx rapport aloso review outcome rating scale results to quantify in which area(s) pt's subjective sense of deterioration lie talk with client about what he reports in outcome surveys and how this is different than what he reports in therapy

referral for consult, med, testing, etc.

involve the client in expectations for therapy - establishment of objectives-goals add other people - significant others, partner, friend; ssstem interview dow(?) (would have moved in this direction after $6^{\text {th }}$ session)

explore SSRI intervention

assess for need of medication; consult with significant other

refer for physical exam; refer for psychiatric consultation for medication, psychological testing (personality), assess for suicidal ideation and plan each session; be sure no guns in house; determine if significant others should be requested to provide additional information; review history for similar episodes and cou__; no change in 3 months required the clinician to review, consult, reevaluate, and refer for second opinion

involve other family members, consider medication consult with all of my 3 consultation groups; suggest full battery testing directly address with patient the conflict between his statements of feeling much better, his outcome measures showing increased symptom severity, and my observations of no significant change. The result of this discussion would help determine the patients actual status and the course of treatment

decrease frequency of sessions

peer supervision and psychiatric consultation

discuss with him the discrepancies between his self-report, the outcome measure and my observation of his affect and behavior

refer back to MD to r/o physical causes (e.g.e thyroid) for the client's worsening condition; administer MMPI or have client interview by a colleague for independent diagnostic assessment

seek clinical supervision

broader based input (sig other)

consider referral for meds

talking about his goal, and maybe the disconnect between sessions and reports - or... maybe prepare for termination

antidepressant meds

obtaining other important information regarding functioning

if no medical exam has been completed, suggest physical by MD and further psychological diagnostics

evaluate for referral for meds

set some specific behavioral goals if client wishes to proceed 
Ask pt what he would like to accomplish in future therapy sessions and discuss if we thought therapy was meeting his goal

refer to psychiatrist for med. eval. re antidepressant

refer for psychiatric consult (either new, or, updated)

closely question brian concerning all aspects of his worsened condition, including interpersonal life

consider referral for meds and/or for adjunctive approaches (medical or

complimentary)

seek peer consultation

send pt for medication eval

if not already considered, $2^{\text {nd }}$ opinion re antidepresat mediaction; I would $\mathrm{p}$ "tx as normal" with comparable pts and explore more

share discrepancy betw measured and verbal report and discuss with client. Delve deeper re assessment. Refer to psychiatrist for med eval and/or second opinion consider referral for medication; more focused goals, with more concrete homework discuss w pt whats going on

ask brian what he thinks would be useful; re-evaluate and alter services way earlier than 3 months if I didn't notice change. I might also get a medical and or psychiatric consult, esp. for pan. meds

feedback to pt re: my observation that affect/beh incongruent with test scores

I would discuss with brian the discrepancy btwn his reported decrease in s/o and my observation - if he is "truly" doing better, would discuss because of tx, but most likely I would check "B" to re-evaluate tx and see what other areas need to be addressed; I would also address why he is only "somewhat satisfied" by tx and see how we need to modify tx to better address his needs with client's agreement, invite participation in therapy of significant others psychiatric consultation re: medication psych testing (millon or MMPI)

seek information regarding precipitating events this week, compliance with medication, and external stressors

consider 1) refer for psychiatric eval; 2) discuss with brian the discrepancy between his self-report and your measures and observations in an effort to understand this; 3) ask about feedback from signif other possibly conduct a collateral interview with signif other

showing him the outcome measure and discussing it with him consider Rx evaluation

talking about discrepancy between assessment data and client presentation of behavior and affect

reassess what he wants help for and with what are his goals seek psychiatric/psychopharmacological consultation and monitoring do additional assessment and/or testing and reevaluate treatment plan accordingly getting more info on behavioral changes homework assignments with follow through data 
give MMPI-2

seek medication consult

re-evaluate/re-assess client which will lead to new treatment plan possibly

a formal psychological using projectives

review/make contract fro safety

present client with conflicting data - ask him what is going on with him; don't think a trustful relationship has been established; figure out what is going on with the client, don't think you know

addressing status directly with client

none of these, but if I had to choose, it would be B. I would address therapeutic impasse and reasons why client wants to possibly end or is feeling better.

Share discrepancy between my observations and his self-report

referring for medication evaluation; obtaining consultation from colleague; involving significant others in tx

gathering additional evaluation data

conduct in depth discussion regarding what has changed and how. What is patient's idea of next steps. All of this will determine next phase of treatment, if any med consult

determine what causes discrepancy between how pt presents and what he is reporting; determine if there are factors which may have caused an increase in depressive symptoms and if so, what

reevaluate appropriateness of treatment plan for this patient

seeking medication evaluation or re-evaluation; seeking other sources of information (family, sig relationships)

collaborative process to reassess status, confirm or modify goals, confirm or alter treatment plan, investigate potential obstacles to effective implementation, etc.

finding out why brian says he is much worse

psychiatric consultation for meds for depression

refer to psychiatrist

deciding to confront his resistance, be worried about suicide because he is ly saying hi is better, he is hiding something

get a medication consult

need more info as to particulars of his feeling worse. Reexamine initial hx

explore specific items from outcome measures that indicates he's worse

1) consider medications, 2) evaluate therapy relationship

consider medication consultation

eval with MD possible addition of psychopharm

refer for medication evaluation

actively questioning and exploring specifically how he is doing

discuss results and alter plan based on that discussion

refer for medication eval 
ascertain discrepancy - reasons for- between our perception vs. brains: brains expect _ therapy, a ___ to make use of therapy provided-verbal?, collaborate to hopefully ascertain a consentualment of actual condition perhaps reevaluate assessment and treatment after; consider consultation; ascertain extent of crisis/rush

review initial treatment goals and alter if needed gather more information from primary care physician and extended family discuss with him - his progress, oals, etc adm MMPI and Rorschach - ask client if he's interested in having spouse come to a session for providing a larger perspective

discuss progress with pt shy is he not seeming different in affect and behavior when symptoms are decreasing?

if not medicated, have feasibility double checked consider termination with client and reassess treatment goals depending on client's gls peer supervision; refer for psychiatric eval testing refer for antidepressant meds consider medication psychiatric consultation medication evaluation refer to a psychiatrist for Tx eval consider medication begin to ask more direct questions about info on outcome measure peer consultation address with client and then alter treatment plan as indicated peer consultation, more social history info discuss with brian the differences in outcome measure and presentation in sessions probably change the treatment plan in terms of more time in between sessions, e.g. instead of weekly change to every other week explore discrepancy between outcome measure and other observations discuss with pt the disparity discussing my concerns about progress with client explore discrepancy bt outcome measures and self rating. Consider biological roots fro sy. Refer fro meds eval discuss other tx options with client bring in other family members (using additional informants) peer consultation med eval address incongruities, i.e. satisfaction, outcome measure, observation delve more deeply into understanding symptoms; was he masking symptom severity? Is there greater depression, or character disorder? Has his context changed? Why more severe now?

process the contradictory signals you are getting as well as the absence of behavioral change - then decide if you want to change your approach or refer him on 


\section{Appendix I}

Answers to the "Other" category of "Would you consider taking steps towards termination?"

(copied directly written, indicates illegibility).

Possibly give depression inventory and discuss symptoms and areas of concern and go from there

referral

discuss discrepancy in report and observation

assess potential for relapse

assess for suicidal ideation/plan/intent and assess how pt defines feeling much better then if no warning signs arise try decreasing frequency of sessions to see if improvement continues

reevaluate goals - ?interpersonal problems

consider movement toward termination if he's able to provide more substantial evidence of his progress. If not, I would discuss his feelings about his progress i.e. why he feels that way; if other issues involved (eg his wanting to end therapy etc) if other issues involved and he's receptive then continue therapy. If not receptive, then terminate explore specific reason client feels better

check for signs that the improvements are only apparent, and might indicate a "resolve to suicide" which can masquerade as an up lifted mood; I would do an MMPI and Rorschach as well as an interview with family, if the pt. permitted me to do so

Confront brian re: his decision to not get much better than he already is. Brian seems to be finding a benefit/"payoff" for remaining in his current state

have pt discuss his tx goals

refine remaining goals 